\title{
Intramolecular Azide-Alkyne Cycloaddition for the Fast Assembly of Structurally Diverse, Tricyclic 1,2,3-Triazoles
}

Ana I. Oliva, ${ }^{\dagger}$ Ute Christmann, ${ }^{\dagger}$ Daniel Font,${ }^{\dagger}$ Félix Cuevas, ${ }^{\dagger}$ Pablo Ballester, ${ }^{\ddagger}$ Helmut Buschmann, ${ }^{ \pm}$Antoni Torrens, ${ }^{ \pm}$Susana Yenes, ${ }^{ \pm}$and Miquel A. Pericàs* ${ }^{*}$

Institute of Chemical Research of Catalonia (ICIQ), Av. Països Catalans, 16. 43007 Tarragona, Spain, Departament de Química Orgànica, Universitat de Barcelona (UB), 08028 Barcelona, Spain, ICREA and Laboratorios Dr. Esteve, S.A., Avda. Mare de Deu de Montserrat, 221, 08041 Barcelona, Spain

mapericas@iciq.es

- General Information $\quad$ S1

- Detailed experimental procedures $\quad$ S2

- NMR spectra $\quad$ S20

- HPLC chromatograms $\quad$ S52

- X-Ray crystallographic analysis of (S,S)-5a $(2 \mathrm{HCl}) \quad$ S54

- Pharmacological study S54

- References $\quad$ S55

\section{General Information}

All commercial reagents were used as received. Compounds $\mathbf{1}^{1}$ and $\mathbf{8 a - \mathbf { d } ^ { 2 }}$ were prepared according to reported methods. ${ }^{1} \mathrm{H}$ NMR spectra were registered in a Bruker Avance400 (400 MHz) spectrometer. The following abbreviations are used for NMR peak multiplicities: s, singlet; d, doblet; t, triplet; q, quartet; dd, doublet of doublets; m, multiplet, bs, broad signal. Chemical shifts are given in parts per million (ppm) relative to either TMS $(\delta 0.0)$, chloroform $(\delta$ 7.26), DMSO $(\delta 2.50)$ methanol $(\delta 3.34)$. Coupling constants are given in Hz. ${ }^{13} \mathrm{C}$ NMR and DEPTQ135 spectra were recorded in a Bruker Avance400 (100 MHz) using the carbon signal of the deuterated solvent as the internal standard. Mass spectra were measured on a Waters LCT Premier instrument. Optical rotations were measured at room 
temperature on a Jasco P-1030 polarimeter. High performance liquid chromatography (HPLC) was performed on Agilent Technologies chromatograph (serie 1200) using Chiralcel OD-H or Chiralpak AS columns. Microwave experiments were performed in a CEM Discover reactor. Melting points were determined in a Büchi B-540 melting poing apparatus and were uncorrected.

\section{Detailed experimental procedures}

\section{(3,4-trans)-4-azido-1-benzylpyrrolidin-3-ol (2):}

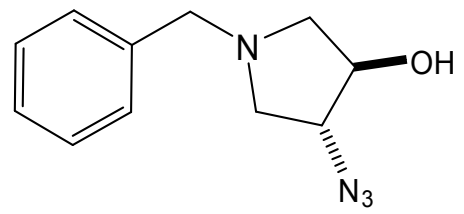

To a solution of 3-benzyl-6-oxa-3-azabicyclo[3.1.0]hexane (1) (7.08 g, $108 \mathrm{mmol})$ in acetonitrile (20 $\mathrm{ml}), \mathrm{NaN}_{3}(7.08 \mathrm{~g}, 108 \mathrm{mmol})$ and $\mathrm{LiClO}_{4}(4.70 \mathrm{~g}, 43.3 \mathrm{mmol})$ were added. The reaction mixture was heated at $95^{\circ} \mathrm{C}$ with stirring for 16 hours. After cooling at room temperature, water $(20 \mathrm{ml})$ was added and extracted with ethyl acetate $(3 \times 20 \mathrm{ml})$. The combined organic layers was washed with water and sat. solution of $\mathrm{NaCl}$, dried over $\mathrm{Na}_{2} \mathrm{SO}_{4}$, filtered and concentrated under reduced pressure to give the title compound (4.28 g, 90\% yield).

${ }^{1} \mathrm{H}$ NMR (400 MHz, $\left.\mathrm{CDCl}_{3}\right): \delta(\mathrm{ppm}) 7.31(\mathrm{~m}, 5 \mathrm{H}), 4.20(\mathrm{~m}, 1 \mathrm{H}), 3.80(\mathrm{~m}, 1 \mathrm{H}), 3.65(\mathrm{~m}, 2 \mathrm{H}), 3.08(\mathrm{~m}$, $1 \mathrm{H}), 2.86(\mathrm{~m}, 1 \mathrm{H}), 2.60(\mathrm{~m}, 1 \mathrm{H}), 2.46(\mathrm{~m}, 1 \mathrm{H}) .{ }^{13} \mathrm{C} \mathrm{NMR}\left(100 \mathrm{MHz}, \mathrm{CDCl}_{3}\right): \delta(\mathrm{ppm}) 137.83,128.71$, 128.39, 127.32, 76.39, 67.66, 60.54, 59.63, 57.26, 53.41. HR-MS calc for M+H: 219.1246, obs: 219.1241.

\section{General procedure for the synthesis of derivatives of (3-bromoprop-1-ynyl) benzene}

To a solution of the corresponding propargylalcohol $(3.83 \mathrm{mmol})$ in anhydrous DCM (15 $\mathrm{ml})$ under Ar, $\mathrm{CBr}_{4}(5.75 \mathrm{mmol})$ was added and the reaction mixture was cooled at $0^{\circ} \mathrm{C} . \mathrm{PPh}_{3}(5.94 \mathrm{mmol})$ was added slowly. The reaction mixture was allowed to reach room temperature and stirred for 16 hours. Ethanol (2 $\mathrm{ml}$ ) was added and the reaction mixture stirred for $20 \mathrm{~min}$. The solvent was removed under reduced pressure and the crude purified by flash chromatography, silica gel, hexane.

\section{(3-bromoprop-1-ynyl)benzene}

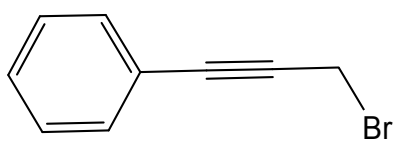


From 3-phenylprop-2-yn-1-ol (828 mg, $6.26 \mathrm{mmol}), \mathrm{CBr}_{4}(2.49 \mathrm{~g}, 7.51 \mathrm{mmol}), \mathrm{Ph}_{3} \mathrm{P}(2.05 \mathrm{~g}, 7.83$ mmol) and DCM (15 ml), afforded the titled compound (1.01 g, 83\%).

${ }^{1} \mathrm{H}$ NMR (400 MHz, $\left.\mathrm{CDCl}_{3}\right): \delta(\mathrm{ppm}) 7.47(\mathrm{~m}, 2 \mathrm{H}), 7.34(\mathrm{~m}, 3 \mathrm{H}), 4.18(\mathrm{~s}, 2 \mathrm{H}) .{ }^{3}$

\section{1-(3-bromoprop-1-ynyl)-4-chlorobenzene}

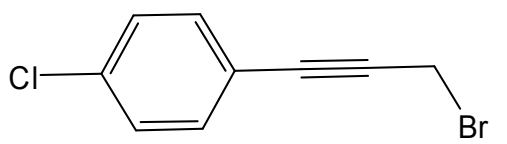

From 3-(4-chlorophenyl)prop-2-yn-1-ol (350 mg, $2.64 \mathrm{mmol}), \mathrm{CBr}_{4}$ (2.67 g, 8.07 mmol), $\mathrm{Ph}_{3} \mathrm{P}$ (2.15 g, $8.20 \mathrm{mmol})$ and DCM (10 ml), afforded the titled compound (186 mg, 31\%).

${ }^{1} \mathrm{H}$ NMR (400 MHz, $\left.\mathrm{CDCl}_{3}\right): \delta(\mathrm{ppm}) 7.34(\mathrm{~m}, 4 \mathrm{H}), 4.16(\mathrm{~s}, 2 \mathrm{H}) .{ }^{4}$

\section{1-(3-bromoprop-1-ynyl)-2-fluorobenzene}

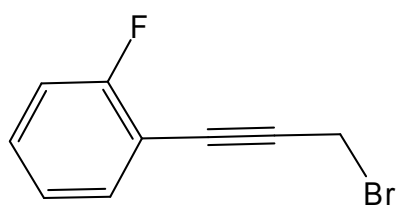

From 3-(2-fluorophenyl)prop-2-yn-1-ol (383 mg, $2.55 \mathrm{mmol}), \mathrm{CBr}_{4}(2.58 \mathrm{~g}, 7.77 \mathrm{mmol}), \mathrm{Ph}_{3} \mathrm{P}(2.07 \mathrm{~g}$, $7.90 \mathrm{mmol})$ and DCM (10 ml), afforded the titled compound (149 $\mathrm{mg}, 27 \%)$.

${ }^{1} \mathrm{H} \mathrm{NMR}\left(400 \mathrm{MHz}, \mathrm{CDCl}_{3}\right): \delta(\mathrm{ppm}) 7.46(\mathrm{~m}, 1 \mathrm{H}), 7.34(\mathrm{~m}, 1 \mathrm{H}), 7.11(\mathrm{~m}, 2 \mathrm{H}), 4.20(\mathrm{~s}, 2 \mathrm{H})$.

\section{1-(3-bromoprop-1-ynyl)-4-(trifluoromethyl)benzene}

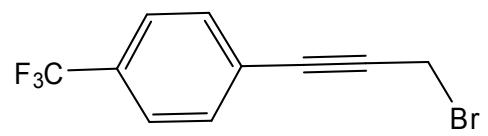

From 3-(4-(trifluoromethyl)phenyl)prop-2-yn-1-ol (768 mg, $3.83 \mathrm{mmol}), \mathrm{CBr}_{4}(1.90 \mathrm{~g}, 5.75 \mathrm{mmol})$, $\mathrm{Ph}_{3} \mathrm{P}(1.56 \mathrm{~g}, 5.94 \mathrm{mmol})$ and DCM (15 ml), afforded the titled compound (742 $\left.\mathrm{mg}, 73 \%\right)$.

${ }^{1} \mathrm{H}$ NMR (400 MHz, $\mathrm{CDCl}_{3}$ ): $\delta$ (ppm) 7.59 (AB system, 4H), 4.17 (s, 2H). ${ }^{3}$

\section{1-(3-bromoprop-1-ynyl)-3-fluorobenzene}

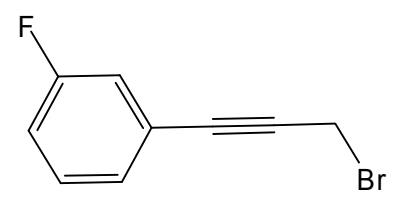


From 3-(3-fluorophenyl)prop-2-yn-1-ol (614 mg, $4.08 \mathrm{mmol}), \mathrm{CBr}_{4}(1.62 \mathrm{~g}, 4.90 \mathrm{mmol}), \mathrm{Ph}_{3} \mathrm{P}(1.39 \mathrm{~g}$, $5.31 \mathrm{mmol})$ and DCM (12 ml), afforded the titled compound (634 mg, 73\%).

${ }^{1} \mathrm{H}$ NMR $\left(400 \mathrm{MHz}, \mathrm{CDCl}_{3}\right): \delta(\mathrm{ppm}) 7.31(\mathrm{~m}, 1 \mathrm{H}), 7.24(\mathrm{~m}, 1 \mathrm{H}), 7.15(\mathrm{~m}, 1 \mathrm{H}), 7.06(\mathrm{~m}, 1 \mathrm{H}), 4.16(\mathrm{~s}$, 2H). ${ }^{13} \mathrm{C}$ NMR $\left(100 \mathrm{MHz}, \mathrm{CDCl}_{3}\right): \delta(\mathrm{ppm}) 162.51\left(\mathrm{~d}, \mathrm{~J}_{\mathrm{CF}}=246 \mathrm{~Hz}\right), 130.11\left(\mathrm{~d}, \mathrm{~J}_{\mathrm{CF}}=9 \mathrm{~Hz}\right), 127.90(\mathrm{~d}$, $\left.\mathrm{J}_{\mathrm{CF}}=3 \mathrm{~Hz}\right), 124.08\left(\mathrm{~d}, \mathrm{~J}_{\mathrm{CF}}=9 \mathrm{~Hz}\right), 118.81\left(\mathrm{~d}, \mathrm{~J}_{\mathrm{CF}}=23 \mathrm{~Hz}\right), 116.41\left(\mathrm{~d}, \mathrm{~J}_{\mathrm{CF}}=21 \mathrm{~Hz}\right), 85.46,85.38,14.91$. HRMS calc for M+: 211.9637, obs: 211.9646.

\section{General procedure for the synthesis of compounds of general formula 3 and 9.}

A solution of azido alcohol $(0.8 \mathrm{mmol})$ in anhydrous THF $(5 \mathrm{ml})$ was cooled to $0^{\circ} \mathrm{C}$ and $\mathrm{NaH}(1.6 \mathrm{mmol}$, $60 \%$ dispersion in mineral oil) was added. The reaction mixture was stirred at $0^{\circ} \mathrm{C}$ under $\mathrm{Ar}$, for 10 minutes and then allowed to warm at room temperature and stirred for 1 hour. The reaction mixture was cooled again at $0^{\circ} \mathrm{C}$ and tetrabutyl ammonium iodide $(0.08 \mathrm{mmol})$ and the alkyne $(1.6 \mathrm{mmol})$ were added. The reaction was allowed to warm at room temperature and stirred for 16 hours. A saturated solution of $\mathrm{NH}_{4} \mathrm{Cl}$ was added and extracted with EtOAc. The organic layer was washed with water, dried over $\mathrm{Na}_{2} \mathrm{SO}_{4}$, filtered and concentrated under reduced pressure. Purification by flash chromatography, silica gel, gradient hexane to hexane:ethyl acetate 3:1.

\section{(3,4-trans)- 3-azido-1-benzyl-4-(prop-2-ynyloxy)pyrrolidine (3a):}

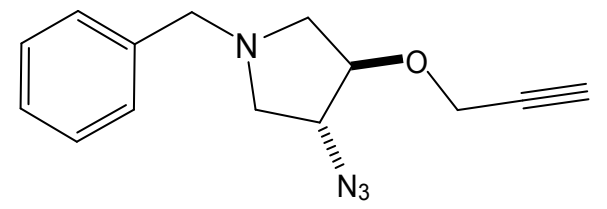

From 2 (3.0 g, $13.7 \mathrm{mmol}), \mathrm{NaH}(0.50 \mathrm{~g}, 20.6 \mathrm{mmol})$, propargyl bromide (80\% solution in toluene, 2.30 $\mathrm{ml}, 20.6 \mathrm{mmol})$ and THF (30 ml), afforded the titled compound (3.5 g, 99\% yield).

${ }^{1} \mathrm{H}$ NMR (400 MHz, $\left.\mathrm{CDCl}_{3}\right): \delta(\mathrm{ppm}) 7.33(\mathrm{~m}, 5 \mathrm{H}), 4.20(\mathrm{~m}, 2 \mathrm{H}), 4.17(\mathrm{~m}, 1 \mathrm{H}), 3.87(\mathrm{~m}, 1 \mathrm{H}), 3.62(\mathrm{AB}$ system, 2H), $3.08(\mathrm{dd}, \mathrm{J} 1=6.4 \mathrm{~Hz}, \mathrm{~J} 2=10.3 \mathrm{~Hz}, 1 \mathrm{H}), 2.89(\mathrm{dd}, \mathrm{J} 1=6.7 \mathrm{~Hz}, \mathrm{~J} 2=10.6 \mathrm{~Hz}, 1 \mathrm{H}), 2.70$ (dd, $\mathrm{J} 1=4.1 \mathrm{~Hz}, \mathrm{~J} 2=10.3 \mathrm{~Hz}, 1 \mathrm{H}), 2.52(\mathrm{dd}, \mathrm{J} 1=4.5 \mathrm{~Hz}, \mathrm{~J} 2=10.3 \mathrm{~Hz}, 1 \mathrm{H}), 2.48(\mathrm{t}, \mathrm{J}=2.5 \mathrm{~Hz}, 1 \mathrm{H}) .{ }^{13} \mathrm{C} \mathrm{NMR}$ $\left(100 \mathrm{MHz}, \mathrm{CDCl}_{3}\right): \delta$ (ppm) 137.93, 128.71, 128.36, 127.25, 83.28, 79.11, 75.00, 65.12, 59.72, 58.52, 57.47, 57.14. HR-MS calc for M+H: 257.1402, obs: 257.1402.

\section{(3,4-trans)-3-azido-4-(but-2-ynyloxy)-1-(4-methoxybenzyl)pyrrolidine (3b):}




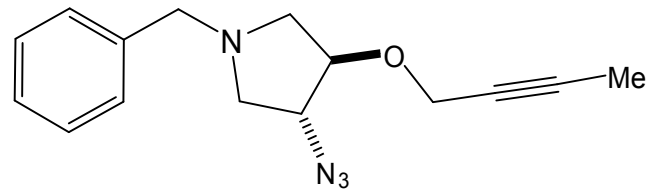

From 2 (479 mg, $2.19 \mathrm{mmol})$, NaH (175 mg, $4.38 \mathrm{mmol})$, 1-bromo-2-butyne (583 mg, $4.38 \mathrm{mmol})$, tetrabutyl ammonium iodide $(81 \mathrm{mg}, 0.21 \mathrm{mmol})$ and THF $(10 \mathrm{ml})$, afforded the titled compound (456 mg, $77 \%$ yield).

${ }^{1} \mathrm{H}$ NMR (400 MHz, $\left.\mathrm{CDCl}_{3}\right): \delta(\mathrm{ppm}) 7.33(\mathrm{~m}, 5 \mathrm{H}), 4.15(\mathrm{~s}, 2 \mathrm{H}), 3.86(\mathrm{~m}, 1 \mathrm{H}), 3.64$ (AB system, $\left.2 \mathrm{H}\right)$, $3.09(\mathrm{dd}, \mathrm{J} 1=6.7 \mathrm{~Hz}, \mathrm{~J} 2=10.3 \mathrm{~Hz}, 1 \mathrm{H}), 2.86(\mathrm{dd}, \mathrm{J} 1=6.5 \mathrm{~Hz}, \mathrm{~J} 2=10.3 \mathrm{~Hz}, 1 \mathrm{H}), 2.69(\mathrm{dd}, \mathrm{J} 1=4.0 \mathrm{~Hz}, \mathrm{~J} 2=$ $10.3 \mathrm{~Hz}, 1 \mathrm{H}), 2.50(\mathrm{dd}, \mathrm{J} 1=4.4 \mathrm{~Hz}, \mathrm{~J} 2=10.0 \mathrm{~Hz}, 1 \mathrm{H}), 1.87(\mathrm{t}, \mathrm{J}=2.3 \mathrm{~Hz}, 3 \mathrm{H}) .{ }^{13} \mathrm{C}$ NMR $(100 \mathrm{MHz}$, $\left.\mathrm{CDCl}_{3}\right): \delta(\mathrm{ppm}) 138.02,128.72,128.34,127.20,83.15,82.91,74.53,65.16,60.45,58.65,57.70,57.55$, 3.62. HR-MS calc for M+H: 271.1559 , obs: 271.1563 .

\section{(3,4-trans)- 3-azido-1-benzyl-4-(pent-2-ynyloxy)pyrrolidine (3c):}

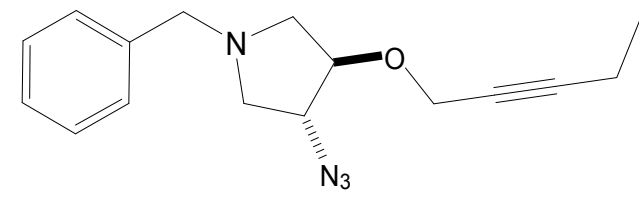

From 2 (414 mg, $1.89 \mathrm{mmol})$, NaH (151 mg, $3.79 \mathrm{mmol}$ ), 1-bromo-2-pentyne (557 mg, $3.79 \mathrm{mmol})$, tetrabutyl ammonium iodide $(70 \mathrm{mg}, 0.189 \mathrm{mmol})$ and THF $(10 \mathrm{ml})$, afforded the titled compound (484 $\mathrm{mg}, 90 \%$ yield).

${ }^{1} \mathrm{H}$ NMR (400 MHz, $\left.\mathrm{CDCl}_{3}\right): \delta(\mathrm{ppm}) 7.28(\mathrm{~m}, 5 \mathrm{H}), 4.17(\mathrm{~m}, 3 \mathrm{H}), 3.86(\mathrm{~m}, 1 \mathrm{H}), 3.64$ (AB system, $\left.2 \mathrm{H}\right)$, $3.09(\mathrm{dd}, \mathrm{J} 1=6.6 \mathrm{~Hz}, \mathrm{~J} 2=10.0 \mathrm{~Hz}, 1 \mathrm{H}), 2.86(\mathrm{dd}, \mathrm{J} 1=6.5 \mathrm{~Hz}, \mathrm{~J} 2=10.2 \mathrm{~Hz}, 1 \mathrm{H}), 2.69(\mathrm{dd}, \mathrm{J} 1=3.9 \mathrm{~Hz}, \mathrm{~J} 2=$ $10.2 \mathrm{~Hz}, 1 \mathrm{H}), 2.50(\mathrm{dd}, \mathrm{J} 1=4.8 \mathrm{~Hz}, \mathrm{~J} 2=10.0 \mathrm{~Hz}, 1 \mathrm{H}), 2.24(\mathrm{~m}, 2 \mathrm{H}), 1.16(\mathrm{t}, \mathrm{J}=7.6 \mathrm{~Hz}, 3 \mathrm{H}) .{ }^{13} \mathrm{C}$ NMR $(100$ $\mathrm{MHz}, \mathrm{CDCl}_{3}$ ): $\delta$ (ppm) 138.01, 128.73, 128.33, 127.20, 88.97, 82.90, 74.67, 65.15, 59.76, 58.67, 57.74, 57.53, 13.64, 12.45. HR-MS calc for M+H: 285.1715, obs: 285.1712 .

\section{(3,4-trans)- 3-azido-1-benzyl-4-(3-phenylprop-2-ynyloxy)pyrrolidine (3d):}

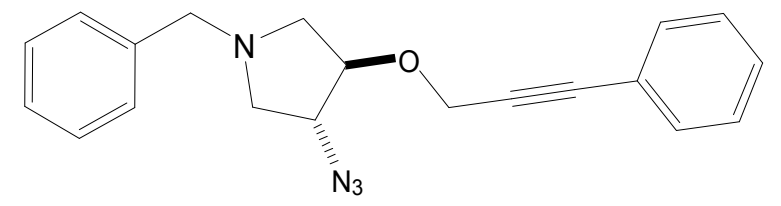


From 2 (200 mg, $0.91 \mathrm{mmol}$ ), NaH (73 mg, $1.83 \mathrm{mmol})$, (3-bromoprop-1-ynyl)benzene (303 mg, 1.55 mmol), tetrabutyl ammonium iodide $(203 \mathrm{mg}, 0.54 \mathrm{mmol})$ and THF $(5 \mathrm{ml})$, afforded the titled compound (254 mg, 84\% yield).

${ }^{1} \mathrm{H}$ NMR (400 MHz, $\left.\mathrm{CDCl}_{3}\right): \delta(\mathrm{ppm}) 7.48(\mathrm{~m}, 2 \mathrm{H}), 7.32(\mathrm{~m}, 8 \mathrm{H}), 4.45(\mathrm{~s}, 2 \mathrm{H}), 4.28(\mathrm{~m}, 1 \mathrm{H}), 3.95(\mathrm{~m}$, 1H), 3.68 (AB system, 2H), $3.15(\mathrm{dd}, \mathrm{J} 1=6.6 \mathrm{~Hz}, \mathrm{~J} 2=10.3 \mathrm{~Hz}, 1 \mathrm{H}), 2.92(\mathrm{dd}, \mathrm{J} 1=6.6 \mathrm{~Hz}, \mathrm{~J} 2=10.2 \mathrm{~Hz}, 1 \mathrm{H})$, $2.72(\mathrm{dd}, \mathrm{J} 1=3.9 \mathrm{~Hz}, \mathrm{~J} 2=10.2 \mathrm{~Hz}, 1 \mathrm{H}), 2.60(\mathrm{dd}, \mathrm{J} 1=4.7 \mathrm{~Hz}, \mathrm{~J} 2=10.3 \mathrm{~Hz}, 1 \mathrm{H}) .{ }^{13} \mathrm{C} \mathrm{NMR}(100 \mathrm{MHz}$, $\left.\mathrm{CDCl}_{3}\right): \delta(\mathrm{ppm}) 138.03,131.83,128.77,128.65,128.40,128.36,127.27,122.42,86.78,84.55,83.31$, 65.21, 59.80, 58.70, 58.01, 57.53. HR-MS calc for M+H: 333.1715, obs: 333.1709.

\section{(3,4-trans)-3-azido-1-benzyl-4-(3-(2-fluorophenyl)prop-2-ynyloxy) pyrrolidine (3e):}

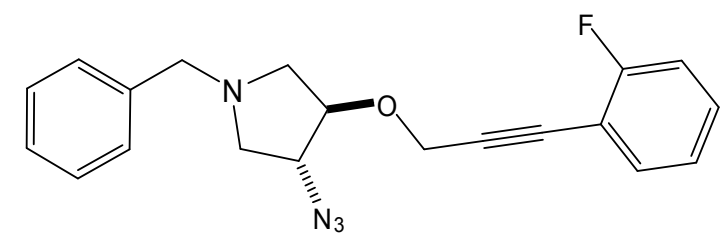

From 2 (150 mg, $0.68 \mathrm{mmol}), \mathrm{NaH}$ (55 mg, $1.37 \mathrm{mmol}), 1$-(3-bromoprop-1-ynyl)-2-fluorobenzene (146 $\mathrm{mg}, 0.68 \mathrm{mmol})$, tetrabutyl ammonium iodide $(25 \mathrm{mg}, 0.068 \mathrm{mmol})$ and THF $(5 \mathrm{ml})$, afforded the titled compound (120 mg, 50\% yield).

${ }^{1} \mathrm{H}$ NMR (400 MHz, $\left.\mathrm{CDCl}_{3}\right): \delta(\mathrm{ppm}) 7.44(\mathrm{~m}, 1 \mathrm{H}), 7.34(\mathrm{~m}, 6 \mathrm{H}), 7.10(\mathrm{~m}, 2 \mathrm{H}), 4.46(\mathrm{~s}, 2 \mathrm{H}), 4.25(\mathrm{~m}$, 1H), $3.94(\mathrm{~m}, 1 \mathrm{H}), 3.66$ (AB system, 2H), $3.12(\mathrm{dd}, \mathrm{J} 1=6.5 \mathrm{~Hz}, \mathrm{~J} 2=10.4 \mathrm{~Hz}, 1 \mathrm{H}), 2.90(\mathrm{dd}, \mathrm{J} 1=6.5 \mathrm{~Hz}$, $\mathrm{J} 2=9.8 \mathrm{~Hz}, 1 \mathrm{H}), 2.71(\mathrm{dd}, \mathrm{J} 1=4.1 \mathrm{~Hz}, \mathrm{~J} 2=10.1 \mathrm{~Hz}, 1 \mathrm{H}), 2.59(\mathrm{dd}, \mathrm{J} 1=4.4 \mathrm{~Hz}, \mathrm{~J} 2=10.1 \mathrm{~Hz}, 1 \mathrm{H}) .{ }^{13} \mathrm{C} \mathrm{NMR}$ $\left(100 \mathrm{MHz}, \mathrm{CDCl}_{3}\right): \delta(\mathrm{ppm}) 163.0\left(\mathrm{~d}, \mathrm{~J}_{\mathrm{CF}}=252 \mathrm{~Hz}\right), 137.98,133.65,130.40\left(\mathrm{~d}, \mathrm{~J}_{\mathrm{CF}}=8 \mathrm{~Hz}\right), 128.74$, 128.36, 127.22, $123.94\left(\mathrm{~d}, \mathrm{~J}_{\mathrm{CF}}=4 \mathrm{~Hz}\right), 115.50\left(\mathrm{~d}, \mathrm{~J}_{\mathrm{CF}}=24 \mathrm{~Hz}\right), 110.90\left(\mathrm{~d}, \mathrm{~J}_{\mathrm{CF}}=20 \mathrm{~Hz}\right), 89.74,83.43,80.18$, 65.19, 59.77, 58.65, 57.98, 57.47. HR-MS calc for M+H: 351.1621, obs: 351.1621.

\section{(3,4-trans)-3-azido-1-benzyl-4-(3-(3-fluorophenyl)prop-2-ynyloxy) pyrrolidine (3f):}

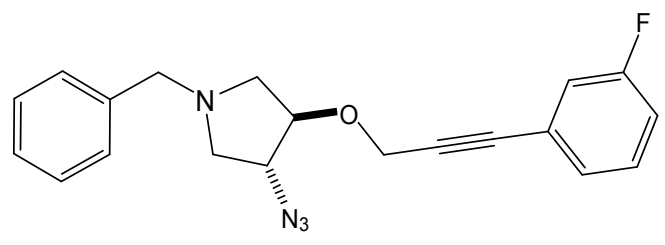


From 2 (100 mg, 0.73 mmol), NaH (58 mg, 1.46 mmol), 1-(3-bromoprop-1-ynyl)-3-fluorobenzene (234 $\mathrm{mg}, 1.09 \mathrm{mmol})$, tetrabutyl ammonium iodide $(81 \mathrm{mg}, 0.21 \mathrm{mmol})$ and THF $(5 \mathrm{ml})$, afforded the titled compound (120 mg, 47\% yield).

${ }^{1} \mathrm{H}$ NMR (400 MHz, $\left.\mathrm{CDCl}_{3}\right): \delta(\mathrm{ppm}) 7.36(\mathrm{~m}, 4 \mathrm{H}), 7.30(\mathrm{~m}, 5 \mathrm{H}), 7.30(\mathrm{~m}, 2 \mathrm{H}), 7.25(\mathrm{~m}, 1 \mathrm{H}), 7.17(\mathrm{~m}$, 1H), $7.07(\mathrm{~m}, 1 \mathrm{H}), 4.43(\mathrm{~s}, 2 \mathrm{H}), 4.24(\mathrm{~m}, 1 \mathrm{H}), 3.93(\mathrm{~m}, 1 \mathrm{H}), 3.66$ (AB system, 2H), $3.12(\mathrm{dd}, \mathrm{J} 1=6.5 \mathrm{~Hz}$, $\mathrm{J} 2=10.0 \mathrm{~Hz}, 1 \mathrm{H}), 2.92(\mathrm{dd}, \mathrm{J} 1=6.5 \mathrm{~Hz}, \mathrm{~J} 2=10.2 \mathrm{~Hz}, 1 \mathrm{H}), 2.72(\mathrm{dd}, \mathrm{J} 1=4.0 \mathrm{~Hz}, \mathrm{~J} 2=10.0 \mathrm{~Hz}, 1 \mathrm{H}), 2.58(\mathrm{dd}$, $\mathrm{J} 1=4.5 \mathrm{~Hz}, \mathrm{~J} 2=10.0 \mathrm{~Hz}, 1 \mathrm{H}) .{ }^{13} \mathrm{C} \mathrm{NMR}\left(100 \mathrm{MHz}, \mathrm{CDCl}_{3}\right): \delta(\mathrm{ppm}) 162.30\left(\mathrm{~d}, \mathrm{~J}_{\mathrm{CF}}=252 \mathrm{~Hz}\right), 137.95$, $129.95(\mathrm{~d}, \mathrm{~J}=8 \mathrm{~Hz}), 128.80,128.39,127.70\left(\mathrm{~d}, \mathrm{~J}_{\mathrm{CF}}=3 \mathrm{~Hz}\right), 127.28,124.20\left(\mathrm{~d}, \mathrm{~J}_{\mathrm{CF}}=9 \mathrm{~Hz}\right), 118.60(\mathrm{~d}$, $\left.\mathrm{J}_{\mathrm{CF}}=22 \mathrm{~Hz}\right), 116.10\left(\mathrm{~d}, \mathrm{~J}_{\mathrm{CF}}=22 \mathrm{~Hz}\right), 85.53,85.47,83.41,65.18,59.77,58.62,57.86,57.52$. HR-MS calc for $\mathrm{M}+\mathrm{H}: 351.1621$, obs: 351.1622 .

\section{(3,4-trans)-3-azido-1-benzyl-4-(3-(4-chlorophenyl)prop-2-ynyloxy) pyrrolidine (3g):}

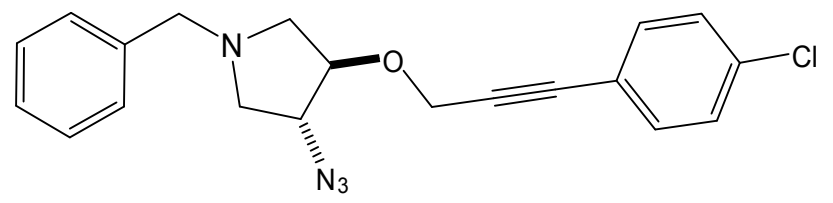

From 2 (150 mg, $0.68 \mathrm{mmol})$, NaH (55 mg, 1.37 mmol), 1-(3-bromoprop-1-ynyl)-4-chlorobenzene (157 $\mathrm{mg}, 0.68 \mathrm{mmol})$, tetrabutyl ammonium iodide $(25 \mathrm{mg}, 0.068 \mathrm{mmol})$ and THF $(5 \mathrm{ml})$, afforded the titled compound (154 mg, 61\% yield).

${ }^{1} \mathrm{H}$ NMR (400 MHz, $\left.\mathrm{CDCl}_{3}\right): \delta(\mathrm{ppm}) 7.34(\mathrm{~m}, 9 \mathrm{H}), 4.41(\mathrm{~s}, 2 \mathrm{H}), 4.23(\mathrm{~m}, 1 \mathrm{H}), 3.92(\mathrm{~m}, 1 \mathrm{H}), 3.65(\mathrm{AB}$ system, 2H), $3.10(\mathrm{dd}, \mathrm{J} 1=6.5 \mathrm{~Hz}, \mathrm{~J} 2=10.0 \mathrm{~Hz}, 1 \mathrm{H}), 2.90(\mathrm{dd}, \mathrm{J} 1=6.5 \mathrm{~Hz}, \mathrm{~J} 2=10.0 \mathrm{~Hz}, 1 \mathrm{H}), 2.70(\mathrm{dd}$, $\mathrm{J} 1=3.9 \mathrm{~Hz}, \mathrm{~J} 2=10.1 \mathrm{~Hz}, 1 \mathrm{H}), 2.56(\mathrm{dd}, \mathrm{J} 1=4.7 \mathrm{~Hz}, \mathrm{~J} 2=10.1 \mathrm{~Hz}, 1 \mathrm{H}) .{ }^{13} \mathrm{C} \mathrm{NMR}\left(100 \mathrm{MHz}, \mathrm{CDCl}_{3}\right): \delta$ (ppm) 137.95, 134.72, 133.03, 128.74, 128.69, 128.37, 127.26, 120.84, 85.62, 85.49, 83.37, 65.18, 59.77, 58.63, 57.92, 57.53. HR-MS calc for M+H: 367.1326, obs: 367.1313.

\section{(3,4-trans)-3-azido-1-benzyl-4-(3-(4-(trifluoromethyl)phenyl)prop-2-nyloxy)pyrrolidine (3h):}

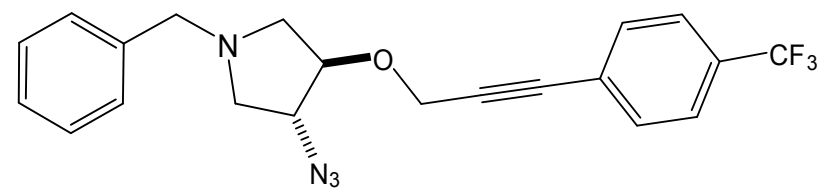

From $2 \quad(150 \mathrm{mg}, \quad 0.68 \mathrm{mmol}), \quad \mathrm{NaH} \quad(55 \quad \mathrm{mg}, \quad 1.37 \quad \mathrm{mmol}), \quad$ 1-(3-bromoprop-1-ynyl)-4(trifluoromethyl)benzene $(219 \mathrm{mg}, 1.03 \mathrm{mmol})$, tetrabutyl ammonium iodide (25 mg, $0.068 \mathrm{mmol})$ and THF ( $5 \mathrm{ml}$ ), afforded the titled compound (95 mg, 35\% yield). 
${ }^{1} \mathrm{H}$ NMR (400 MHz, $\left.\mathrm{CDCl}_{3}\right): \delta(\mathrm{ppm}) 7.58$ (AB system, 4H), $7.30(\mathrm{~m}, 5 \mathrm{H}), 4.44(\mathrm{~s}, 2 \mathrm{H}), 4.24(\mathrm{~m}, 1 \mathrm{H})$, $3.93(\mathrm{~m}, 1 \mathrm{H}), 3.66(\mathrm{AB}$ system, 2H), $3.11(\mathrm{dd}, \mathrm{J} 1=6.6 \mathrm{~Hz}, \mathrm{~J} 2=10.2 \mathrm{~Hz}, 1 \mathrm{H}), 2.93(\mathrm{dd}, \mathrm{J} 1=6.6 \mathrm{~Hz}, \mathrm{~J} 2=$ $10.1 \mathrm{~Hz}, 1 \mathrm{H}), 2.72(\mathrm{dd}, \mathrm{J} 1=4.0 \mathrm{~Hz}, \mathrm{~J} 2=10.1 \mathrm{~Hz}, 1 \mathrm{H}), 2.58(\mathrm{dd}, \mathrm{J} 1=4.6 \mathrm{~Hz}, \mathrm{~J} 2=10.1 \mathrm{~Hz}, 1 \mathrm{H}) .{ }^{13} \mathrm{C} \mathrm{NMR}$ $\left(100 \mathrm{MHz}, \mathrm{CDCl}_{3}\right): \delta(\mathrm{ppm}) 137.93,132.02,130.22\left(\mathrm{q}, \mathrm{J}_{\mathrm{CF}}=32 \mathrm{~Hz}\right), 128.74,128.38,127.27,125.26(\mathrm{q}$, $\left.\mathrm{J}_{\mathrm{CF}}=4 \mathrm{~Hz}\right), 124.27\left(\mathrm{q}, \mathrm{J}_{\mathrm{CF}}=272 \mathrm{~Hz}\right), 87.02,85.34,83.49,65.19,59.76,58.59,57.85,57.52$. HR-MS calc for M+H: 401.1589, obs: 401.1594 .

\section{(3S,4S)-tert-butyl 3-azido-4-(prop-2-ynyloxy)pyrrolidine-1-carboxylate (9a):}

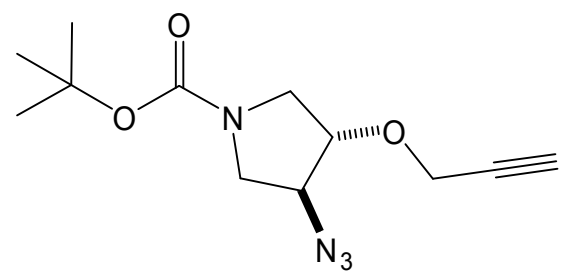

From 8a (250 mg, $1.09 \mathrm{mmol}), \mathrm{NaH}$ (57 mg, $1.42 \mathrm{mmol})$, propargyl bromide (80\% solution in toluene, $0.32 \mathrm{ml}, 2.19 \mathrm{mmol})$, tetrabutyl ammonium iodide (283 $\mathrm{mg}, 0.76 \mathrm{mmol})$ and THF (8 ml), afforded the titled compound (268 mg, 92\% yield) as yellow oil.

${ }^{1} \mathrm{H}$ NMR (400 MHz, $\left.\mathrm{CDCl}_{3}\right)$ : mixture of rotamers, $\delta(\mathrm{ppm}) 4.20(\mathrm{~m}, 2 \mathrm{H}), 4.08(\mathrm{~m}, 1 \mathrm{H}), 4.03(\mathrm{~m}, 1 \mathrm{H})$, $3.58(\mathrm{~m}, 2 \mathrm{H}), 3.40(\mathrm{~m}, 2 \mathrm{H}), 2.48(\mathrm{~s}, 1 \mathrm{H}), 1.43(\mathrm{~s}, 9 \mathrm{H}) .{ }^{13} \mathrm{C} \mathrm{NMR}\left(100 \mathrm{MHz}, \mathrm{CDCl}_{3}\right): \delta(\mathrm{ppm}) 154.16$, $80.51,79.73,75.42,63.39,62.48,56.91,49.33,48.59,48.56,48.23,28.52 . \mathrm{MS}(\mathrm{EI}+) \mathrm{m} / \mathrm{z}: 289.1$ $\left(\mathrm{M}+\mathrm{Na}^{+}\right)$.

\section{(3S,4S)-tert-butyl 3-azido-4-(but-2-ynyloxy)pyrrolidine-1-carboxylate (9b):}

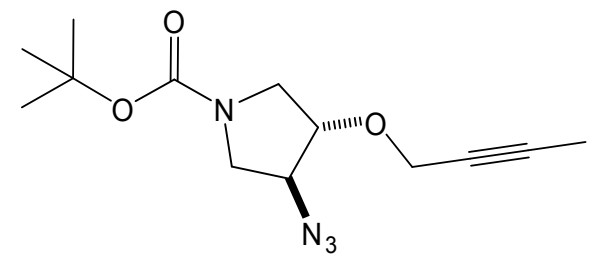

From 8a (100 mg, $0.43 \mathrm{mmol}), \mathrm{NaH}$ (23 mg, $0.57 \mathrm{mmol})$, 1-bromo-2-butyne (117 mg, $0.87 \mathrm{mmol})$, tetrabutylammonium iodide (113 $\mathrm{mg}, 0.30 \mathrm{mmol})$ and THF $(4 \mathrm{ml})$, afforded the titled compound (118 mg, 96\% yield) as colourless oil.

${ }^{1} \mathrm{H}$ NMR (400 MHz, $\left.\mathrm{CDCl}_{3}\right)$ : mixture of rotamers, $\delta(\mathrm{ppm}) 4.14(\mathrm{~m}, 2 \mathrm{H}), 4.05(\mathrm{~m}, 1 \mathrm{H}), 3.99(\mathrm{~m}, 1 \mathrm{H})$, $3.55(\mathrm{~m}, 2 \mathrm{H}), 3.37(\mathrm{~m}, 2 \mathrm{H}), 1.82(\mathrm{t}, \mathrm{J}=2.3 \mathrm{~Hz}, 3 \mathrm{H}), 1.41(\mathrm{~s}, 9 \mathrm{H}) .{ }^{13} \mathrm{C} \mathrm{NMR}\left(100 \mathrm{MHz}, \mathrm{CDCl}_{3}\right): \delta(\mathrm{ppm})$ 
$154.31,83.36,80.12,79.74,79.17,74.02,63.45,62.49,57.43,49.37,48.62,48.55,48.20,28.27,3.42$. HR-MS calc for M+Na: 303.1433, obs: 303.1431.

(3S,4S)-tert-butyl 3-azido-4-(3-phenylprop-2-ynyloxy)pyrrolidine-1-carboxylate (9c):

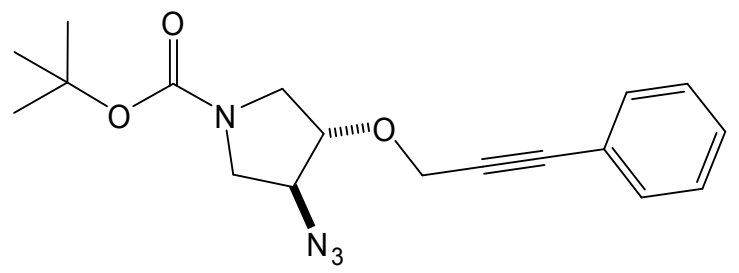

From 8a (100 mg, $0.43 \mathrm{mmol})$, NaH (23 mg, $0.57 \mathrm{mmol}$ ), (3-bromoprop-1-ynyl)benzene (102 mg, 0.52 $\mathrm{mmol}$ ), tetrabutylammonium iodide $(113 \mathrm{mg}, 0.30 \mathrm{mmol})$ and THF (4 ml), afforded the titled compound (120 mg, 80\% yield) as yellow oil.

${ }^{1} \mathrm{H}$ NMR (400 MHz, $\left.\mathrm{CDCl}_{3}\right)$ : mixture of rotamers, $\delta(\mathrm{ppm}) 7.44(\mathrm{~m}, 2 \mathrm{H}), 7.32(\mathrm{~m}, 3 \mathrm{H}), 4.44(\mathrm{~m}, 2 \mathrm{H})$, $4.17(\mathrm{~m}, 1 \mathrm{H}), 4.08(\mathrm{~m}, 1 \mathrm{H}), 3.63(\mathrm{~m}, 2 \mathrm{H}), 3.44(\mathrm{~m}, 2 \mathrm{H}), 1.45(\mathrm{~s}, 9 \mathrm{H}) .{ }^{13} \mathrm{C} \mathrm{NMR}\left(100 \mathrm{MHz}, \mathrm{CDCl}_{3}\right): \delta$ (ppm) 154.13, 131.67, 128.71, 128.29, 122.04, 87.11, 83.96, 80.59, 79.87, 79.64, 63.40, 62.61, 57.81, 49.43, 48.72, 48.59, 48.15, 28.32. HR-MS calc for M+Na: 365.1590, obs: 365.1575.

(3S,4S)-tert-butyl 3-azido-4-(3-(3-fluorophenyl)prop-2-ynyloxy) pyrrolidine-1-carboxylate (9d):

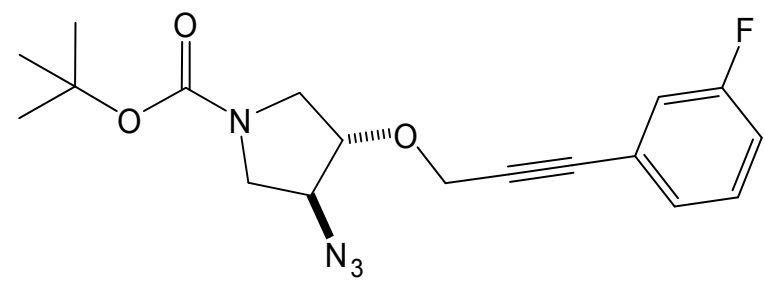

From 8a (100 mg, $0.43 \mathrm{mmol})$, NaH (23 mg, $0.57 \mathrm{mmol})$, 1-(3-bromoprop-1-ynyl)-3-fluorobenzene $(112 \mathrm{mg}, 0.52 \mathrm{mmol})$, tetrabutylammonium iodide $(113 \mathrm{mg}, 0.30 \mathrm{mmol})$ and THF (4 ml), afforded the titled compound (144 $\mathrm{mg}, 91 \%$ yield) as yellow oil.

${ }^{1} \mathrm{H}$ NMR (400 MHz, $\left.\mathrm{CDCl}_{3}\right)$ : mixture of rotamers, $\delta(\mathrm{ppm}) 7.25(\mathrm{~m}, 2 \mathrm{H}), 7.14(\mathrm{~m}, 1 \mathrm{H}), 7.04(\mathrm{~m}, 1 \mathrm{H})$, $4.44(\mathrm{~m}, 2 \mathrm{H}), 4.16(\mathrm{~m}, 1 \mathrm{H}), 4.08(\mathrm{~m}, 1 \mathrm{H}), 3.64(\mathrm{~m}, 2 \mathrm{H}), 3.46(\mathrm{~m}, 2 \mathrm{H}), 1.46(\mathrm{~s}, 9 \mathrm{H}) .{ }^{13} \mathrm{C}$ NMR $(100$ $\left.\mathrm{MHz}, \mathrm{CDCl}_{3}\right): \delta(\mathrm{ppm}) 162.21\left(\mathrm{~d}, \mathrm{~J}_{\mathrm{CF}}=247 \mathrm{~Hz}\right), 154.11,129.90\left(\mathrm{~d}, \mathrm{~J}_{\mathrm{CF}}=8 \mathrm{~Hz}\right), 127.56,123.85(\mathrm{~d}$, $\left.\mathrm{J}_{\mathrm{CF}}=10 \mathrm{~Hz}\right), 118.50\left(\mathrm{~d}, \mathrm{~J}_{\mathrm{CF}}=23 \mathrm{~Hz}\right), 116.03\left(\mathrm{~d}, \mathrm{~J}_{\mathrm{CF}}=21 \mathrm{~Hz}\right), 85.78,85.00,80.72,79.90,79.79,63.49$, 
62.58, 57.67, 57.60, 49.43, 48.67, 48.57, 48.14, 28.31. HR-MS calc for M+Na: 383.1495, obs: 383.1502 .

\section{General procedure for the synthesis of compounds of general formula 4 and 10:}

A solution of azido alkyne in toluene or xylene was heated at $110^{\circ} \mathrm{C}$ for 16 hours or until TLC analysis shows completed reaction. The solvent was removed under reduced pressure and the residue was purified by flash chromatography, silica gel, gradient hexane:ethyl acetate (3:1) to neat ethyl acetate.

\section{(5a,8a-trans)-7-benzyl-4,5a,6,7,8,8a-hexahydropyrrolo[3,4-b][1,2,3]triazolo[1,5-d][1,4]oxazine} (4a):

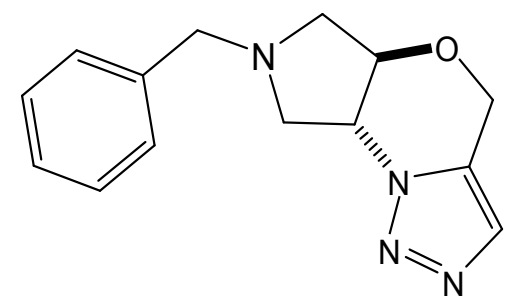

Compound 4a was prepared according the general method from 3a (1.44 g, $5.60 \mathrm{mmol})$ and xylene (40 $\mathrm{ml}$ ) afforded the titled compound (1.25 g, 87\% yield) as yellow solid. M.p. $101-102^{\circ} \mathrm{C}$.

${ }^{1} \mathrm{H}$ NMR $\left(400 \mathrm{MHz}, \mathrm{CDCl}_{3}\right): \delta(\mathrm{ppm}) 7.53(\mathrm{~s}, 1 \mathrm{H}), 7.31(\mathrm{~m}, 5 \mathrm{H}), 5.12(\mathrm{AB}$ system, 2H), $4.32(\mathrm{~m}, 1 \mathrm{H})$, $3.91(\mathrm{~m}, 3 \mathrm{H}), 3.71(\mathrm{dd}, \mathrm{J} 1=7.5 \mathrm{~Hz}, \mathrm{~J} 2=9.7 \mathrm{~Hz}, 1 \mathrm{H}), 3.16(\mathrm{~m}, 2 \mathrm{H}), 3.02(\mathrm{t}, \mathrm{J}=9.7 \mathrm{~Hz}, 1 \mathrm{H}) .{ }^{13} \mathrm{C} \mathrm{NMR}(100$ $\left.\mathrm{MHz}, \mathrm{CDCl}_{3}\right): \delta(\mathrm{ppm}) 138.23,130.79,128.72,128.55,128.51,127.39,79.29,63.87,60.82,58.91$, 51.84, 50.79. HR-MS calc for M+H: 257.1402, obs: 257.1401.

(5a,8a-trans)-7-benzyl-3-methyl-4,5a,6,7,8,8a-hexahydropyrrolo[3,4-b][1,2,3]triazolo[1,5-d][1,4] oxazine (4b):

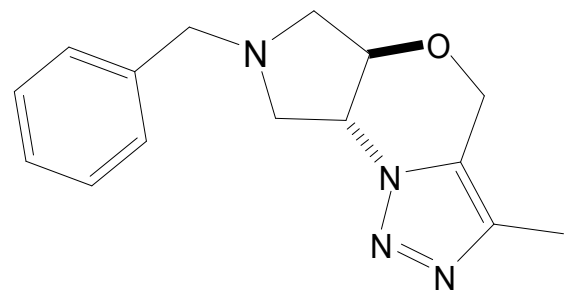

From $3 \mathbf{b}(150 \mathrm{mg}, 0.50 \mathrm{mmol})$ and toluene $(6 \mathrm{ml})$ afforded the titled compound $(136 \mathrm{mg}, 93 \%$ yield $)$ as yellow solid. M.p. $103-104^{\circ} \mathrm{C}$. 
${ }^{1} \mathrm{H}$ NMR (400 MHz, $\mathrm{CDCl}_{3}$ ): $\delta$ (ppm) 7.32 (m, 5H), 5.01 (AB system, 2H), $4.26(\mathrm{~m}, 1 \mathrm{H}), 3.90(\mathrm{~m}, 3 \mathrm{H})$, $3.67(\mathrm{dd}, \mathrm{J} 1=7.1 \mathrm{~Hz}, \mathrm{~J} 2=9.4 \mathrm{~Hz}, 1 \mathrm{H}), 3.14(\mathrm{~m}, 2 \mathrm{H}), 2.99(\mathrm{t}, \mathrm{J}=9.7 \mathrm{~Hz}, 1 \mathrm{H}), 2.25(\mathrm{~s}, 3 \mathrm{H}) .{ }^{13} \mathrm{C} \mathrm{NMR}(100$ $\left.\mathrm{MHz}_{\mathrm{CDCl}}\right): \delta(\mathrm{ppm}) 138.25,137.57,128.56,128.49,127.36,127.24,79.17,63.76,60.85,58.97$, 51.84, 50.76, 10.16. HR-MS calc for M+H: 293.1378, obs: 293.1372.

(5a,8a-trans)-7-benzyl-3-ethyl-4,5a,6,7,8,8a-hexahydropyrrolo[3,4-b][1,2,3]triazolo[1,5-d][1,4] oxazine (4c):

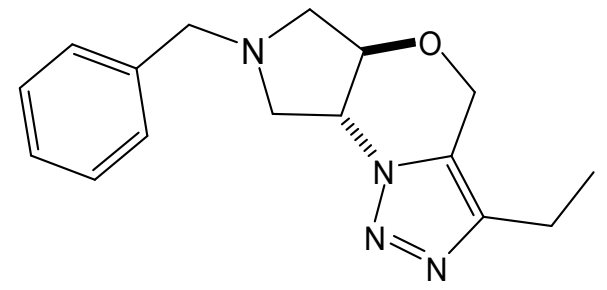

From 3c (130 mg, $0.31 \mathrm{mmol})$ and xylene $(5 \mathrm{ml})$ afforded the titled compound $(103 \mathrm{mg}, 79 \%$ yield $)$ as light brown solid. M.p. $106-107^{\circ} \mathrm{C}$.

${ }^{1} \mathrm{H}$ NMR (400 MHz, $\left.\mathrm{CDCl}_{3}\right): \delta(\mathrm{ppm}) 7.34(\mathrm{~m}, 5 \mathrm{H}), 5.10$ (AB system, 2H), $4.29(\mathrm{~m}, 1 \mathrm{H}), 3.90(\mathrm{~m}, 3 \mathrm{H})$, $3.69(\mathrm{~m}, 1 \mathrm{H}), 3.16(\mathrm{~m}, 2 \mathrm{H}), 3.02(\mathrm{t}, \mathrm{J}=9.5 \mathrm{~Hz}, 1 \mathrm{H}), 2.67(\mathrm{q}, \mathrm{J}=7.6 \mathrm{~Hz}, 2 \mathrm{H}), 1.26(\mathrm{t}, \mathrm{J}=7.6 \mathrm{~Hz}, 3 \mathrm{H}) .{ }^{13} \mathrm{C}$ NMR (100 MHz, $\left.\mathrm{CDCl}_{3}\right): \delta$ (ppm) 143.37, 138.19, 128.58, 128.50, 127.39, 126.70, 79.14, 63.89, 60.86, 58.96, 51.87, 50.81, 18.64, 13.19. HR-MS calc for M+H: 285.1715, obs: 285.1714.

(5a,8a-trans)-7-benzyl-3-phenyl-4,5a,6,7,8,8a-hexahydropyrrolo[3,4-b][1,2,3]triazolo[1,5-d][1,4] oxazine (4d):

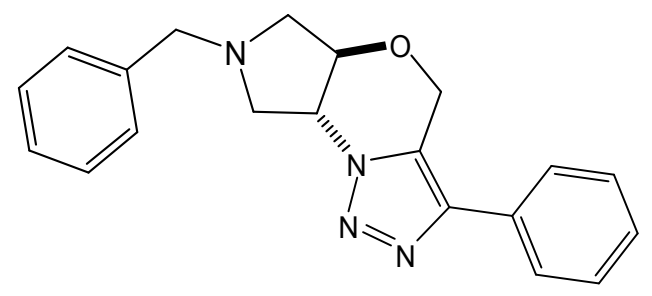

From 3d (170 mg, $0.51 \mathrm{mmol})$ and xylene $(7 \mathrm{ml})$ afforded the titled compound (144 $\mathrm{mg}, 85 \%$ yield $)$ as light brown solid. M.p. $154-155^{\circ} \mathrm{C}$.

${ }^{1} \mathrm{H}$ NMR $\left(400 \mathrm{MHz}, \mathrm{CDCl}_{3}\right): \delta(\mathrm{ppm}) 7.65(\mathrm{~d}, \mathrm{~J}=8.4 \mathrm{~Hz}, 2 \mathrm{H}), 7.46(\mathrm{t}, \mathrm{J}=7.4 \mathrm{~Hz}, 2 \mathrm{H}), 7.31(\mathrm{~m}, 6 \mathrm{H}), 5.29$ (AB system, 2H), 4.35 (m, 1H), 4.04 (m, 1H), 3.94 (AB system, 2H), $3.74(\mathrm{dd}, \mathrm{J} 1=7.0 \mathrm{~Hz}, \mathrm{~J} 2=9.6 \mathrm{~Hz}$, 1H), $3.22(\mathrm{~m}, 2 \mathrm{H}), 3.05(\mathrm{t}, \mathrm{J}=9.6 \mathrm{~Hz}, 1 \mathrm{H}) .{ }^{13} \mathrm{C} \mathrm{NMR}\left(100 \mathrm{MHz}, \mathrm{CDCl}_{3}\right): \delta(\mathrm{ppm}) 141.79,138.17$, 
$130.76,128.98,128.60,128.54,128.02,127.44,127.12,126.09,78.97,64.95,60.85,59.12,51.88$, 50.82. HR-MS calc for M+H: 333.1715, obs: 333.1704.

(5a,8a-trans)-7-benzyl-3-(2-fluorophenyl)-4,5a,6,7,8,8a-hexahydropyrrolo[3,4-b][1,2,3]triazolo $[1,5-d][1,4]$ oxazine $(4 e)$

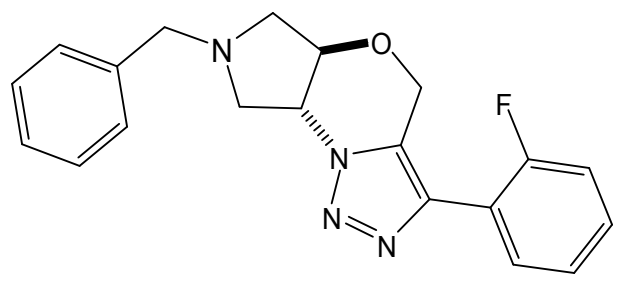

From $3 \mathrm{e}(110 \mathrm{mg}, 0.31 \mathrm{mmol})$ and toluene $(5 \mathrm{ml})$ afforded the titled compound $(73 \mathrm{mg}, 66 \%$ yield $)$ as light brown solid. M.p. $146-147^{\circ} \mathrm{C}$.

${ }^{1} \mathrm{H}$ NMR (400 MHz, $\left.\mathrm{CDCl}_{3}\right): \delta(\mathrm{ppm}) 7.98(\mathrm{~m}, 1 \mathrm{H}), 7.36(\mathrm{~m}, 5 \mathrm{H}), 7.28(\mathrm{~m}, 2 \mathrm{H}), 7.14(\mathrm{~m}, 1 \mathrm{H}), 5.21(\mathrm{~m}$, 2H), $4.39(\mathrm{~m}, 1 \mathrm{H}), 4.05(\mathrm{~m}, 1 \mathrm{H}), 3.95$ (AB system, 2H), $3.75(\mathrm{dd}, \mathrm{J} 1=7.3 \mathrm{~Hz}, \mathrm{~J} 2=9.8 \mathrm{~Hz}, 1 \mathrm{H}), 3.21(\mathrm{~m}$, 2H), $3.05(\mathrm{t}, \mathrm{J}=9.8 \mathrm{~Hz}, 1 \mathrm{H}) .{ }^{13} \mathrm{C} \mathrm{NMR}\left(100 \mathrm{MHz}, \mathrm{CDCl}_{3}\right): \delta(\mathrm{ppm}) 158.90\left(\mathrm{~d}, \mathrm{~J}_{\mathrm{CF}}=247 \mathrm{~Hz}\right), 138.26$, 136.87, $130.20\left(\mathrm{~d}, \mathrm{~J}_{\mathrm{CF}}=5 \mathrm{~Hz}\right), 130.10\left(\mathrm{~d}, \mathrm{~J}_{\mathrm{CF}}=10 \mathrm{~Hz}\right), 128.77,128.59,128.53,124.77,118.40(\mathrm{~d}$, $\left.\mathrm{J}_{\mathrm{CF}}=15 \mathrm{~Hz}\right), 115.70\left(\mathrm{~d}, \mathrm{~J}_{\mathrm{CF}}=23 \mathrm{~Hz}\right), 79.01,65.10,60.87,59.23,51.89,50.84$. HR-MS calc for $\mathrm{M}+\mathrm{H}$ : 351.1621, obs: 351.1631 .

(5a,8a-trans)-7-benzyl-3-(3-fluorophenyl)-4,5a,6,7,8,8a-hexahydropyrrolo[3,4-b][1,2,3]triazolo $[1,5-d][1,4]$ oxazine $(4 f)$ :

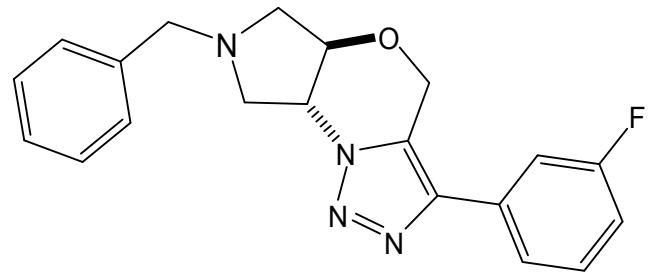

From 3f (110 mg, $0.31 \mathrm{mmol})$ and xylene $(5 \mathrm{ml})$ afforded the titled compound $(93 \mathrm{mg}, 85 \%$ yield $)$ as light brown solid. M.p. $121-122^{\circ} \mathrm{C}$.

${ }^{1} \mathrm{H}$ NMR (400 MHz, $\left.\mathrm{CDCl}_{3}\right): \delta(\mathrm{ppm}) 7.41(\mathrm{~m}, 2 \mathrm{H}), 7.36(\mathrm{~m}, 5 \mathrm{H}), 7.31(\mathrm{~m}, 1 \mathrm{H}), 7.05(\mathrm{~m}, 1 \mathrm{H}), 5.28(\mathrm{AB}$ system, 2H), $4.37(\mathrm{~m}, 1 \mathrm{H}), 4.01(\mathrm{~m}, 1 \mathrm{H}), 3.94$ (AB system, 2H), $3.72(\mathrm{~m}, 1 \mathrm{H}), 3.24(\mathrm{~m}, 2 \mathrm{H}), 3.05(\mathrm{t}$, $\mathrm{J}=9.7 \mathrm{~Hz}, 1 \mathrm{H}) .{ }^{13} \mathrm{C} \mathrm{NMR}\left(100 \mathrm{MHz}, \mathrm{CDCl}_{3}\right): \delta(\mathrm{ppm}) 163.16\left(\mathrm{~d}, \mathrm{~J}_{\mathrm{CF}}=246 \mathrm{~Hz}\right), 140.70,132.90(\mathrm{~d}$, $\left.\mathrm{J}_{\mathrm{CF}}=9 \mathrm{~Hz}\right), 130.60\left(\mathrm{~d}, \mathrm{~J}_{\mathrm{CF}}=9 \mathrm{~Hz}\right), 128.57,128.55,127.57,127.44,121.57\left(\mathrm{~d}, \mathrm{~J}_{\mathrm{CF}}=3 \mathrm{~Hz}\right), 114.86(\mathrm{~d}$, 
$\left.\mathrm{J}_{\mathrm{CF}}=22 \mathrm{~Hz}\right), 113.00\left(\mathrm{~d}, \mathrm{~J}_{\mathrm{CF}}=22 \mathrm{~Hz}\right), 78.97,64.80,60.82,59.14,51.84,50.77$. HR-MS calc for $\mathrm{M}+\mathrm{H}$ : 351.1621, obs: 351.1621 .

(5a,8a-trans)-7-benzyl-3-(4-chlorophenyl)-4,5a,6,7,8,8a-hexahydropyrrolo[3,4-b][1,2,3]triazolo $[1,5-d][1,4]$ oxazine $(4 \mathrm{~g})$ :

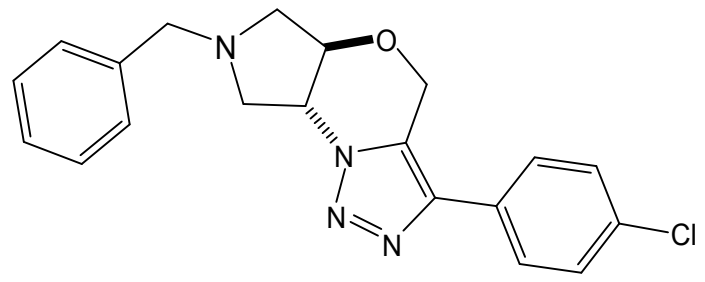

From $\mathbf{3 g}(115 \mathrm{mg}, 0.31 \mathrm{mmol})$ and xylene $(5 \mathrm{ml})$ afforded the titled compound $(89 \mathrm{mg}, 77 \%$ yield) as white solid. M.p. $197-198^{\circ} \mathrm{C}$.

${ }^{1} \mathrm{H}$ NMR $\left(400 \mathrm{MHz}, \mathrm{CDCl}_{3}\right): \delta(\mathrm{ppm}) 7.60(\mathrm{~d}, \mathrm{~J}=7.9 \mathrm{~Hz}, 2 \mathrm{H}), 7.44(\mathrm{~d}, \mathrm{~J}=7.9 \mathrm{~Hz}, 2 \mathrm{H}), 7.34(\mathrm{~m}, 5 \mathrm{H}), 5.28$ (AB system, 2H), $4.39(\mathrm{~m}, 1 \mathrm{H}), 3.98(\mathrm{~m}, 3 \mathrm{H}), 3.75(\mathrm{~m}, 1 \mathrm{H}), 3.24(\mathrm{~m}, 2 \mathrm{H}), 3.06(\mathrm{t}, \mathrm{J}=9.3 \mathrm{~Hz}, 1 \mathrm{H}) .{ }^{13} \mathrm{C}$ NMR (100 MHz, $\left.\mathrm{CDCl}_{3}\right): \delta(\mathrm{ppm}) 140.81,138.05,133.87,129.25,129.20,128.60,128.56,127.49$, 127.28, 127.22, 78.97, 64.83, 60.82, 59.13, 51.83, 50.77. HR-MS calc for M+H: 367.1326, obs: 367.1333.

(5a,8a-trans)-7-benzyl-3-(4-(trifluoromethyl)phenyl)-4,5a,6,7,8,8a-hexahydropyrrolo[3,4-b][1,2,3] triazolo[1,5-d][1,4]oxazine (4h):

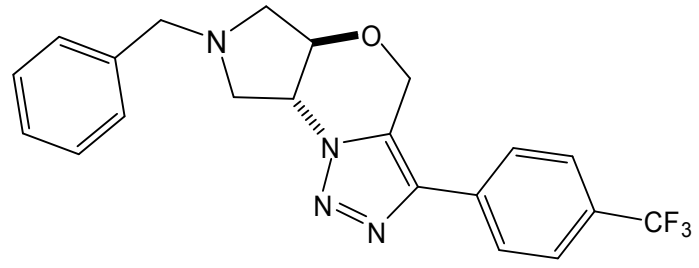

From $3 \mathrm{~h}(87 \mathrm{mg}, 0.21 \mathrm{mmol})$ and toluene $(5 \mathrm{ml})$ afforded the titled compound ( $75 \mathrm{mg}, 86 \%$ yield) as light brown solid. M.p. $137-138^{\circ} \mathrm{C}$.

${ }^{1} \mathrm{H}$ NMR (400 MHz, $\mathrm{CDCl}_{3}$ ): $\delta$ (ppm) 7.75 (AB system, 4H), 7.36 (m, 5H), 5.32 (AB system, 2H), 4.41 (m, 1H), $4.05(\mathrm{~m}, 1 \mathrm{H}), 3.95(\mathrm{AB}$ system, 2H), $3.75(\mathrm{dd}, \mathrm{J} 1=7.1 \mathrm{~Hz}, \mathrm{~J} 2=9.4 \mathrm{~Hz}, 1 \mathrm{H}), 3.22(\mathrm{~m}, 2 \mathrm{H}), 3.06$ $(\mathrm{t}, \mathrm{J}=9.4 \mathrm{~Hz}, 1 \mathrm{H}) .{ }^{13} \mathrm{C} \mathrm{NMR}\left(100 \mathrm{MHz}, \mathrm{CDCl}_{3}\right): \delta(\mathrm{ppm}) 140.50,138.15,134.22,129.80\left(\mathrm{q}, \mathrm{J}_{\mathrm{CF}}=33 \mathrm{~Hz}\right)$, 128.56, 128.06, 127.45, 126.16, 125.90 (q, $\left.\mathrm{J}_{\mathrm{CF}}=4 \mathrm{~Hz}\right), 123.90$ (q, $\left.\mathrm{J}_{\mathrm{CF}}=271 \mathrm{~Hz}\right), 79.05,64.81,60.81$, 59.20, 51.80, 50.75. HR-MS calc for M+H: 401.1589, obs: 401.1580. 


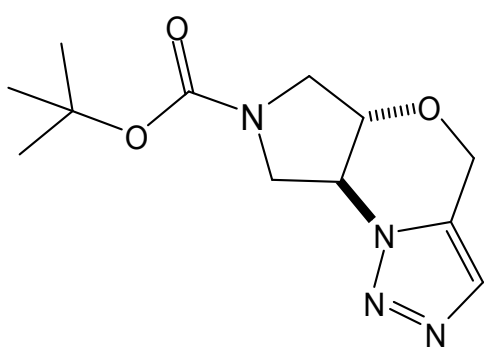

From 9a $(77 \mathrm{mg}, 0.29 \mathrm{mmol})$ and toluene $(5 \mathrm{ml})$ afforded the titled compound $(74 \mathrm{mg}, 96 \%)$ as white solid. M.p. $155-157^{\circ} \mathrm{C}$.

${ }^{1} \mathrm{H}$ NMR (400 MHz, $\mathrm{CDCl}_{3}$ ): mixture of rotamers $\delta(\mathrm{ppm}) 7.49$ (s, 1H), 5.11 (AB system, 2H), 4.37 (m, $1 \mathrm{H}), 4.25(\mathrm{~m}, 1 \mathrm{H}), 3.90(\mathrm{~m}, 2 \mathrm{H}), 3.46(\mathrm{~m}, 1 \mathrm{H}), 3.31(\mathrm{~m}, 1 \mathrm{H}), 1.43(\mathrm{~s}, 9 \mathrm{H}) .{ }^{13} \mathrm{C} \mathrm{NMR}(100 \mathrm{MHz}$, $\left.\mathrm{CDCl}_{3}\right): \delta(\mathrm{ppm}) 154.21,130.59,128.84,80.63,78.02,77.61,63.93,58.19,57.84,46.23,45.58,45.29$, 44.58, 28.41. HR-MS calc for M+Na: 289.1277, obs: 289.1274. $[\alpha]^{20}{ }_{\mathrm{D}}+64.3\left(\mathrm{c}=1, \mathrm{CHCl}_{3}\right)$.

(5aS,8aS)-tert-butyl-3-methyl-5a,6,8,8a-tetrahydropyrrolo[3,4-b][1,2,3]triazolo[1,5-d][1,4]oxazine7(4H)-carboxylate (10b):

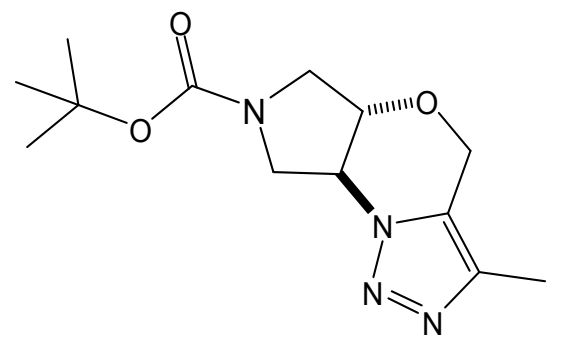

From 9b $(115 \mathrm{mg}, 0.41 \mathrm{mmol})$ and xylene $(10 \mathrm{ml})$, afforded the titled compound $(55 \mathrm{mg}, 47 \%)$ as white solid. M.p. $195-196^{\circ} \mathrm{C}$.

${ }^{1} \mathrm{H}$ NMR (400 MHz, $\mathrm{CDCl}_{3}$ ): mixture of rotamers, $\delta$ (ppm) 5.03 (AB system, 2H), $4.37(\mathrm{~m}, 1 \mathrm{H}), 4.21$ $(\mathrm{m}, 1 \mathrm{H}), 3.88(\mathrm{~m}, 2 \mathrm{H}), 3.47(\mathrm{~m}, 1 \mathrm{H}), 3.31(\mathrm{~m}, 1 \mathrm{H}), 2.23(\mathrm{~s}, 3 \mathrm{H}), 1.45(\mathrm{~s}, 9 \mathrm{H}) .{ }^{13} \mathrm{C} \mathrm{NMR}(100 \mathrm{MHz}$, $\left.\mathrm{CDCl}_{3}\right): \delta(\mathrm{ppm}) 154.14,137.74,126.92,80.57,80.47,77.81,77.46,63.70,58.13,57.78,46.16,45.49$, 45.22, 44.47, 28.28, 10.04. HR-MS calc for $\mathrm{M}+\mathrm{Na}: 303.1433$, obs: 303.1437. $[\alpha]^{20}+126.5(\mathrm{c}=1$, $\left.\mathrm{CHCl}_{3}\right)$. 


\section{7(4H)-carboxylate (10c):}

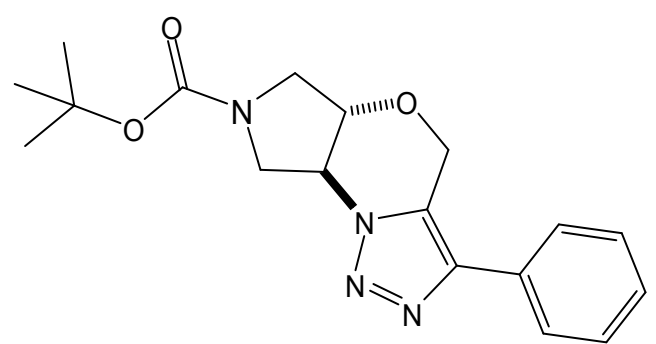

From 9c (120 mg, $0.35 \mathrm{mmol})$ and xylene $(6 \mathrm{ml})$, afforded the titled compound $(68 \mathrm{mg}, 57 \%)$ as white solid. M.p. $236-237^{\circ} \mathrm{C}$.

${ }^{1} \mathrm{H}$ NMR (400 MHz, $\left.\mathrm{CDCl}_{3}\right)$ : mixture of rotamers, $\delta(\mathrm{ppm}) 7.60(\mathrm{~d}, \mathrm{~J}=7.3 \mathrm{~Hz}, 2 \mathrm{H}), 7.42(\mathrm{t}, \mathrm{J}=7.3 \mathrm{~Hz}$, 2H), 7.32 (t, J=7.3Hz), 5.28 (AB system, 2H), $4.42(\mathrm{~m}, 1 \mathrm{H}), 4.28(\mathrm{~m}, 1 \mathrm{H}), 3.90(\mathrm{~m}, 2 \mathrm{H}), 3.52(\mathrm{~m}, 1 \mathrm{H})$, $3.35(\mathrm{~m}, 1 \mathrm{H}), 1.48(\mathrm{~s}, 9 \mathrm{H}) .{ }^{13} \mathrm{C} \mathrm{NMR}\left(100 \mathrm{MHz}, \mathrm{CDCl}_{3}\right): \delta(\mathrm{ppm}) 154.24,141.93,130.43,129.02$, $128.21,126.81,126.08,80.75,77.65,77.28,64.86,58.31,57.97,46.29,45.62,45.35,44.66,28.45$. HRMS calc for $\mathrm{M}+\mathrm{Na}: 365.1590$, obs: $365.1591 .[\alpha]^{20}+82.2\left(\mathrm{c}=1, \mathrm{CHCl}_{3}\right)$.

HPLC: Chiralpak AS, $0.46 \mathrm{~cm}$ x $25 \mathrm{~cm}$; hexane:2-propanol (85:15), $1 \mathrm{ml} / \mathrm{min}, 254$ nm. R.t.: $20.4 \mathrm{~min}$ $(94 \%$ ee).

(5aS,8aS)-tert-butyl-3-(3-fluorophenyl)-5a,6,8,8a-tetrahydropyrrolo[3,4-b][1,2,3]triazolo[1,5-d] $[1,4]$ oxazine-7(4H)-carboxylate $(10 \mathrm{~d})$ :

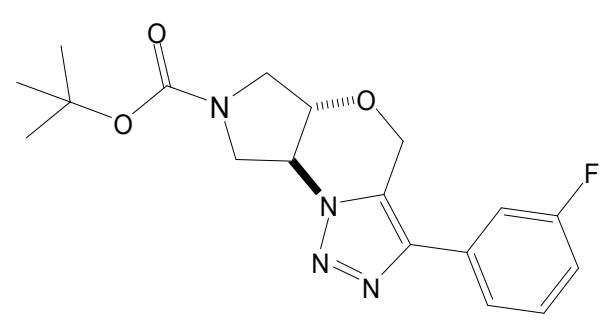

From 9d (143 mg, $0.39 \mathrm{mmol})$ and toluene $(12 \mathrm{ml})$, afforded the titled compound (124 $\mathrm{mg}, 86 \%)$ as white solid. M.p. $249-250^{\circ} \mathrm{C}$.

${ }^{1} \mathrm{H}$ NMR (400 MHz, $\left.\mathrm{CDCl}_{3}\right)$ : mixture of rotamers, $\delta(\mathrm{ppm}) 7.39(\mathrm{~m}, 3 \mathrm{H}), 7.04(\mathrm{~m}, 1 \mathrm{H}), 5.32(\mathrm{AB}$ system, 2H), $4.41(\mathrm{~m}, 2 \mathrm{H}), 3.97(\mathrm{~m}, 2 \mathrm{H}), 3.55(\mathrm{~m}, 1 \mathrm{H}), 3.39(\mathrm{~m}, 1 \mathrm{H}), 1.49(\mathrm{~s}, 9 \mathrm{H}) .{ }^{13} \mathrm{C} \mathrm{NMR}(100 \mathrm{MHz}$, 
$\left.\mathrm{CDCl}_{3}\right): \delta(\mathrm{ppm}) 163.21\left(\mathrm{~d}, \mathrm{~J}_{\mathrm{CF}}=245 \mathrm{~Hz}\right), 154.19,140.94,132.60,130.59\left(\mathrm{~d}, \mathrm{~J}_{\mathrm{CF}}=8 \mathrm{~Hz}\right), 127.18,121.59$, $115.10\left(\mathrm{~d}, \mathrm{~J}_{\mathrm{CF}}=20 \mathrm{~Hz}\right), 113.00\left(\mathrm{~d}, \mathrm{~J}_{\mathrm{CF}}=23 \mathrm{~Hz}\right), 80.81,77.70,64.74,58.36,58.03,46.21,45.58,45.30$, 44.59, 28.35. HR-MS calc for M+H: 361.1676, obs: 361.1673. $[\alpha]^{20}+69.7\left(\mathrm{c}=1, \mathrm{CHCl}_{3}\right)$.

\section{General procedure for the synthesis of compounds of general formula (5):}

A solution of the corresponding N-benzyl compound (4) in methanol or THF was purgued with argon, and $\mathrm{Pd} / \mathrm{C} 10 \%$ was added. The mixture was purgued again with argon and after that with hydrogen. The mixture was stirred at room temperature under hydrogen atmosphere for 48 hours or until TLC analysis shows completed reaction. The suspension was purgued with argon, filtered over celite and washed with dichloromethane. The filtrate was concentrated to dryness to give the product.

(5a,8a-trans)-4,5a,6,7,8,8a-hexahydropyrrolo[3,4-b][1,2,3]triazolo[1,5-d][1,4]oxazine (5a):

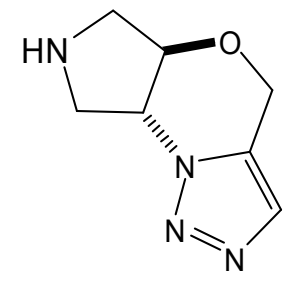

From $4 \mathbf{a}(1.08 \mathrm{~g}, 4.24 \mathrm{mmol}), \mathrm{Pd} / \mathrm{C} 10 \%(220 \mathrm{mg})$ and methanol (20 ml) afforded the titled compound (0.68 g, 97\% yield) as white solid. M.p. $217^{\circ} \mathrm{C} \mathrm{dec}$.

${ }^{1} \mathrm{H}$ NMR (400 MHz, $\mathrm{CDCl}_{3}$ ): $\delta$ (ppm) 7.53 (s, 1H), 5.14 (AB system, 2H), $4.24(\mathrm{~m}, 1 \mathrm{H}), 3.92(\mathrm{~m}, 2 \mathrm{H})$, $3.37(\mathrm{dd}, \mathrm{J} 1=7.2 \mathrm{~Hz}, \mathrm{~J} 2=9.5 \mathrm{~Hz}, 1 \mathrm{H}), 3.23(\mathrm{t}, \mathrm{J}=10.4 \mathrm{~Hz}, 1 \mathrm{H}), 3.07(\mathrm{t}, \mathrm{J}=10.1 \mathrm{~Hz}, 1 \mathrm{H}), 2.00(\mathrm{bs}, 1 \mathrm{H}) .{ }^{13} \mathrm{C}$ NMR (100 MHz, $\left.\mathrm{CDCl}_{3}\right): \delta(\mathrm{ppm})$ 130.82, 128.68, 80.60, 64.04, 59.72, 45.16, 44.41. HR-MS calc for M+H: 167.0933, obs: 167.0936.

\section{(5a,8a-trans)-3-phenyl-4,5a,6,7,8,8a-hexahydropyrrolo[3,4-b][1,2,3]triazolo[1,5-d][1,4]oxazine} (5b):

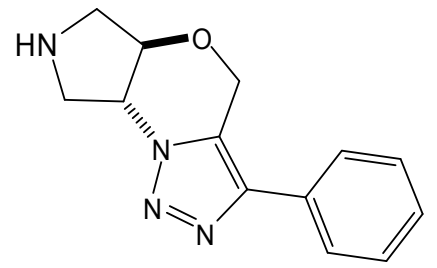

From 4d (1.37 g, $4.12 \mathrm{mmol}), \mathrm{Pd} / \mathrm{C} 10 \%(300 \mathrm{mg})$ and THF (50 ml) afforded the titled compound (0.90 g, $90 \%$ yield) as white solid. M.p. $165-167^{\circ} \mathrm{C}$.

${ }^{1} \mathrm{H}$ NMR (400 MHz, $\left.\mathrm{CDCl}_{3}\right): \delta(\mathrm{ppm}) 7.68(\mathrm{~m}, 2 \mathrm{H}), 7.48(\mathrm{~m}, 2 \mathrm{H}), 7.37$ (m, 1H), 5.36 (AB system, 2H), $4.34(\mathrm{~m}, 1 \mathrm{H}), 4.06(\mathrm{~m}, 1 \mathrm{H}), 3.96(\mathrm{dd}, \mathrm{J} 1=7.2 \mathrm{~Hz}, \mathrm{~J} 2=10.2 \mathrm{~Hz}, 1 \mathrm{H}), 3.44(\mathrm{dd}, \mathrm{J} 1=7.0 \mathrm{~Hz}, \mathrm{~J} 2=9.5 \mathrm{~Hz}, 1 \mathrm{H})$, 
$3.31(\mathrm{t}, \mathrm{J}=10.3 \mathrm{~Hz}, 1 \mathrm{H}), 3.14(\mathrm{t}, \mathrm{J}=10.0 \mathrm{~Hz}, 1 \mathrm{H}), 1.82(\mathrm{bs}, 1 \mathrm{H}) .{ }^{13} \mathrm{C} \mathrm{NMR}\left(100 \mathrm{MHz}, \mathrm{CDCl}_{3}\right): \delta(\mathrm{ppm})$ $141.81,130.74,128.98,128.05,127.12,126.11,80.36,65.12,60.01,45.24,44.53$. HR-MS calc for $\mathrm{M}+\mathrm{Na}: 265.1065$, obs: 265.1074 .

(5aS,8S)-4,5a,6,7,8,8a-hexahydropyrrolo $[3,4-b][1,2,3]$ triazolo[1,5-d] [1,4] oxazine ((S,S)-5a.2HCl):

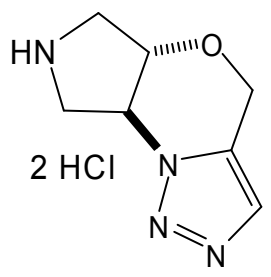

10a (100mg, $0.37 \mathrm{mmol})$ was suspended in a $4 \mathrm{M}$ solution of $\mathrm{HCl}$ in dioxane $(1 \mathrm{ml}, 4.0 \mathrm{mmol})$ and stirred at r.t. for 5 hours. The reaction mixture was concentrated to dryness to give the titled compound (85 mg, 95\%) as dihydrochloride.

${ }^{1}$ H NMR (400 MHz, CD $\left.3 \mathrm{OD}\right): \delta(\mathrm{ppm}) 7.94$ (s, 1H), 5.38 (AB system, 2H), 4.77 (m, 1H), 4.45 (m, 1H), $4.37(\mathrm{~m}, 2 \mathrm{H}), 3.91(\mathrm{~m}, 1 \mathrm{H}), 3.78(\mathrm{~m}, 1 \mathrm{H}), 3.52(\mathrm{~m}, 1 \mathrm{H})$.

\section{General procedure for the synthesis of compounds of general formula (6):}

A schlenk was charged with compound 5 (0.62 mmol), evacuated and backfilled with argon. THF was added and the solution was degassed with argon. Then the aryl halide (0.62 mmol), NaOtBu (0.86 mmol) and the palladium catalyst (7) $(0.0062 \mathrm{mmol})$ were added under argon. The resulting solution was stirred at r.t. for 24 hours. The reaction mixture was concentrated under reduced pressure and the crude was purified by flash chromatography, silica gel, gradient hexane to hexane:ethyl acetate (1:4) or by precipitation with 2-propanol.

\section{(5a,8a-trans)-7-phenyl-4,5a,6,7,8,8a-hexahydropyrrolo[3,4-b][1,2,3] triazolo[1,5-d][1,4]oxazine}

(6a):

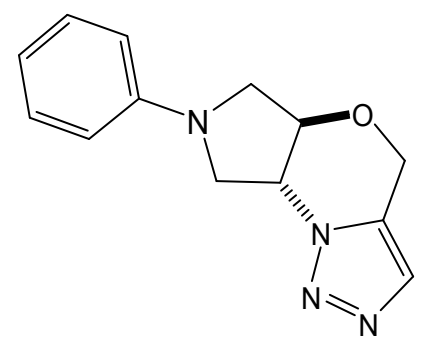


From 5a (161 mg, $0.97 \mathrm{mmol})$, bromobenzene (151 mg, $0.97 \mathrm{mmol}), \mathrm{NaOtBu}$ (130 mg, $1.35 \mathrm{mmol})$, catalyst (7) $(5.8 \mathrm{mg}, 0.0097 \mathrm{mmol})$ and THF (2 ml), afforded the titled compound (126 $\mathrm{mg}, 54 \%)$ as slightly yellow solid. M. p. $222-223^{\circ} \mathrm{C}$.

${ }^{1} \mathrm{H}$ NMR (400 MHz, $\left.\mathrm{CDCl}_{3}\right): \delta(\mathrm{ppm}) 7.58(\mathrm{~s}, 1 \mathrm{H}), 7.29(\mathrm{~m}, 2 \mathrm{H}), 6.79(\mathrm{~m}, 1 \mathrm{H}), 6.62(\mathrm{~m}, 2 \mathrm{H}), 5.20(\mathrm{AB}$ system, 2H), $4.45(\mathrm{~m}, 1 \mathrm{H}), 4.30(\mathrm{t}, \mathrm{J}=8.2 \mathrm{~Hz}, 1 \mathrm{H}), 4.10(\mathrm{~m}, 1 \mathrm{H}), 3.79(\mathrm{t}, \mathrm{J}=7.8 \mathrm{~Hz}, 1 \mathrm{H}), 3.66(\mathrm{t}, \mathrm{J}=9.1 \mathrm{~Hz}$, $1 \mathrm{H}), 3.51(\mathrm{t}, \mathrm{J}=9.1 \mathrm{~Hz}, 1 \mathrm{H}) .{ }^{13} \mathrm{C} \mathrm{NMR}\left(100 \mathrm{MHz}, \mathrm{CDCl}_{3}\right): \delta$ (ppm) 146.61, 130.69, 129.49, 128.90, 117.39, 111.32, 78.41, 63.92, 58.44, 47.67, 46.52. HR-MS calc for M+Na: 265.1065, obs: 265.1069.

(5a,8a-trans)-7-(4-chlorophenyl)-4,5a,6,7,8,8a-hexahydropyrrolo[3,4-b] [1,2,3]triazolo[1,5-d][1,4] oxazine (6b):

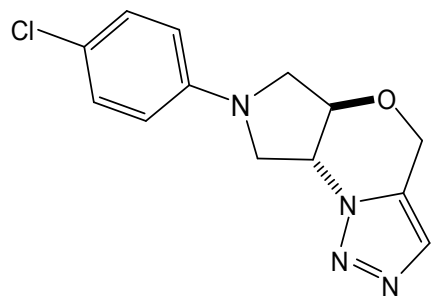

From 5a (103 mg, $0.62 \mathrm{mmol}), 1,4-$ dichlorobenzene (91 mg, $0.62 \mathrm{mmol}), \mathrm{NaOtBu}$ (83 mg, $0.86 \mathrm{mmol})$, catalyst (7) $(3.7 \mathrm{mg}, 0.0062 \mathrm{mmol})$ and THF $(2 \mathrm{ml})$, afforded the titled compound $(106 \mathrm{mg}, 62 \%)$ as white solid. M.p. $238^{\circ} \mathrm{C}$ dec.

${ }^{1} \mathrm{H}$ NMR (400 MHz, $\left.\mathrm{CDCl}_{3}\right): \delta(\mathrm{ppm}) 7.57(\mathrm{~s}, 1 \mathrm{H}), 7.20(\mathrm{~d}, \mathrm{~J}=8.7 \mathrm{~Hz}, 2 \mathrm{H}), 6.50(\mathrm{~d}, \mathrm{~J}=8.7 \mathrm{~Hz}, 2 \mathrm{H}), 5.20$ (AB system, 2H), $4.43(\mathrm{~m}, 1 \mathrm{H}), 4.25(\mathrm{t}, \mathrm{J}=8.3 \mathrm{~Hz}, 1 \mathrm{H}), 4.09(\mathrm{~m}, 1 \mathrm{H}), 3.72(\mathrm{t}, \mathrm{J}=8.3 \mathrm{~Hz}, 1 \mathrm{H}), 3.62(\mathrm{t}$, $\mathrm{J}=9.5 \mathrm{~Hz}, 1 \mathrm{H}), 3.47(\mathrm{t}, \mathrm{J}=8.3 \mathrm{~Hz}, 1 \mathrm{H}) .{ }^{13} \mathrm{C} \mathrm{NMR}\left(100 \mathrm{MHz}, \mathrm{CDCl}_{3}\right): \delta(\mathrm{ppm}) 145.42,130.84,129.43$, 129.11, 122.41, 112.59, 78.44, 64.15, 58.54, 47.97, 46.85. HR-MS calc for M+Na: 299.0676, obs: 299.0680 .

(5a,8a-trans)-7-(pyridine-2-yl)-4,5a,6,7,8,8a-hexahydropyrrolo[3,4-b][1,2,3]triazolo[1,5-d][1,4] oxazine (6c):

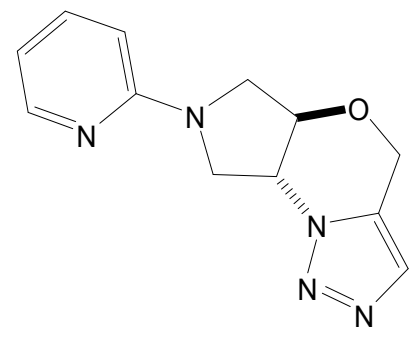


From 5a (61 mg, $0.37 \mathrm{mmol})$, 2-bromopyridine (64 mg, $0.40 \mathrm{mmol})$, NaOtBu (50 mg, $0.51 \mathrm{mmol})$, catalyst (7) $(2.2 \mathrm{mg}, 0.0037 \mathrm{mmol})$ and THF $(1.5 \mathrm{ml})$, afforded the titled compound $(39 \mathrm{mg}, 43 \%)$ as white solid. M.p. $216^{\circ} \mathrm{C}$ dec.

${ }^{1} \mathrm{H}$ NMR $\left(400 \mathrm{MHz}, \mathrm{CDCl}_{3}\right): \delta(\mathrm{ppm}) 8.18(\mathrm{~m}, 1 \mathrm{H}), 7.56(\mathrm{~s}, 1 \mathrm{H}), 7.51(\mathrm{~m}, 1 \mathrm{H}), 6.65(\mathrm{~m}, 1 \mathrm{H}), 6.43(\mathrm{~m}$, 1H), 5.20 (AB system, 2H), $4.53(\mathrm{dd}, \mathrm{J} 1=7.4 \mathrm{~Hz}, \mathrm{~J} 2=9.3 \mathrm{~Hz}, 1 \mathrm{H}), 4.43(\mathrm{~m}, 1 \mathrm{H}), 4.07(\mathrm{~m}, 2 \mathrm{H}), 3.66(\mathrm{t}$, $\mathrm{J}=9.6 \mathrm{~Hz}, 1 \mathrm{H}), 3.52(\mathrm{~m}, 1 \mathrm{H}) .{ }^{13} \mathrm{C} \mathrm{NMR}\left(100 \mathrm{MHz}, \mathrm{CDCl}_{3}\right): \delta(\mathrm{ppm}) 156.82,148.43,137.74,130.87$, $129.05,113.20,106.19,78.45,64.09,58.54,46.84,45.81$. HR-MS calc for $\mathrm{M}+\mathrm{H}: 244.1212$, obs: 244.1198.

(5a,8a-trans)-3,7-diphenyl-4,5a,6,7,8,8a-hexahydropyrrolo[3,4-b][1,2,3]

triazolo[1,5d] $[1,4]$ oxazine (6d):

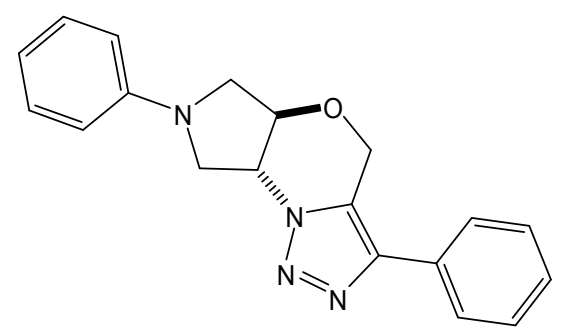

From $5 \mathbf{b}$ (101 mg, $0.42 \mathrm{mmol})$, bromobenzene (78 mg, $0.50 \mathrm{mmol}), \mathrm{NaOtBu}(56 \mathrm{mg}, 0.58 \mathrm{mmol})$, catalyst (7) $(2.5 \mathrm{mg}, 0.0042 \mathrm{mmol})$ and THF $(1.5 \mathrm{ml})$, afforded the titled compound $(83 \mathrm{mg}, 62 \%)$ as white solid. M.p. $256-257^{\circ} \mathrm{C}$.

${ }^{1} \mathrm{H}$ NMR (400 MHz, $\left.\mathrm{CDCl}_{3}\right): \delta(\mathrm{ppm}) 7.68(\mathrm{~d}, \mathrm{~J}=7.7 \mathrm{~Hz}, 2 \mathrm{H}), 7.48(\mathrm{t}, \mathrm{J}=7.7 \mathrm{~Hz}, 2 \mathrm{H}), 7.38(\mathrm{t}, \mathrm{J}=7.3 \mathrm{~Hz}$, $1 \mathrm{H}), 7.31(\mathrm{t}, \mathrm{J}=7.3 \mathrm{~Hz}, 2 \mathrm{H}), 6.81(\mathrm{t}, \mathrm{J}=7.3 \mathrm{~Hz}, 1 \mathrm{H}), 6.65(\mathrm{t}, \mathrm{J}=8.2 \mathrm{~Hz}, 2 \mathrm{H}), 5.40$ (AB system, 2H), 4.51 (m, $1 \mathrm{H}), 4.36(\mathrm{t}, \mathrm{J}=7.7 \mathrm{~Hz}, 1 \mathrm{H}), 4.17(\mathrm{~m}, 1 \mathrm{H}), 3.83(\mathrm{t}, \mathrm{J}=7.7 \mathrm{~Hz}, 1 \mathrm{H}), 3.71(\mathrm{t}, \mathrm{J}=9 \mathrm{~Hz}, 1 \mathrm{H}), 3.54(\mathrm{t}, \mathrm{J}=8.5 \mathrm{~Hz}$, $1 \mathrm{H}) .{ }^{13} \mathrm{C} \mathrm{NMR}\left(100 \mathrm{MHz}, \mathrm{CDCl}_{3}\right): \delta$ (ppm) 146.88, 142.27, 130.76, 129.70, 129.25, 128.40, 127.18, 126.36, 117.59, 111.58, 78.33, 65.21, 58.93, 47.96, 46.86. HR-MS calc for M+Na: 341.1378, obs: 341.1386. 


\section{$\underline{\text { NMR Spectra }}$}
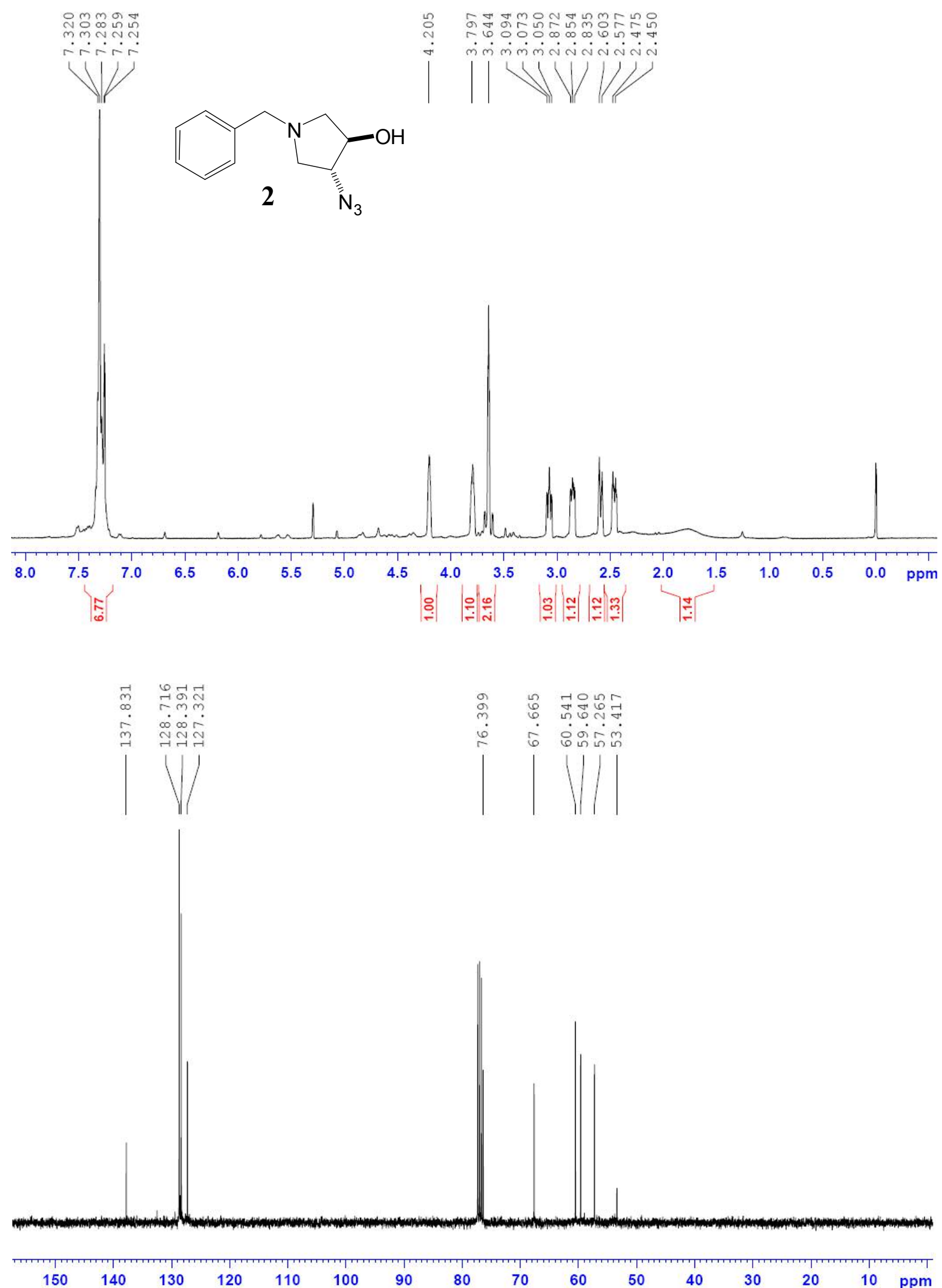


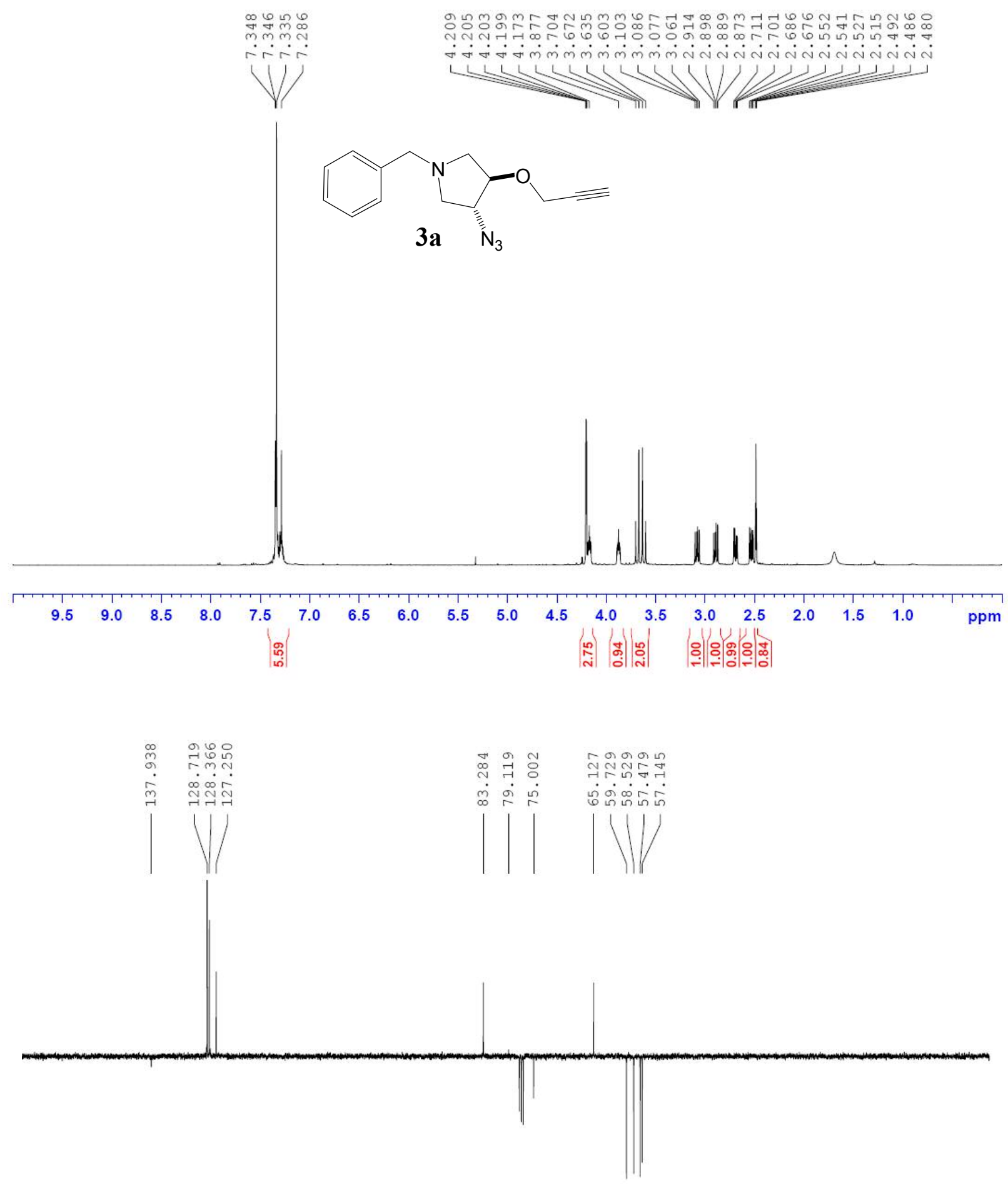

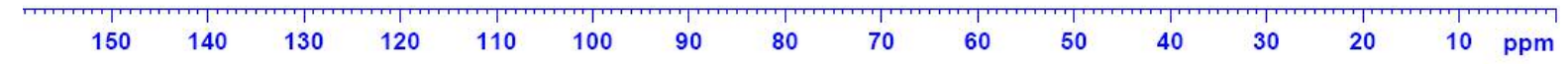




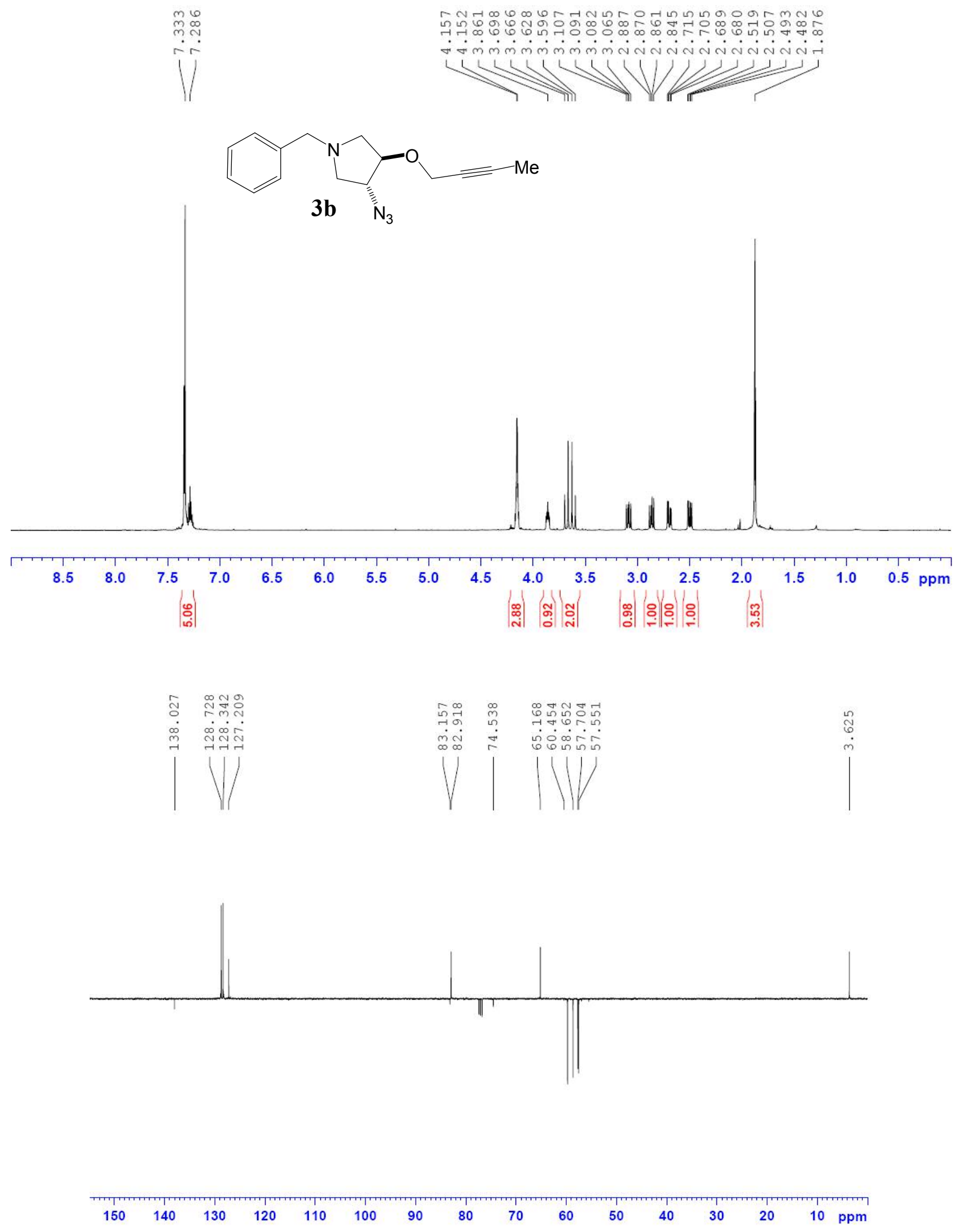


<smiles>CCC#CCOC1CN(Cc2ccccc2)CC1N</smiles>
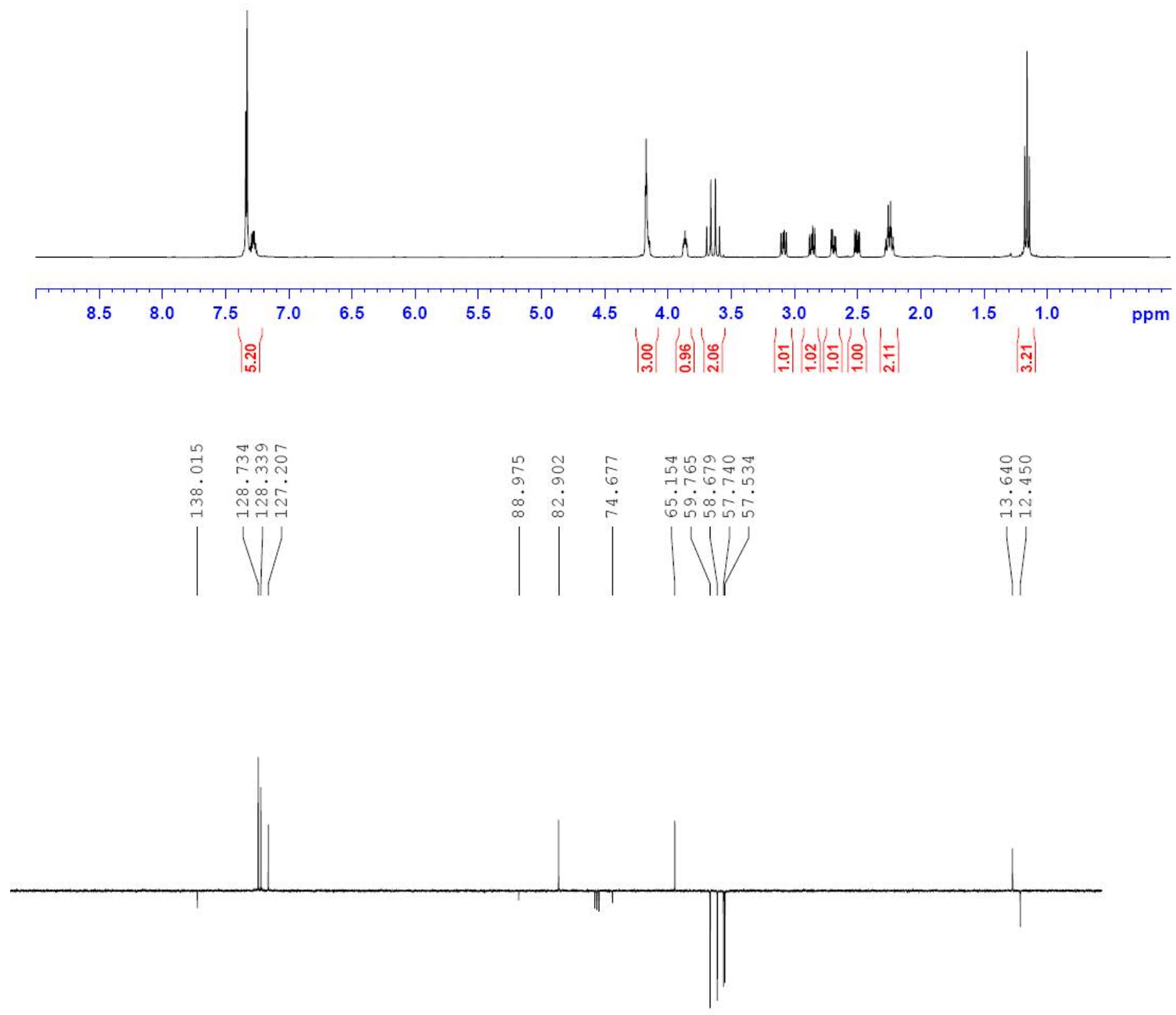

$\begin{array}{llllllllllllllll}160 & 150 & 140 & 130 & 120 & 110 & 100 & 90 & 80 & 70 & 60 & 50 & 40 & 30 & 20 & 10\end{array}$



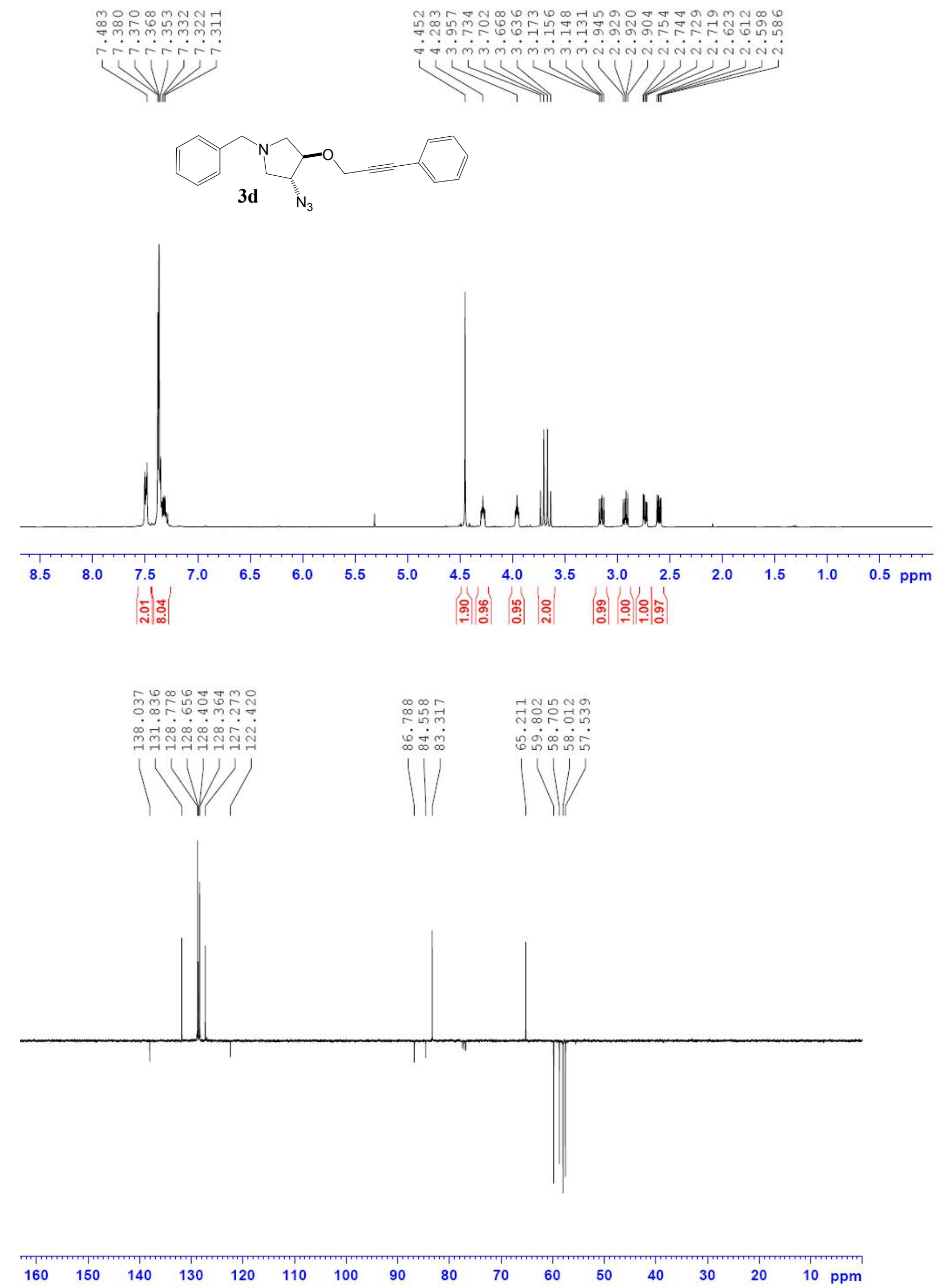

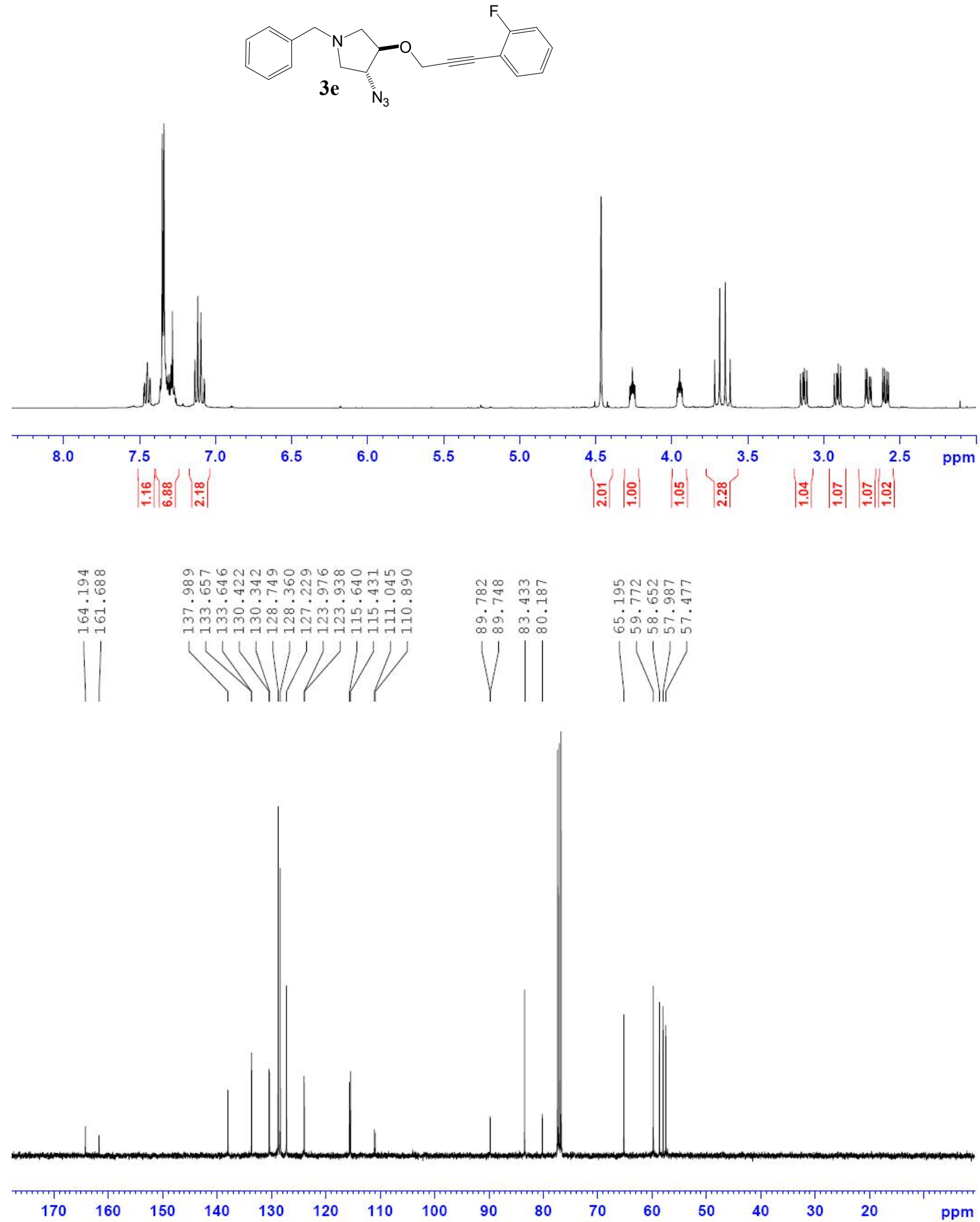


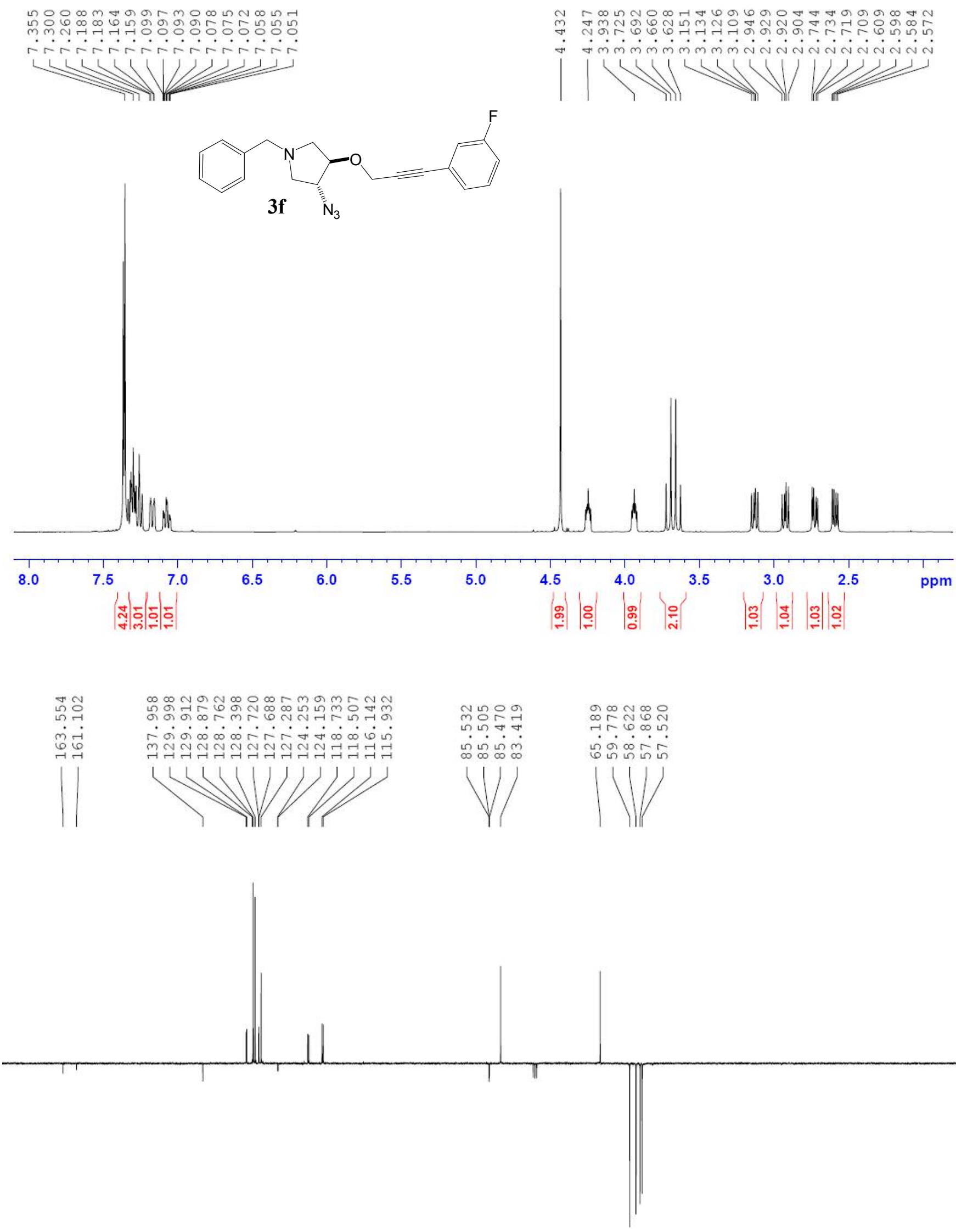

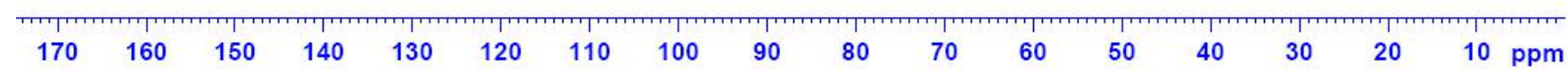




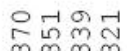

riris

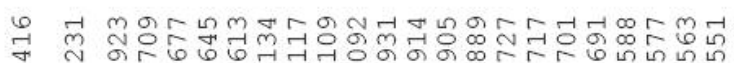

$1 / 1$

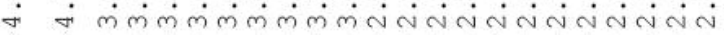

$1<1+1+1 / N$<smiles>NC1CN(Cc2ccccc2)CC1OCC#Cc1ccc(Cl)cc1</smiles>

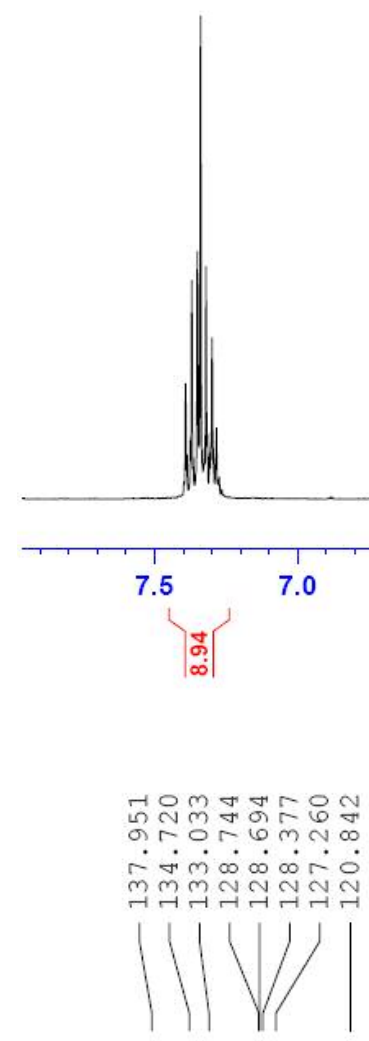

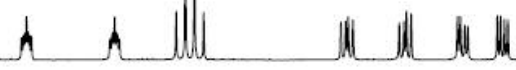

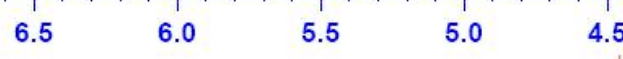

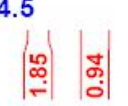

$4.0 \quad 3.5$

@:

ppm

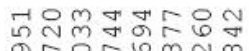

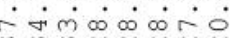

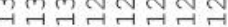

군?

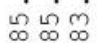

V/

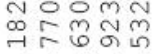

मेंक्षित
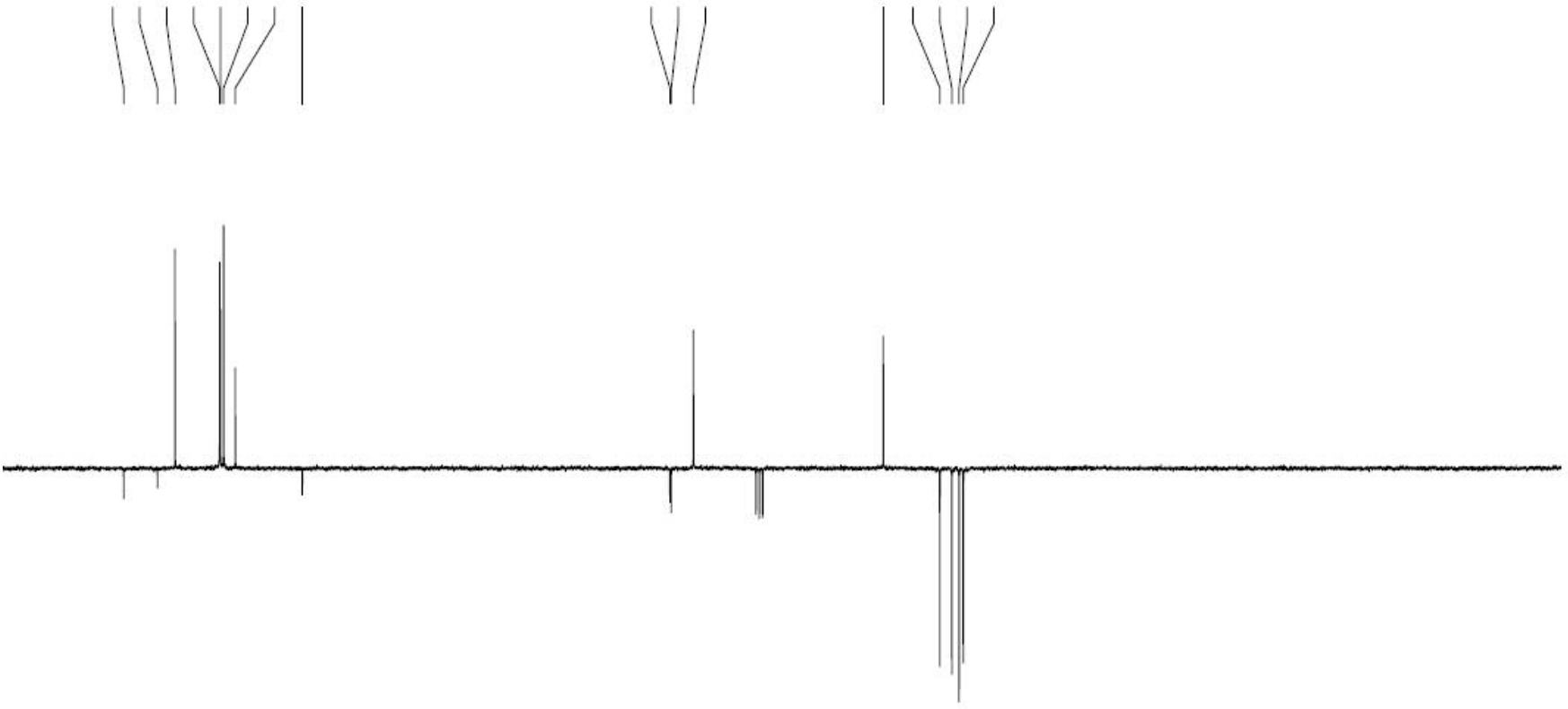


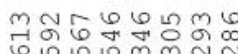

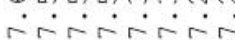

$11 / 1 / 2$

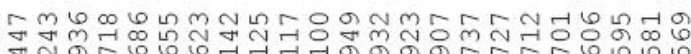

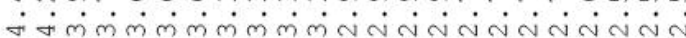

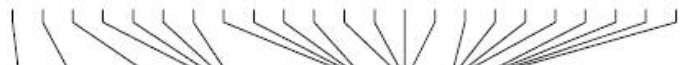<smiles>NC1CN(Cc2ccccc2)CC1OCC#Cc1ccc(C(F)(F)F)cc1</smiles>

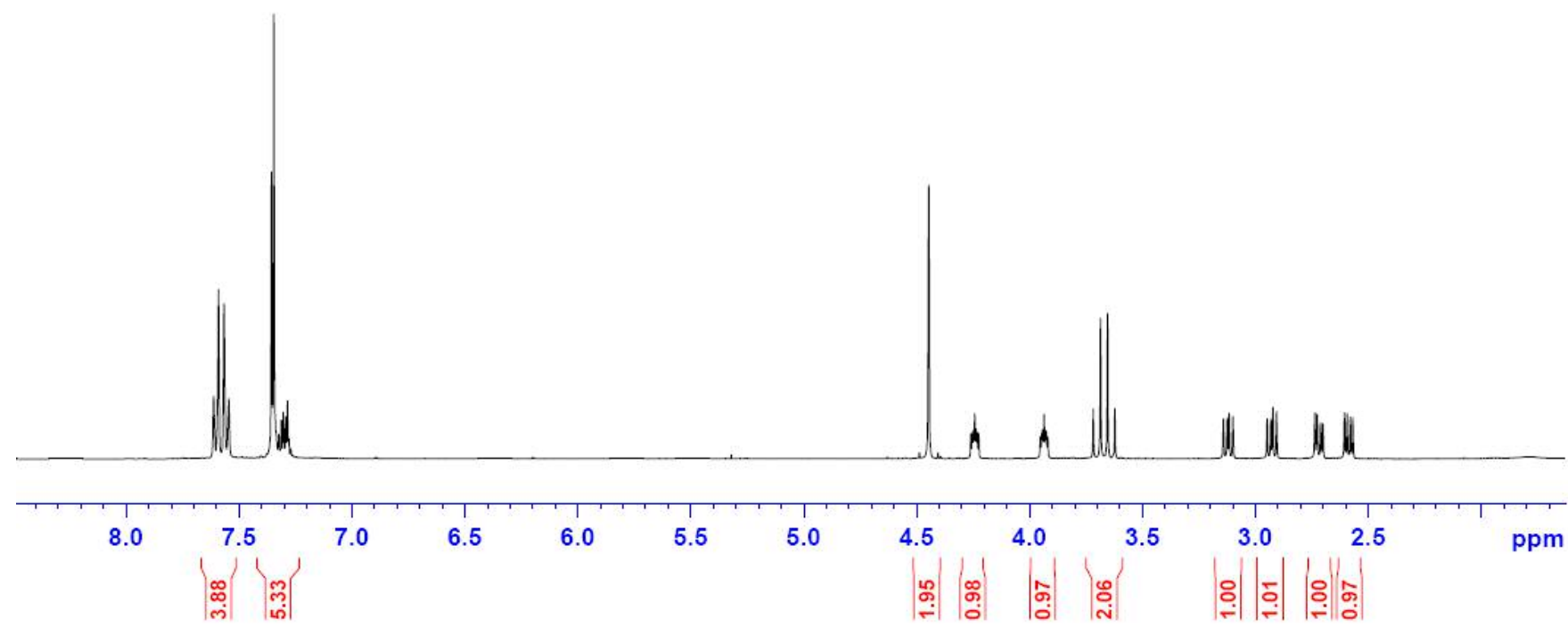

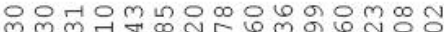

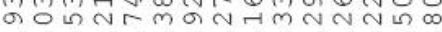

ल०0001-6n

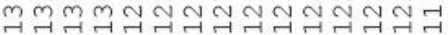

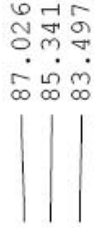

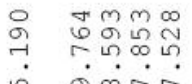

ดि
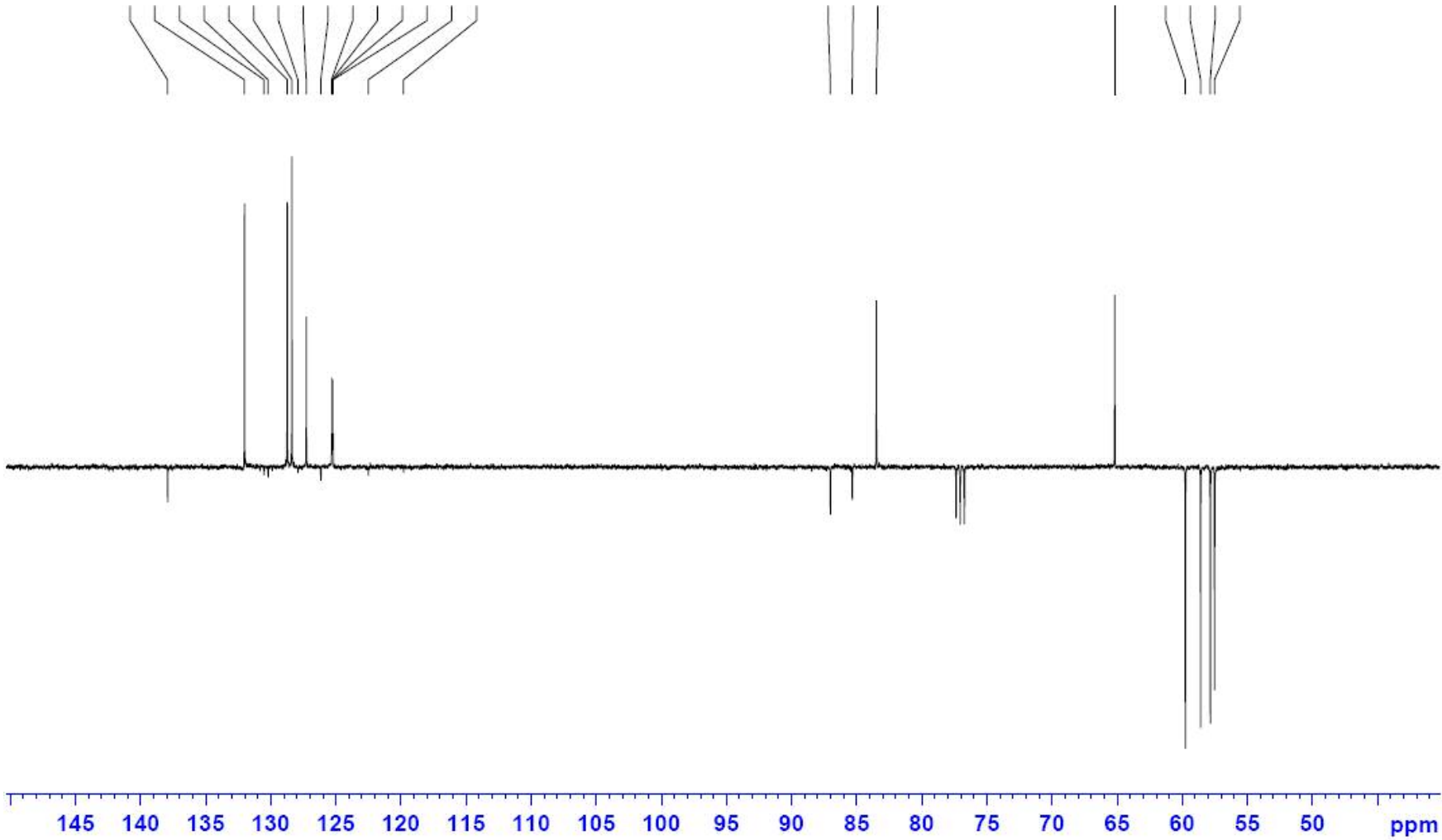


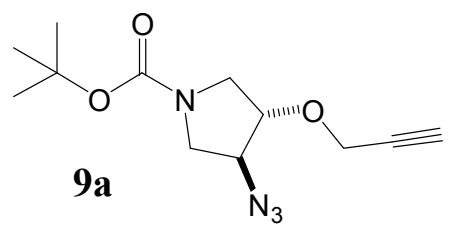

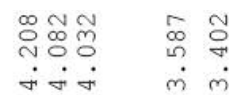

111
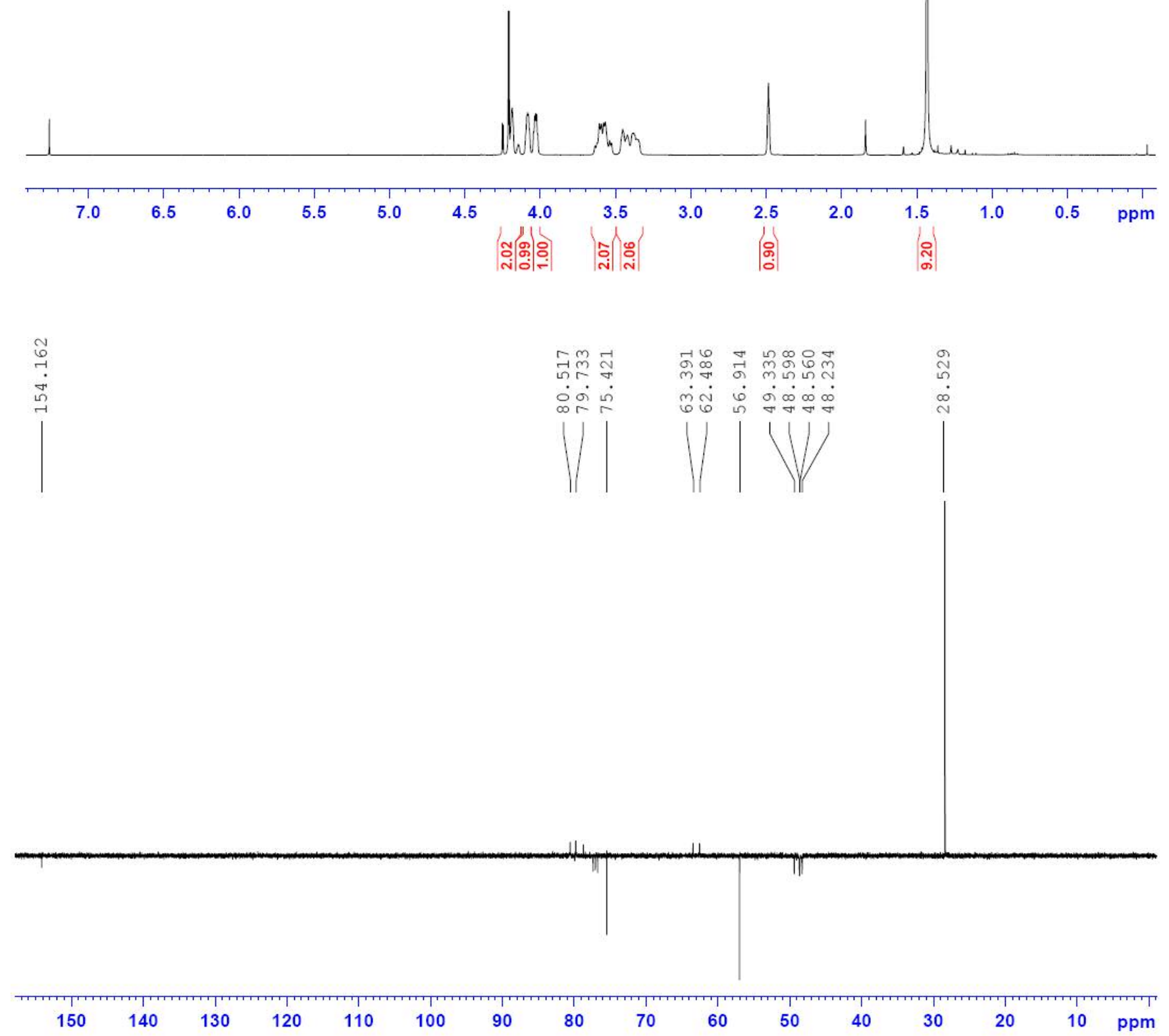

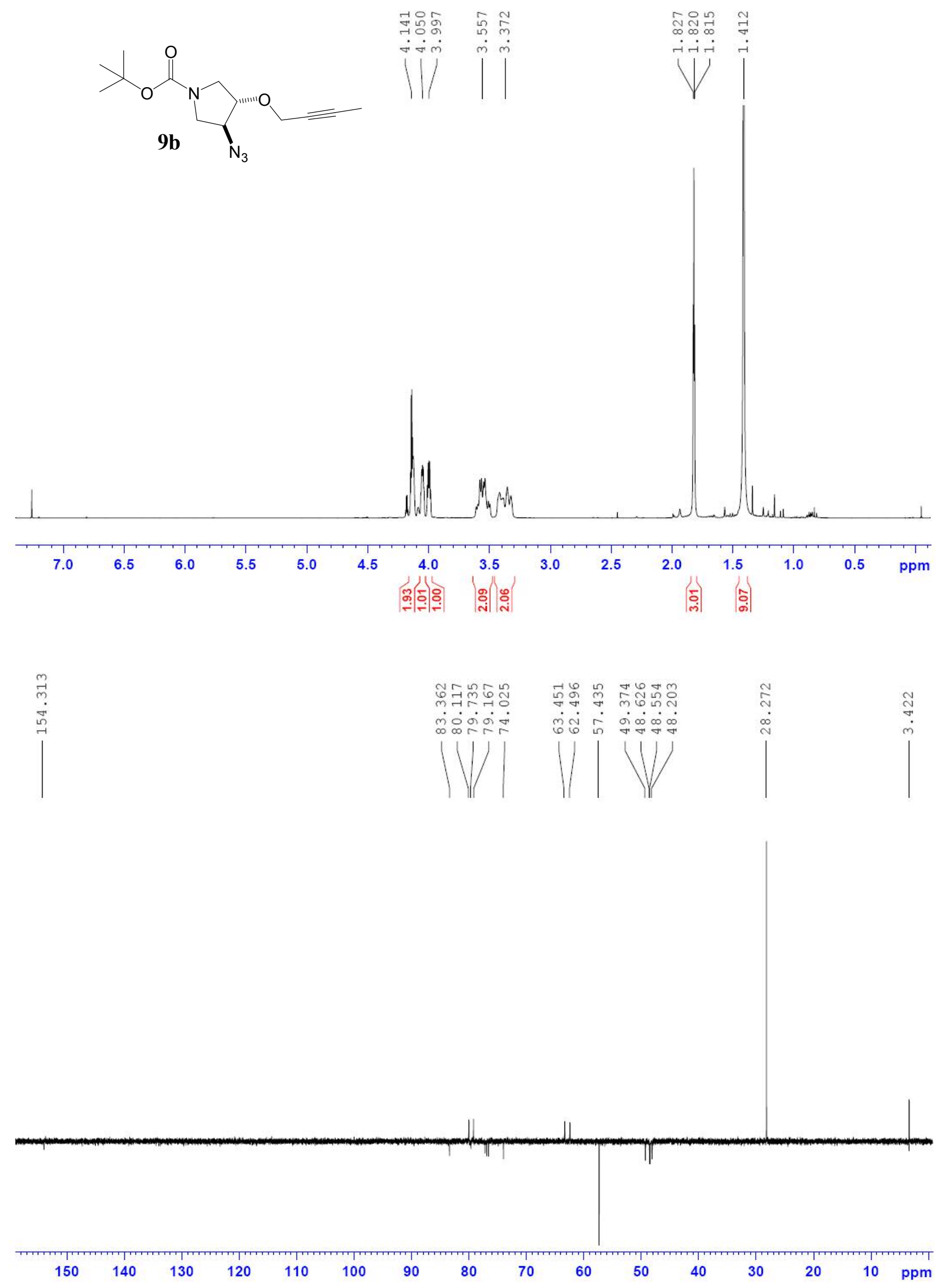

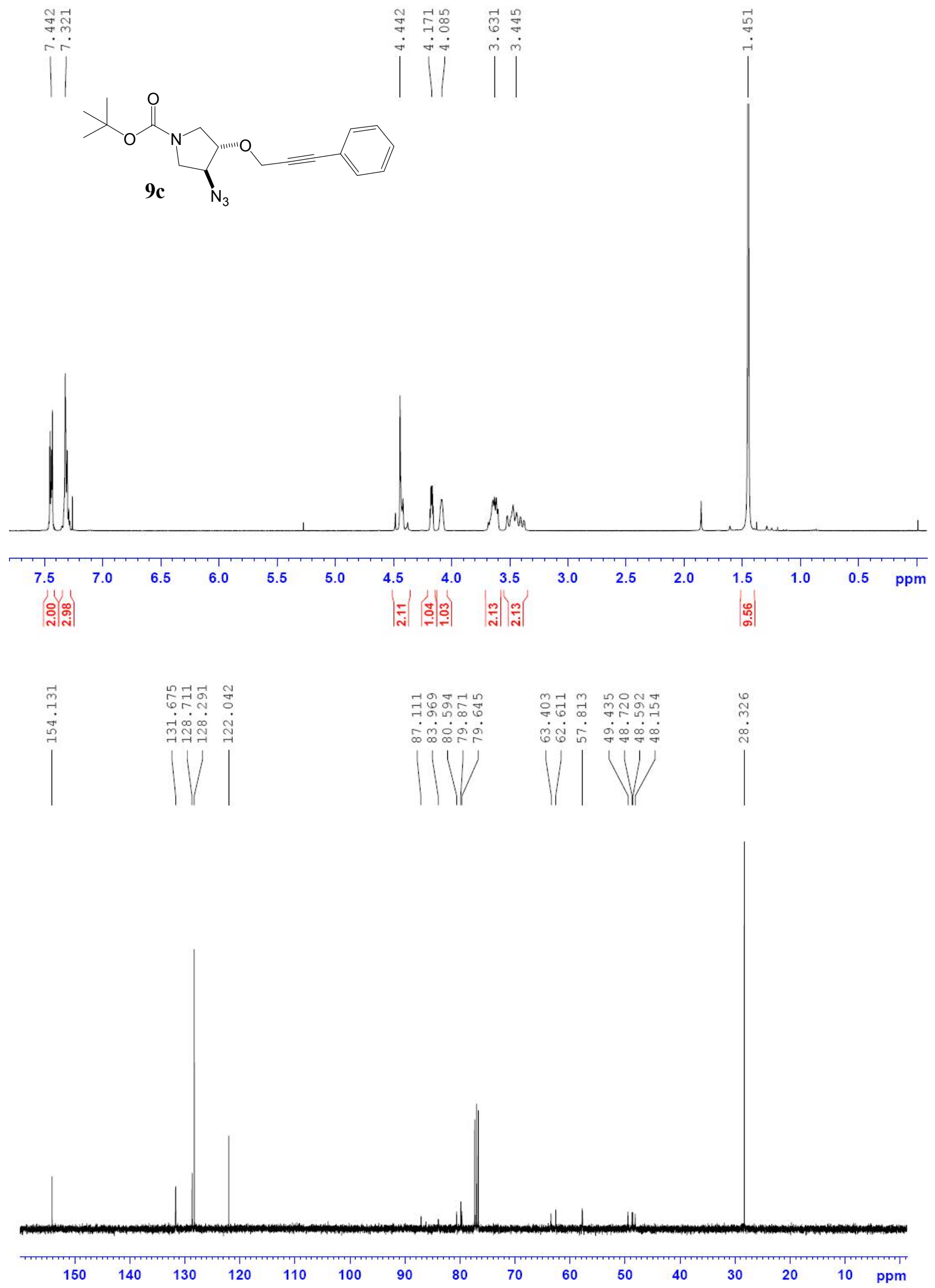


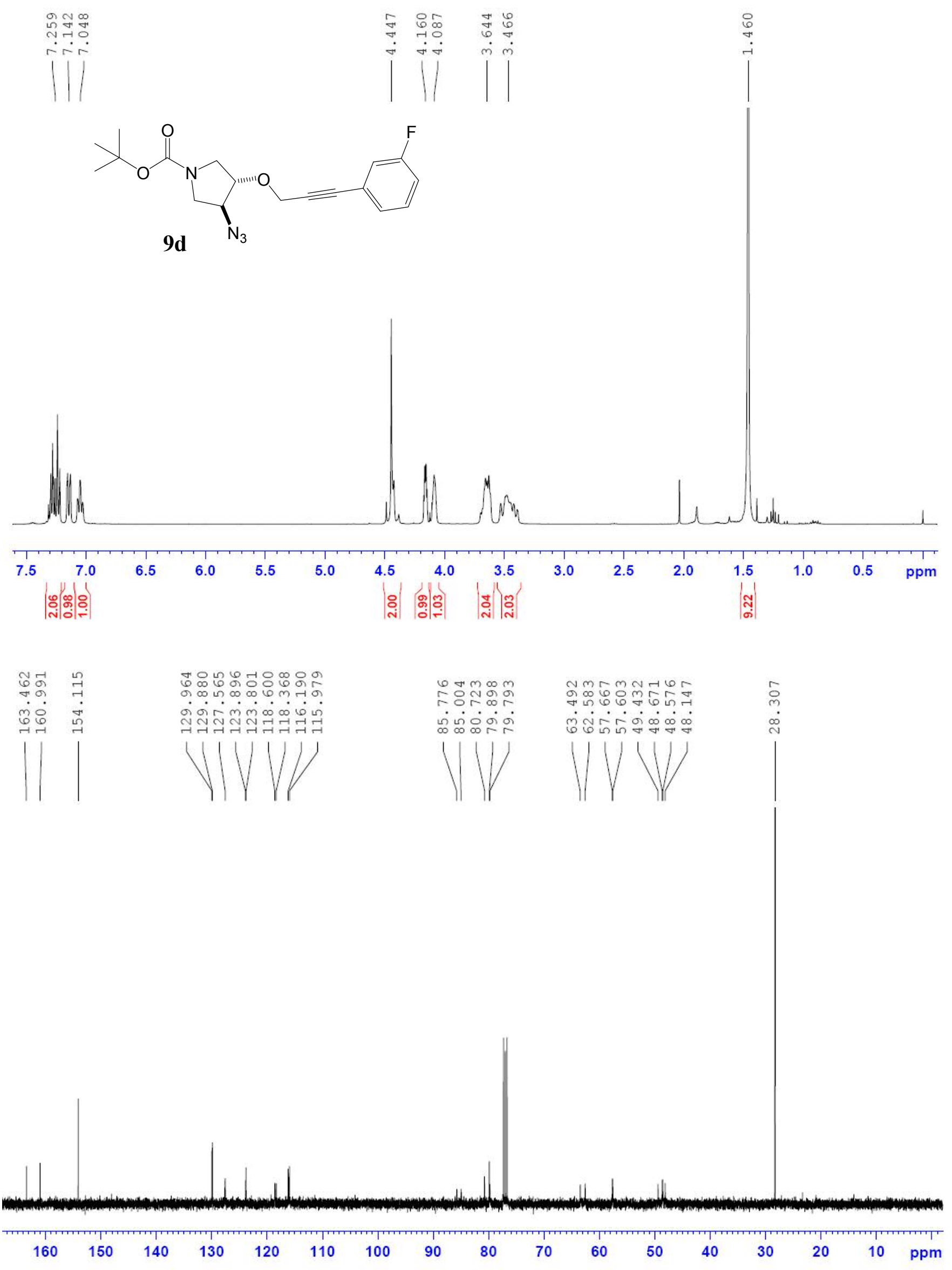


$-7 \in m-7 n \in$

เूलmलm

risinitis

W

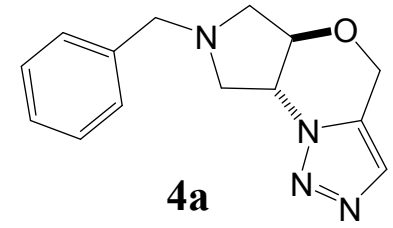

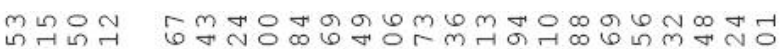

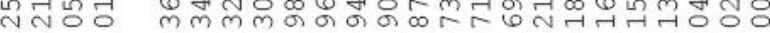

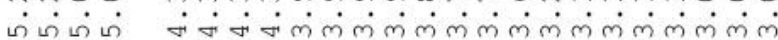

$\mathrm{NH}$
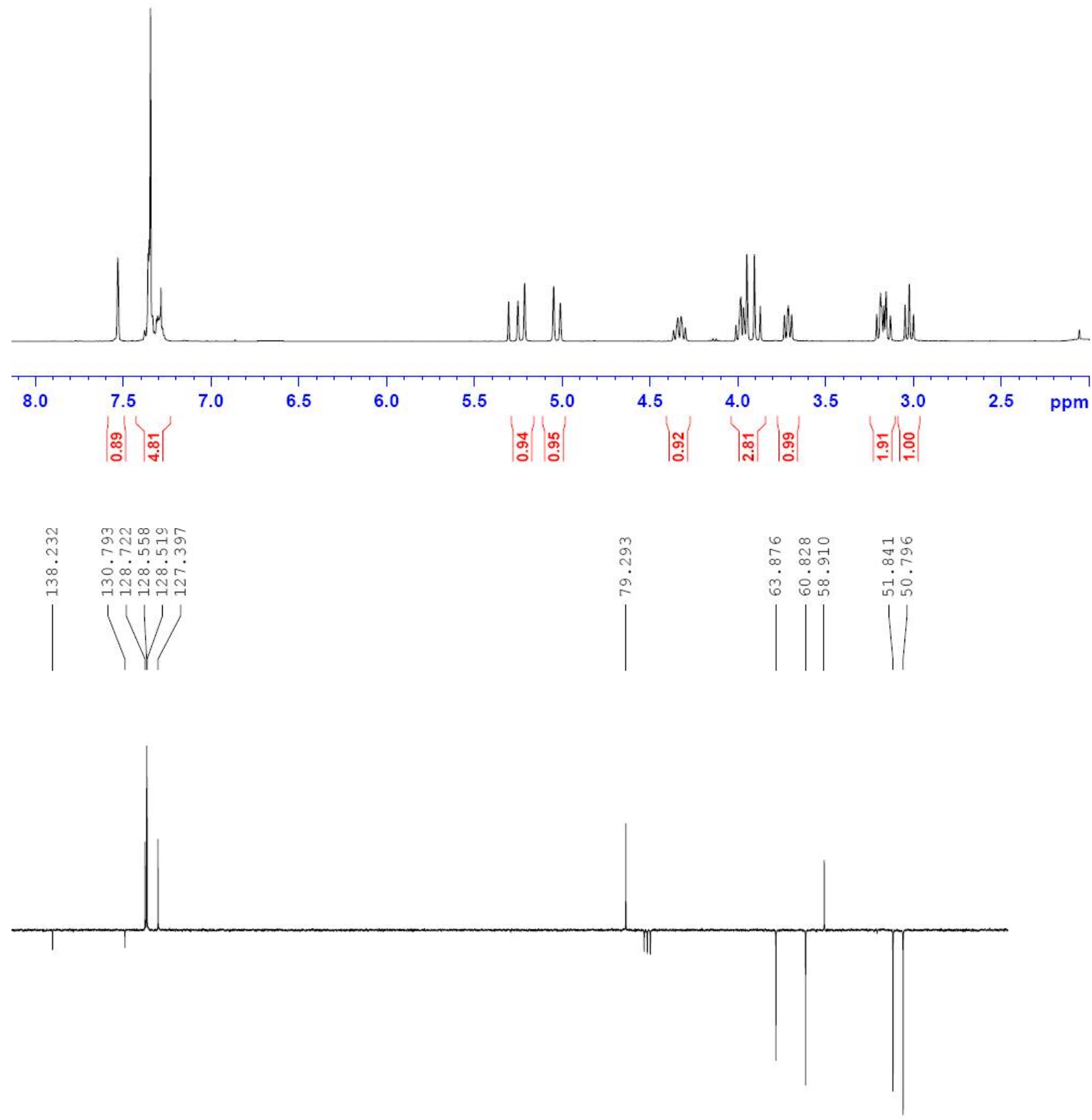

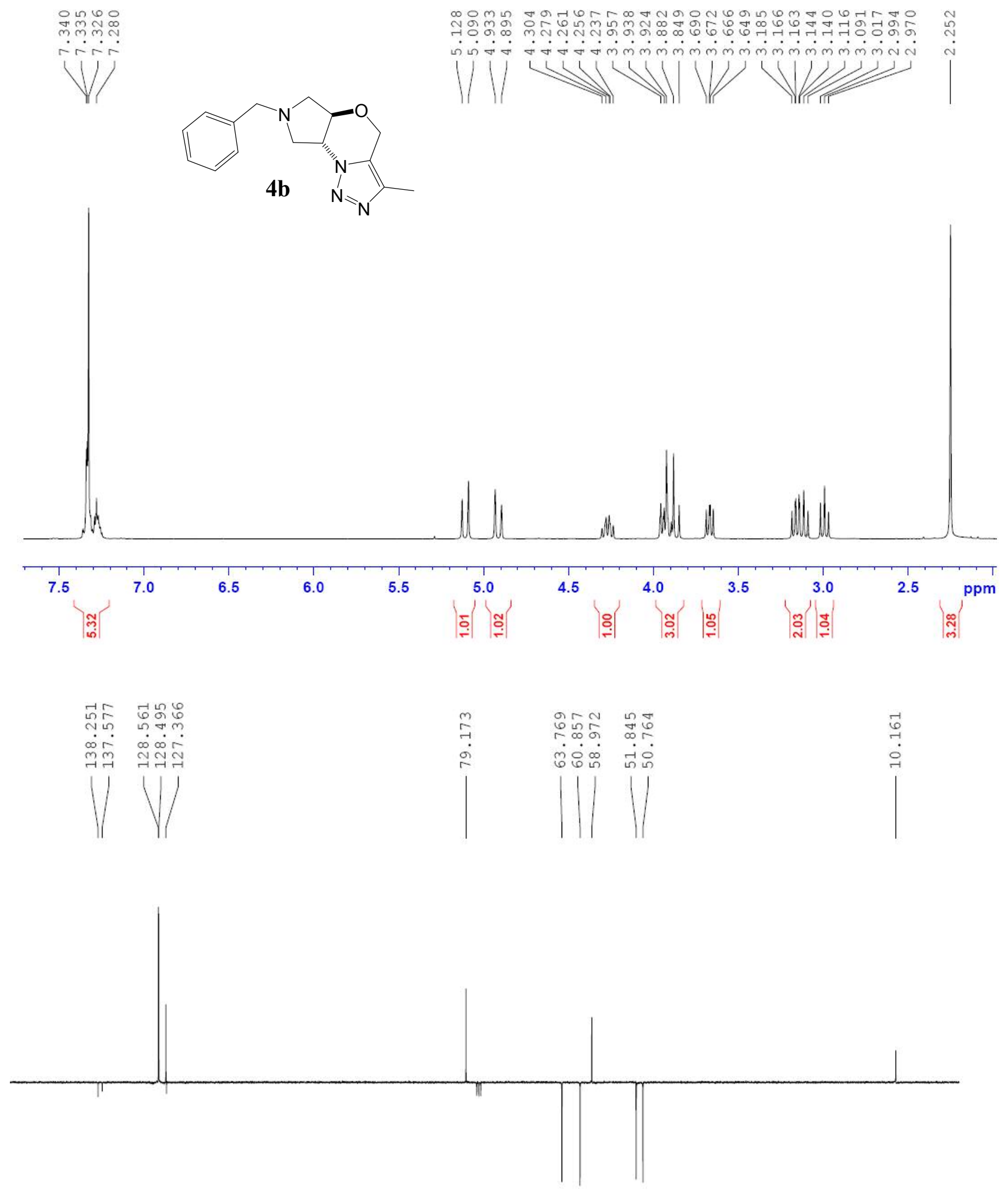

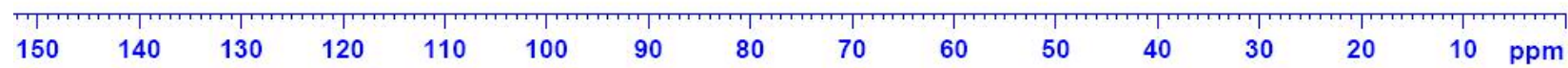




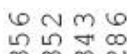

ल m $\mathrm{m}$

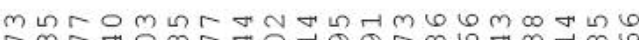

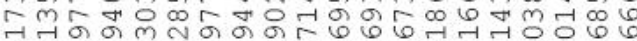

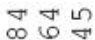

rin

$\dot{\omega} \dot{\nabla} \dot{\nabla} \dot{\nabla} \dot{m} \dot{m} \dot{m} \dot{m} \dot{m} \dot{m} \dot{m} \dot{m} \dot{N}$

N.

मतन

$\sqrt{1}$

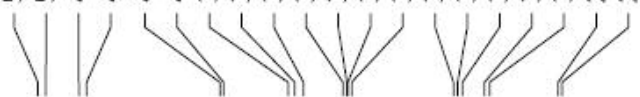

V
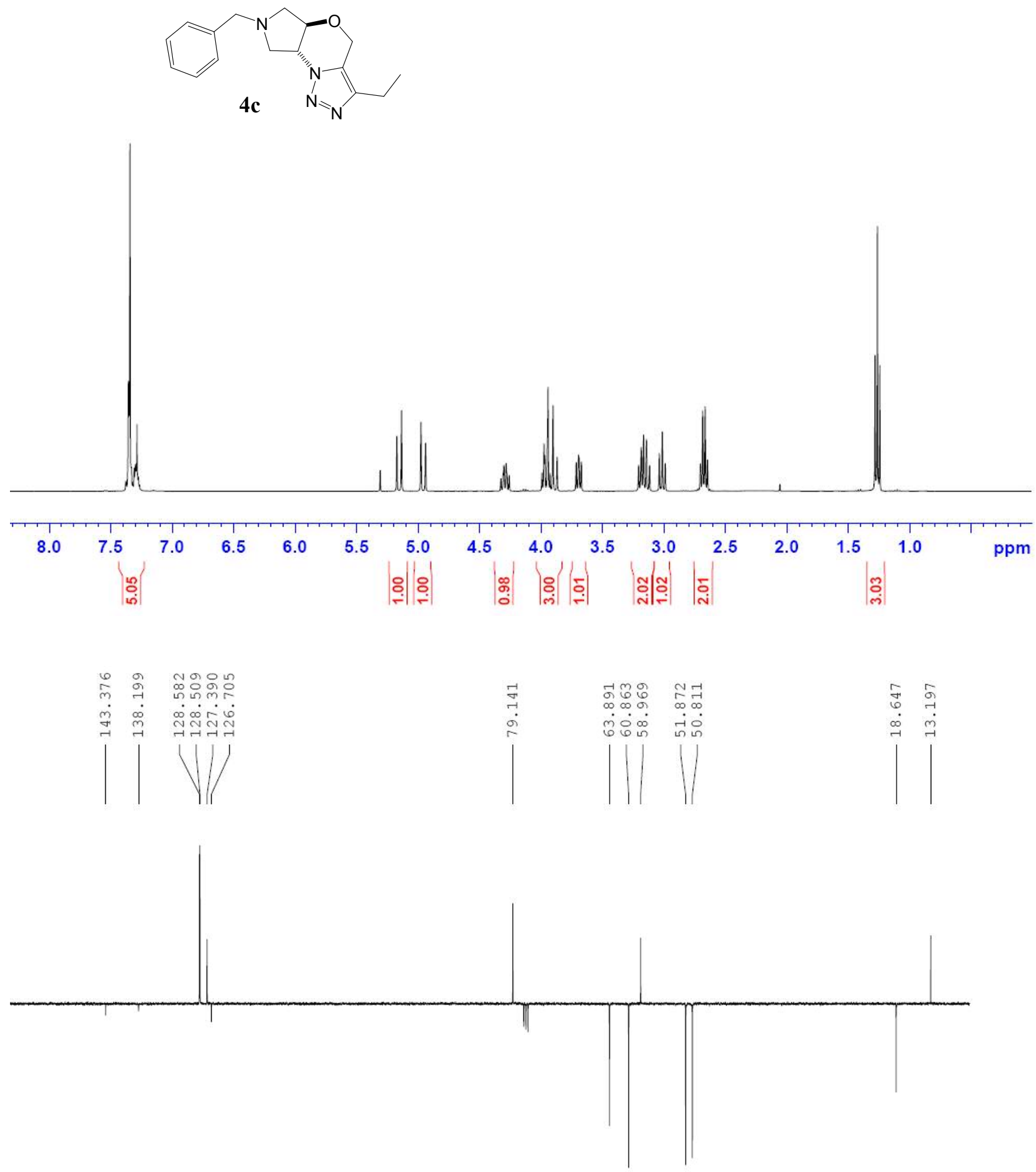

\begin{tabular}{|c|c|c|c|c|c|c|c|c|c|c|c|c|c|}
\hline 150 & 140 & 130 & 120 & 110 & 100 & 90 & 80 & 70 & 60 & 50 & 40 & 30 & 20 \\
\hline
\end{tabular}



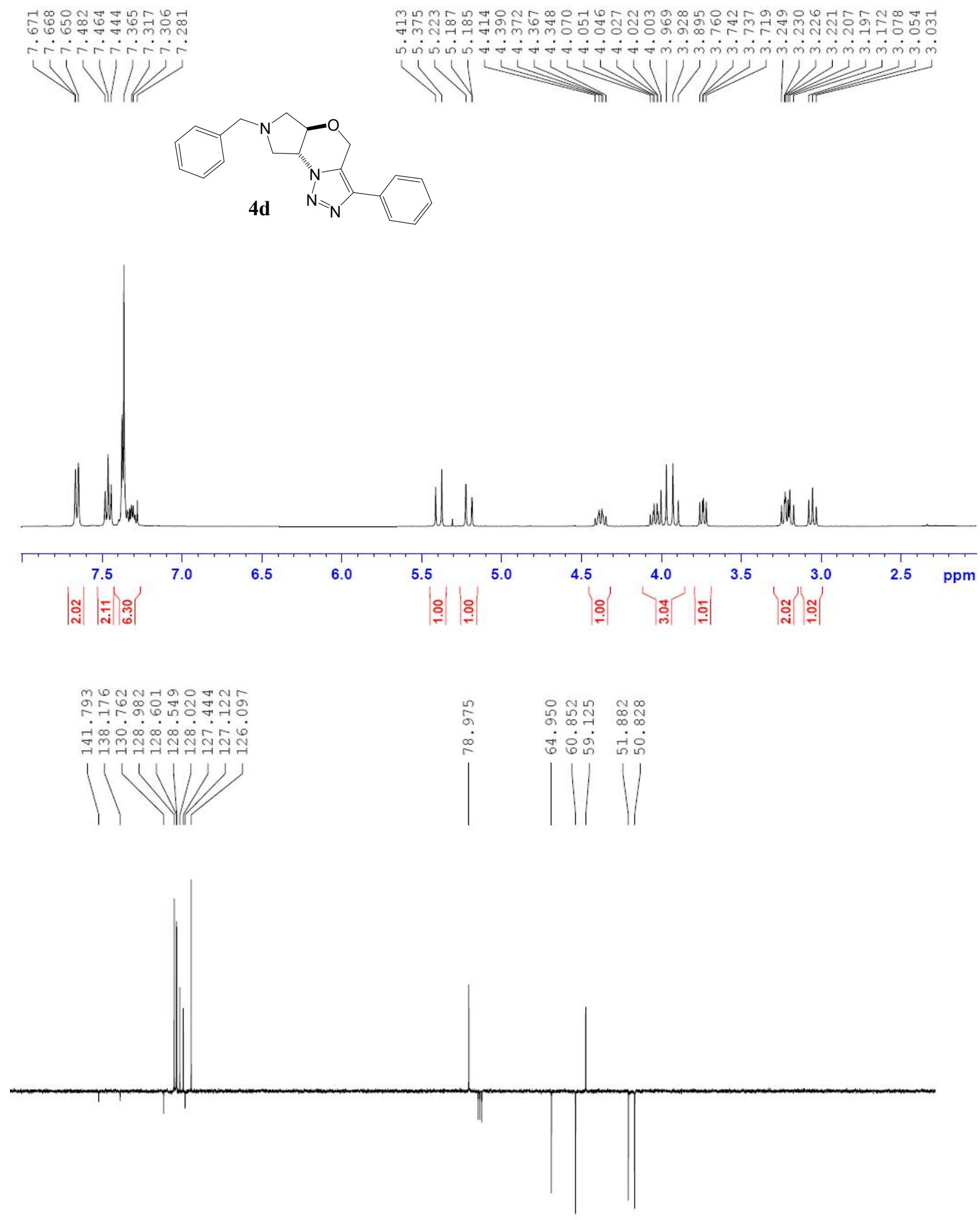

\begin{tabular}{|c|c|c|c|c|c|c|c|c|c|c|c|c|c|}
\hline & & & & & & 90 & 80 & 10 & 60 & 00 & 40 & & 10 \\
\hline
\end{tabular}




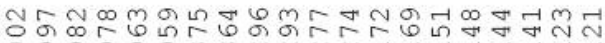

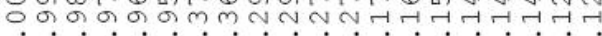

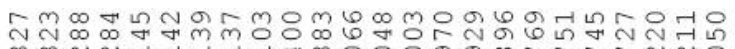

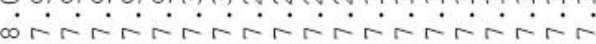

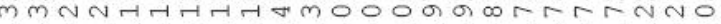

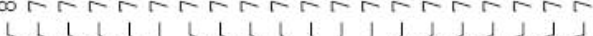

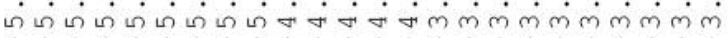

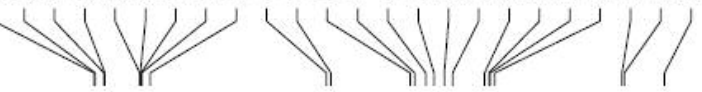
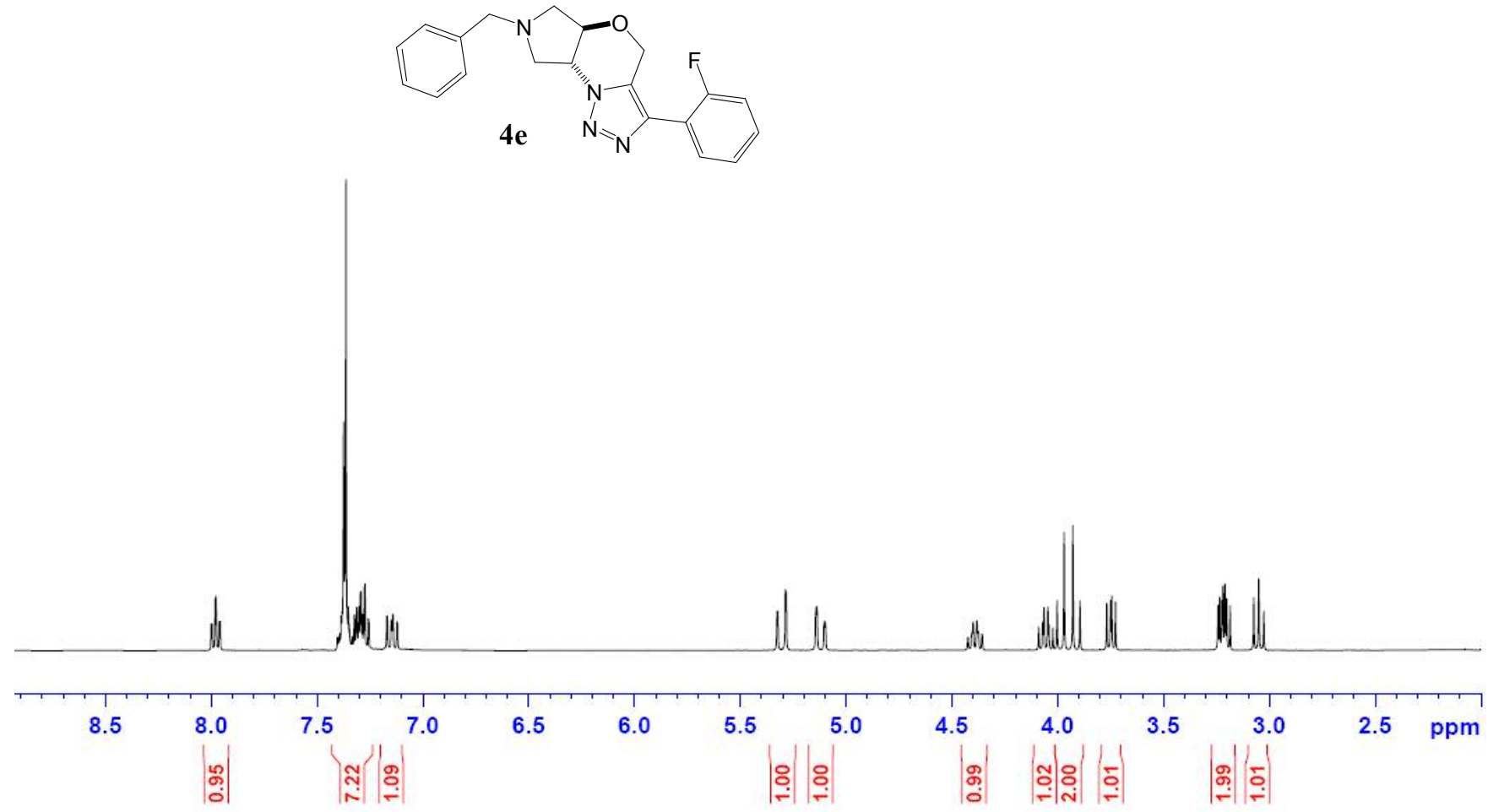

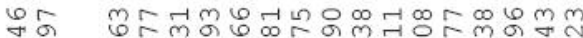

H. vo vor.

in

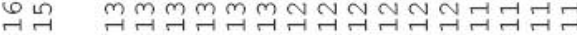
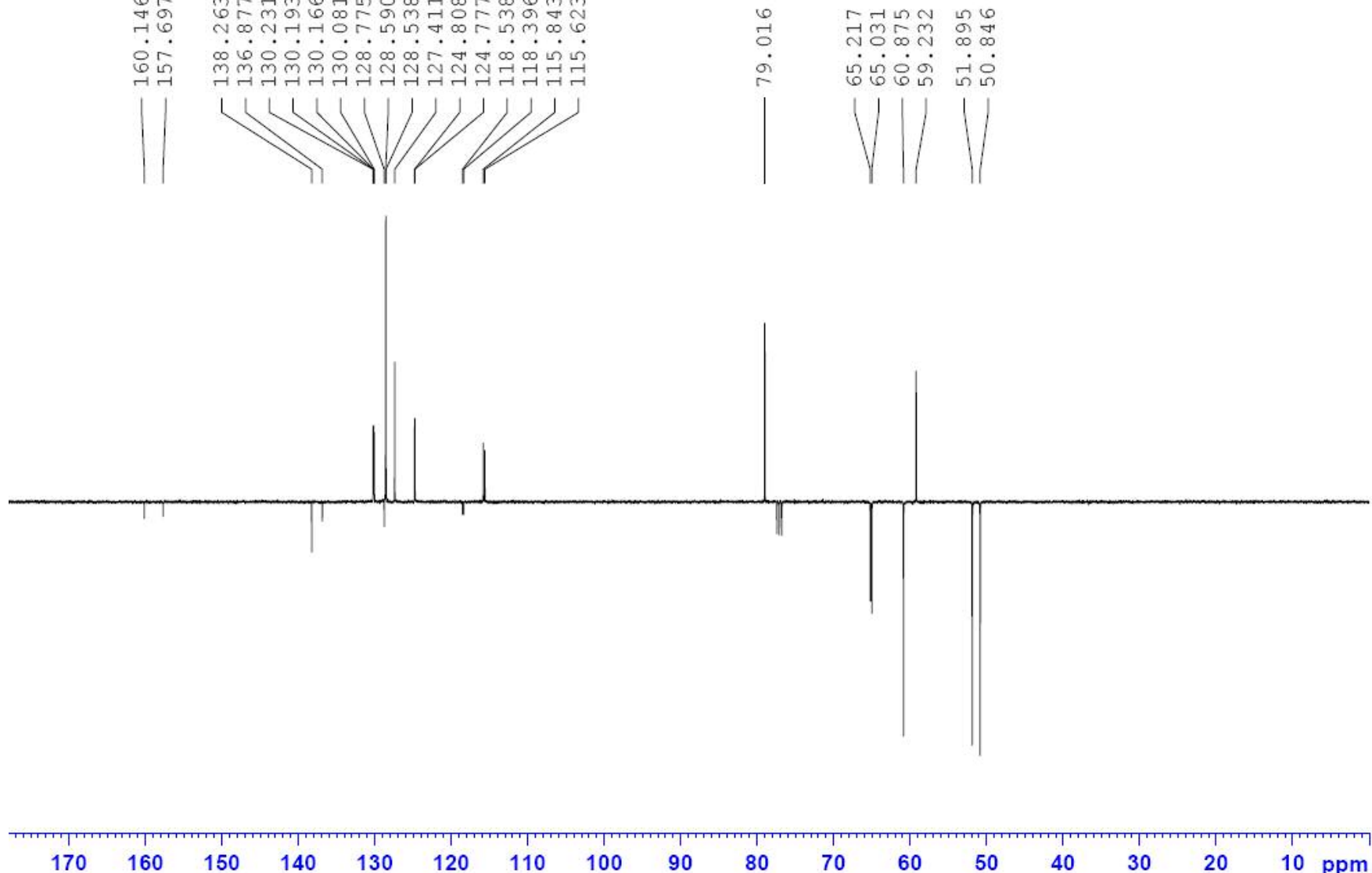

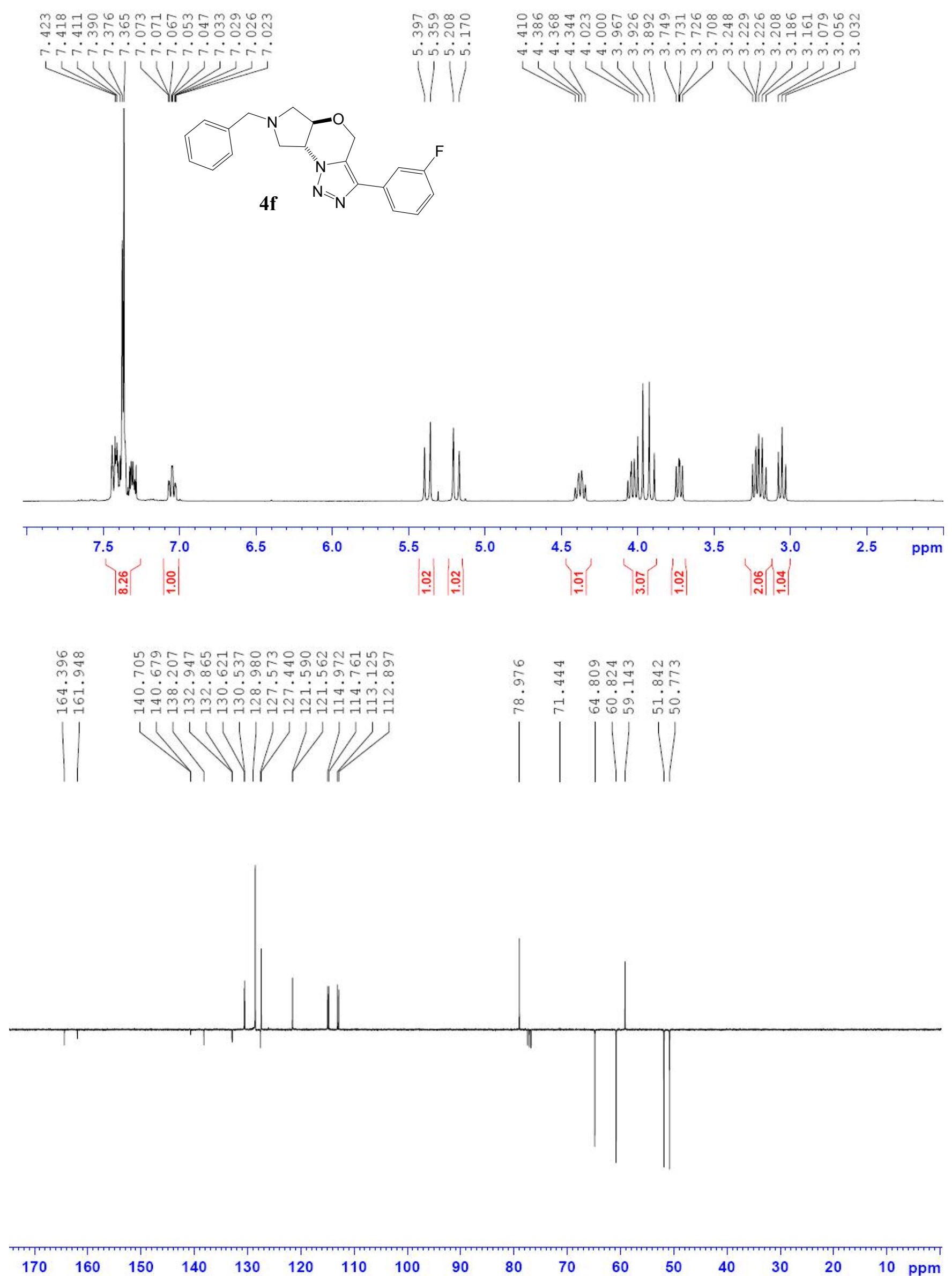

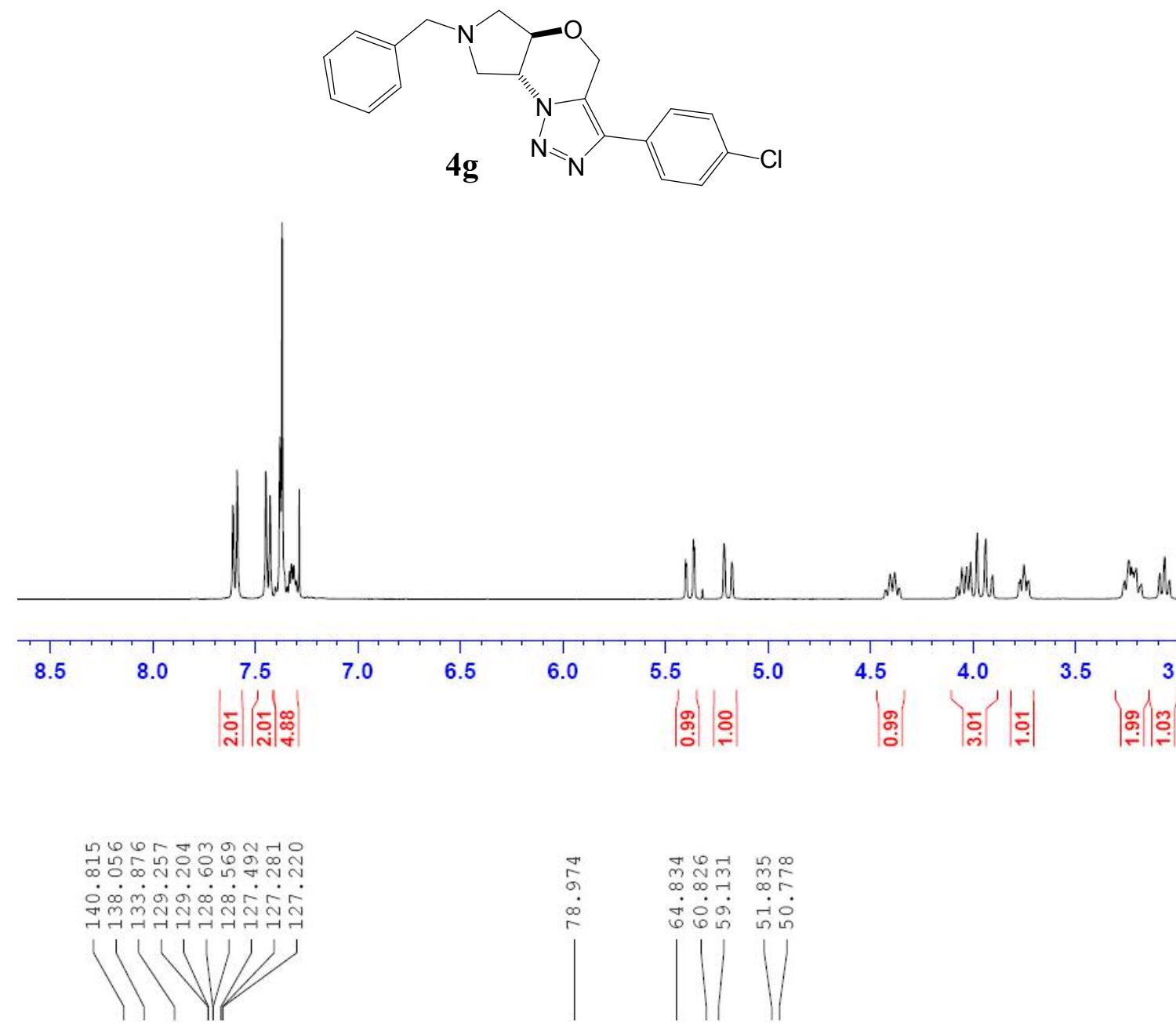

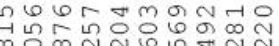

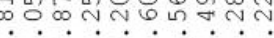

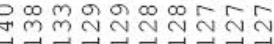

4.

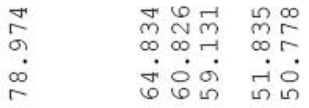

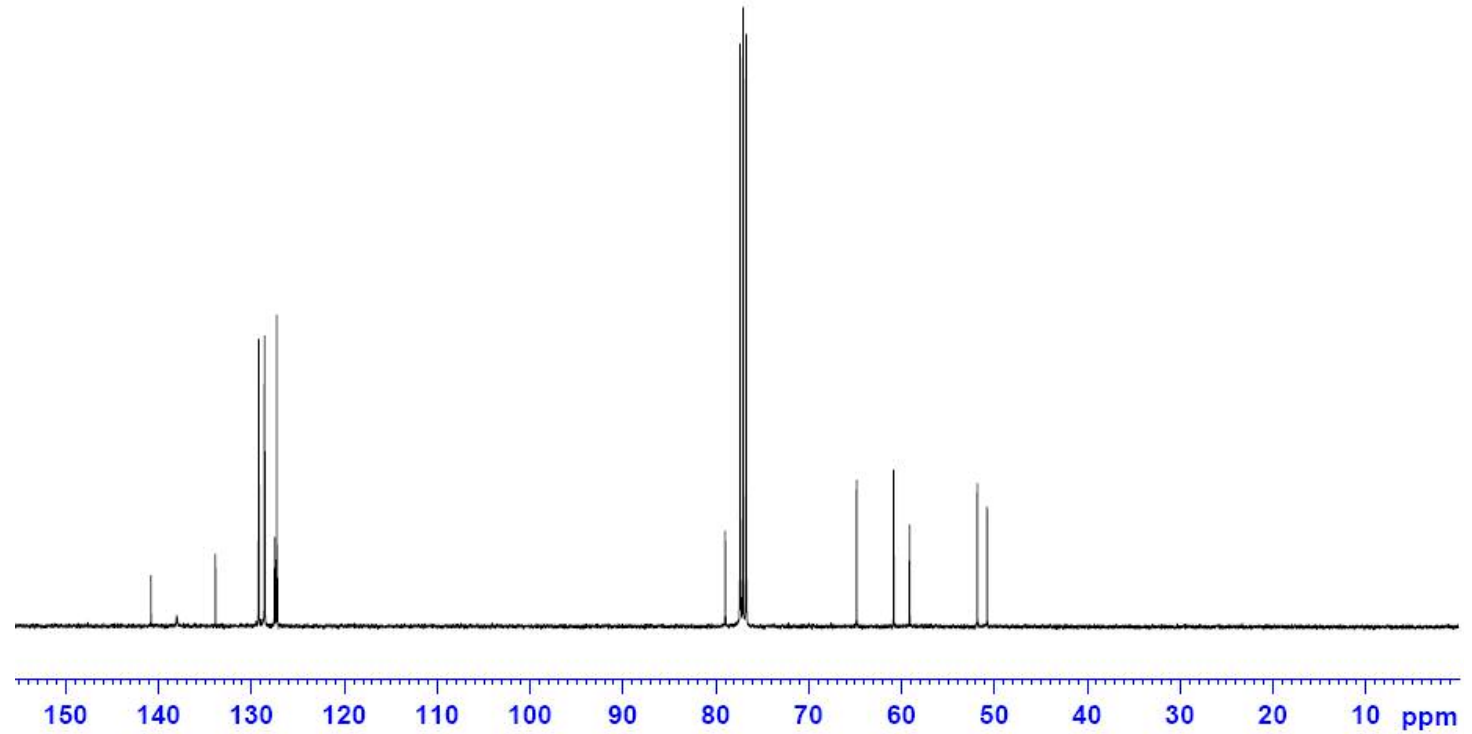




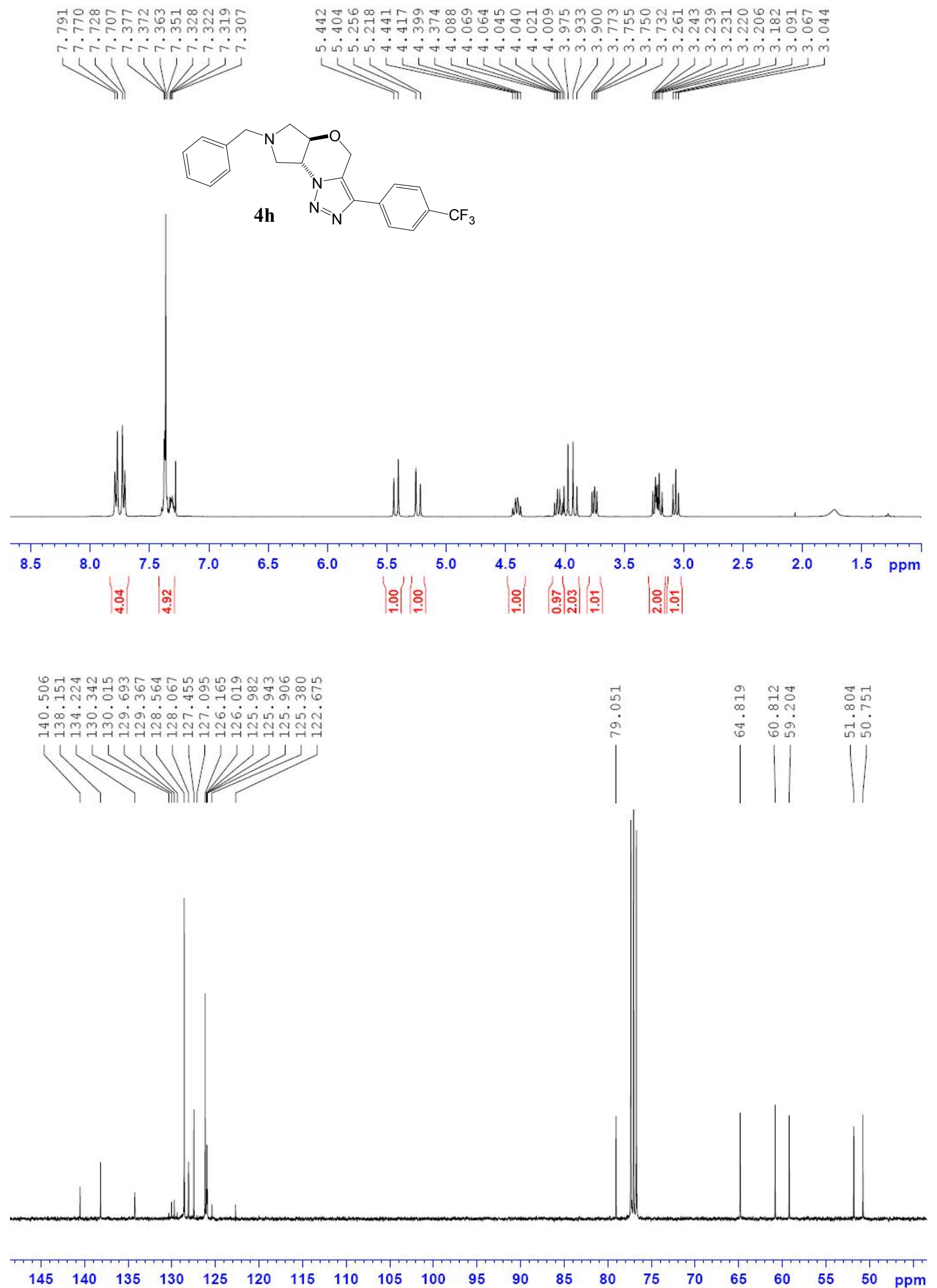



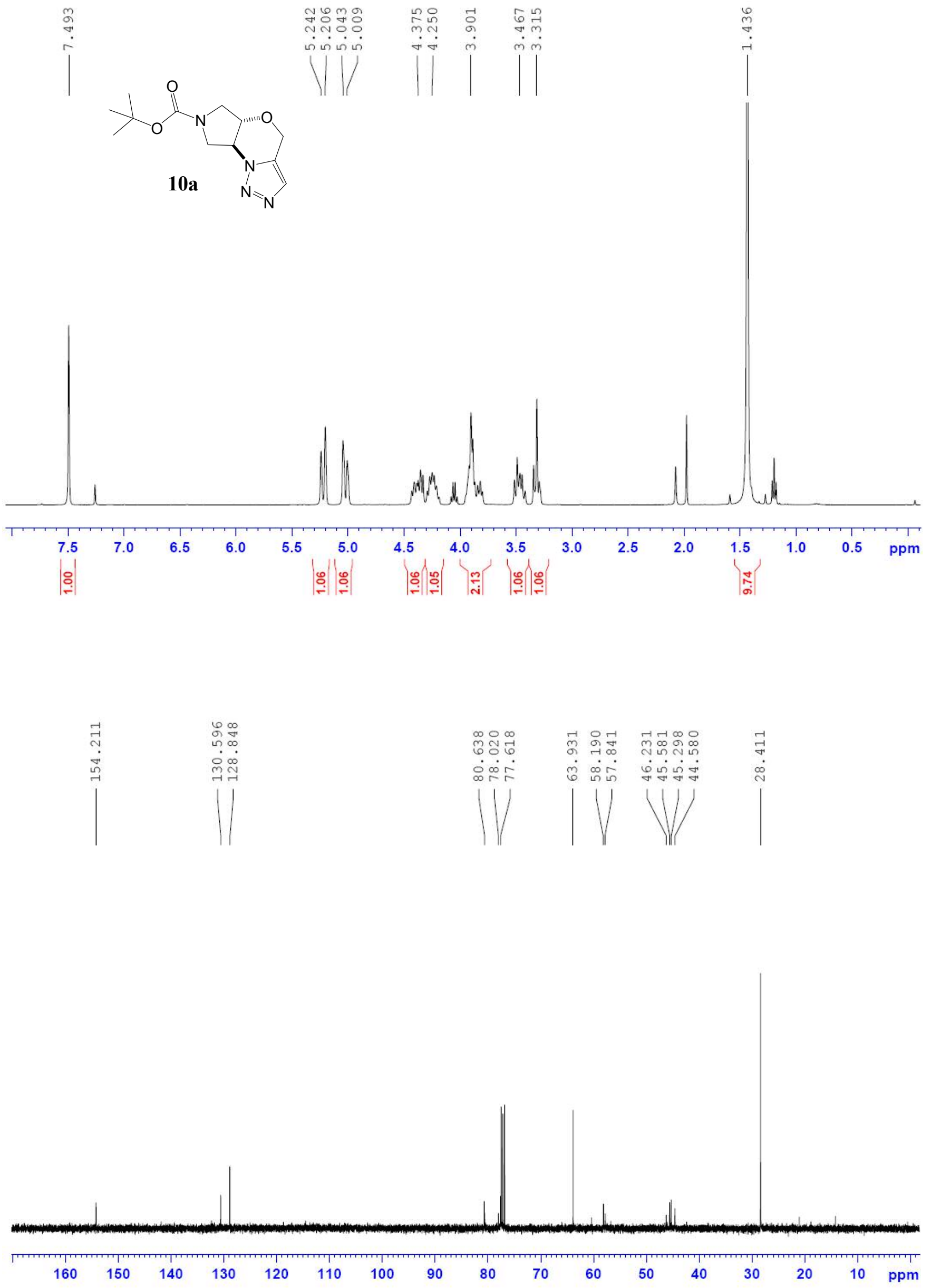

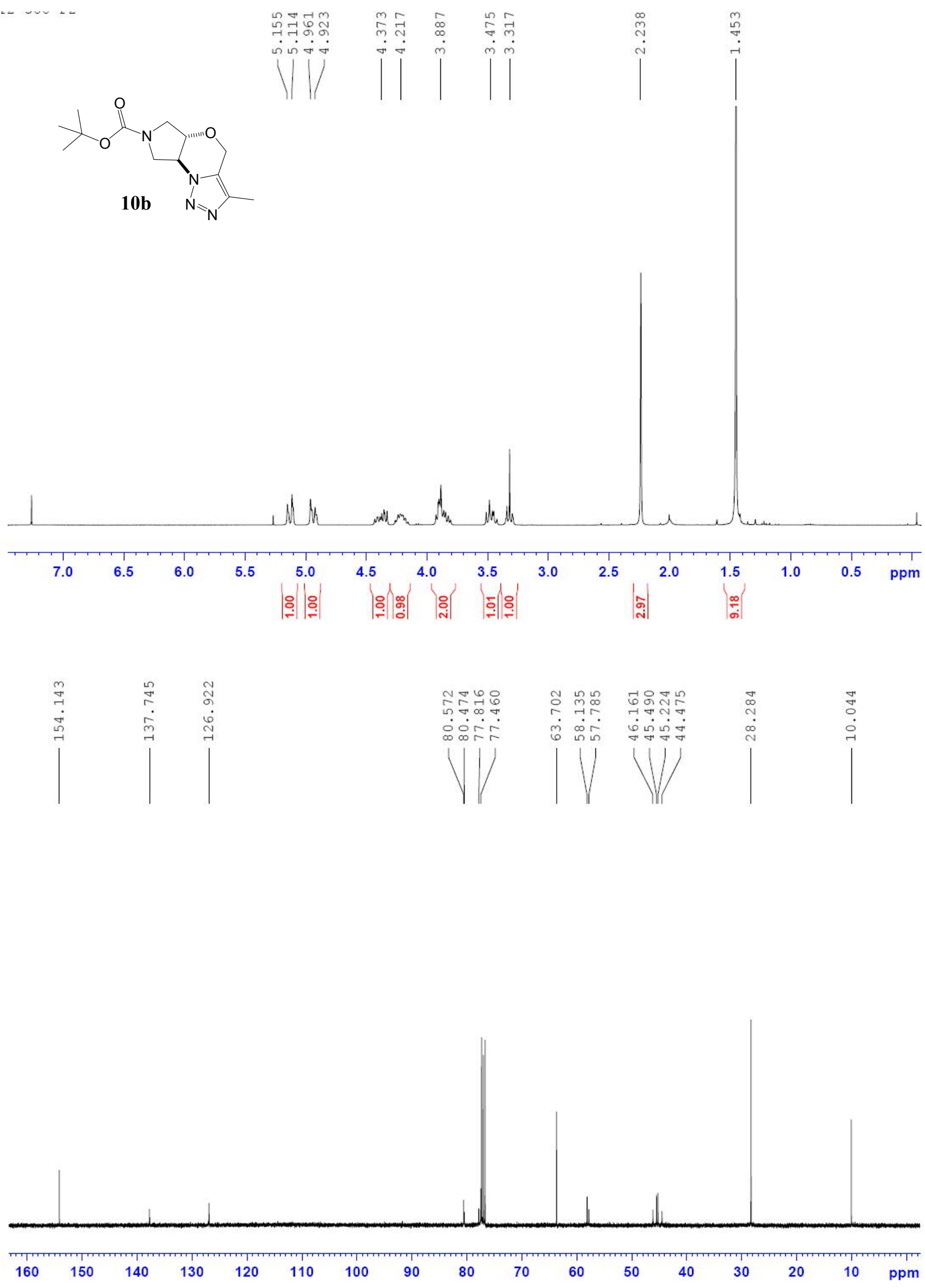

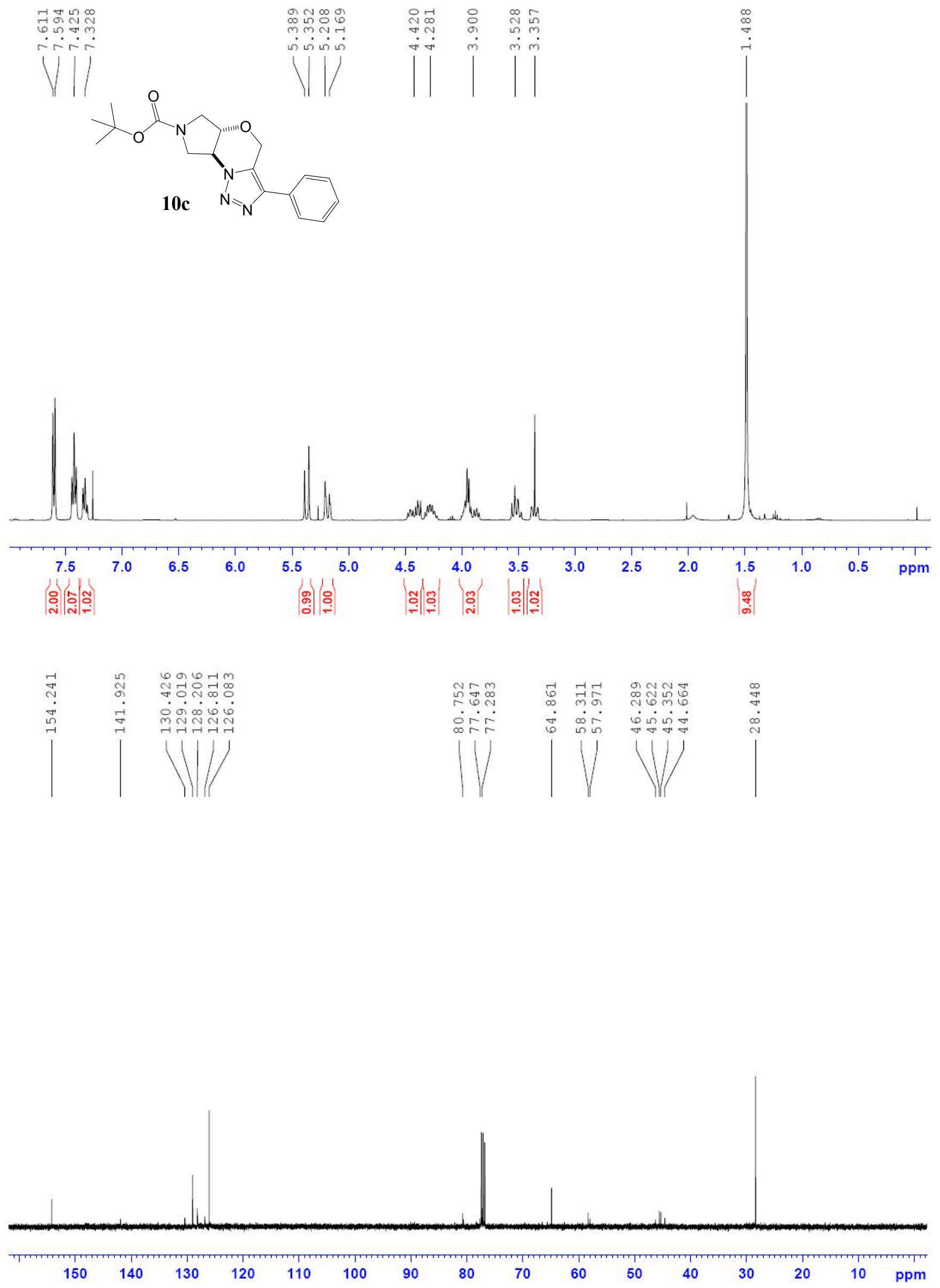
<smiles>CC(C)(C)OC(=O)N1C[C@H]2[C@@H](C1)OCc1c(-c3cccc(F)c3)nnn12</smiles>
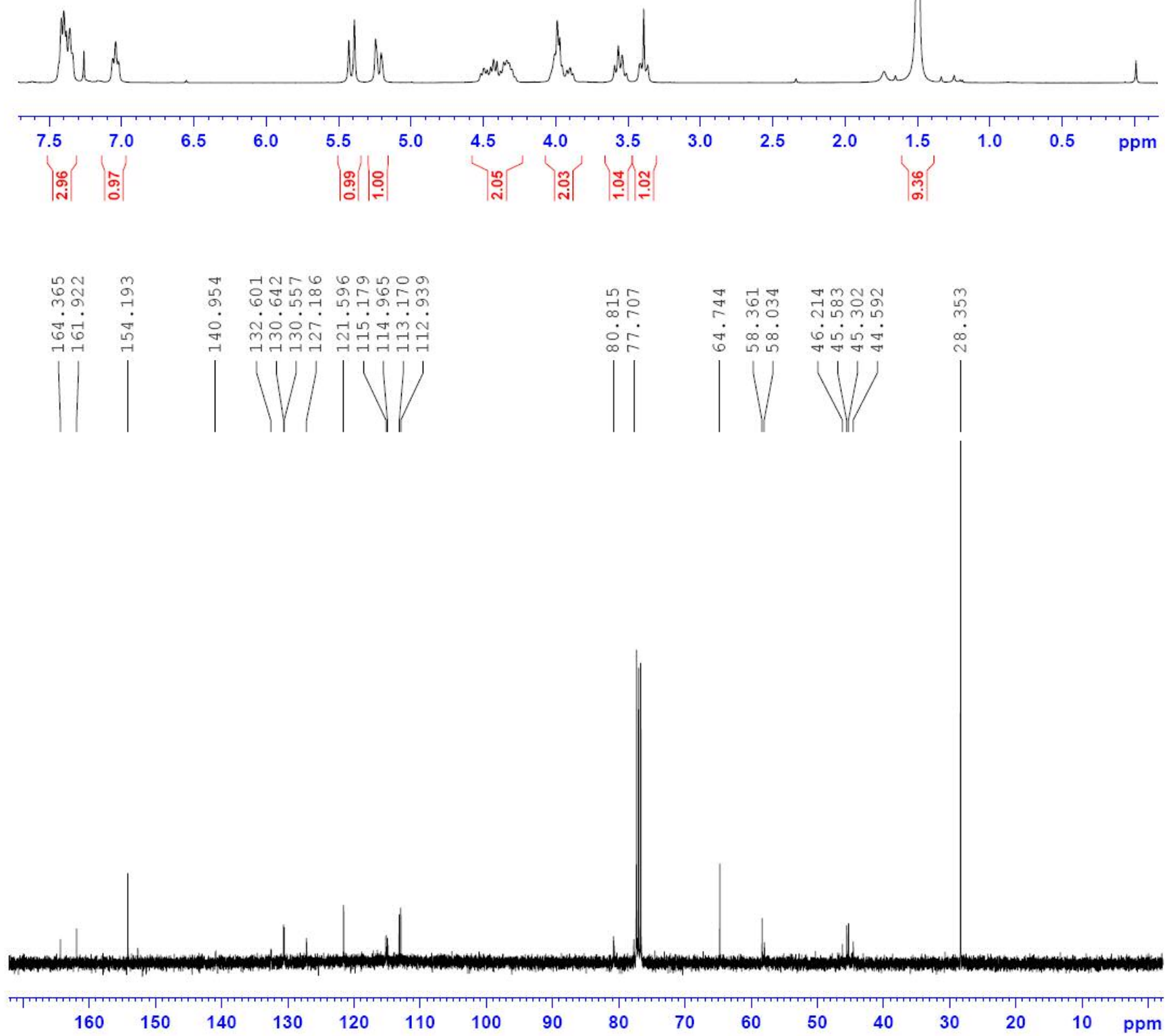

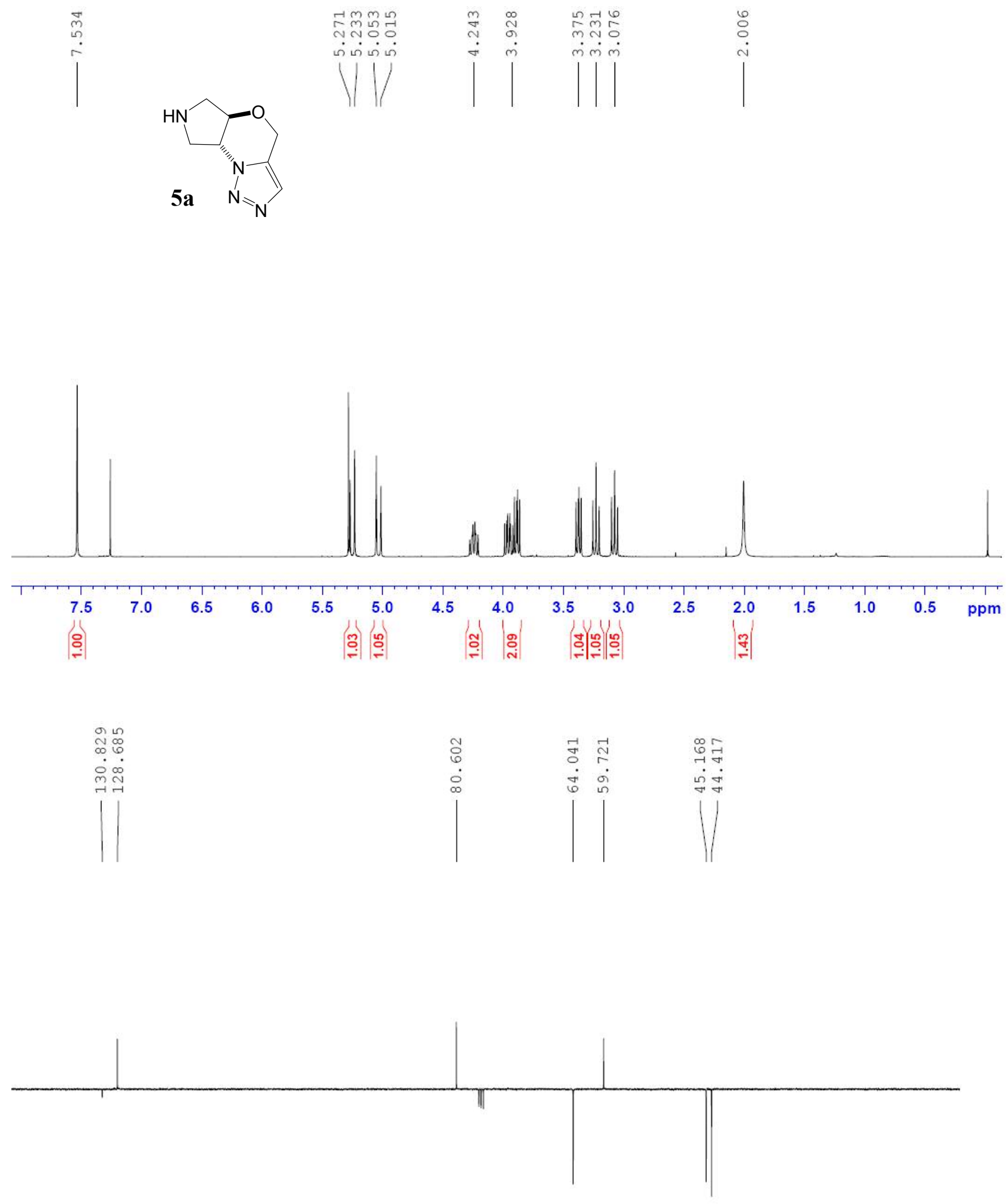

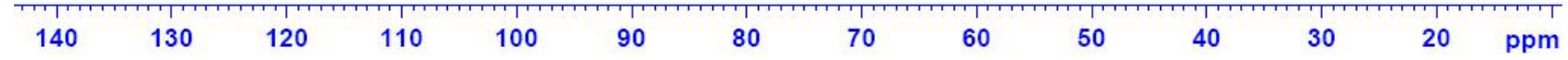



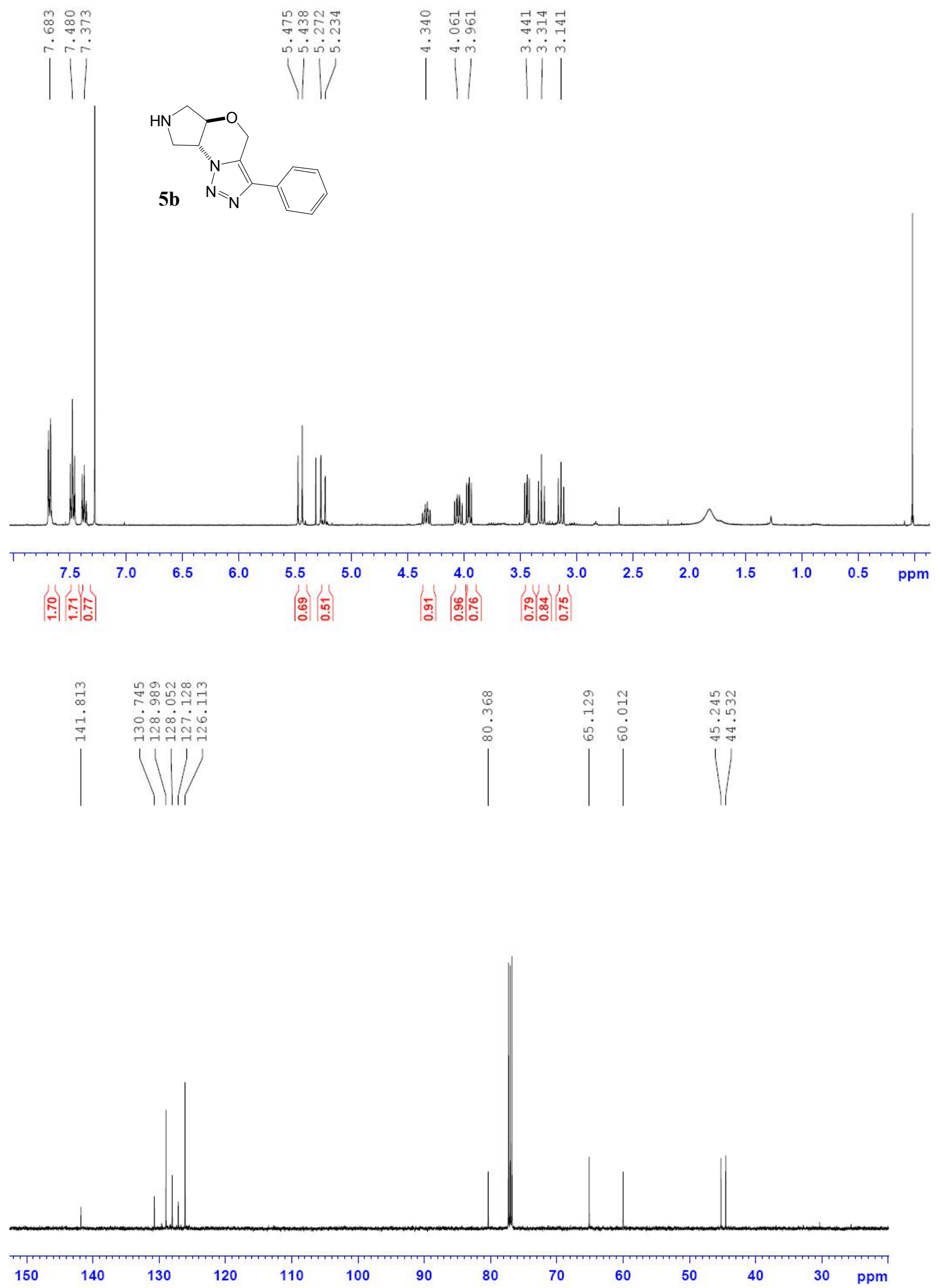


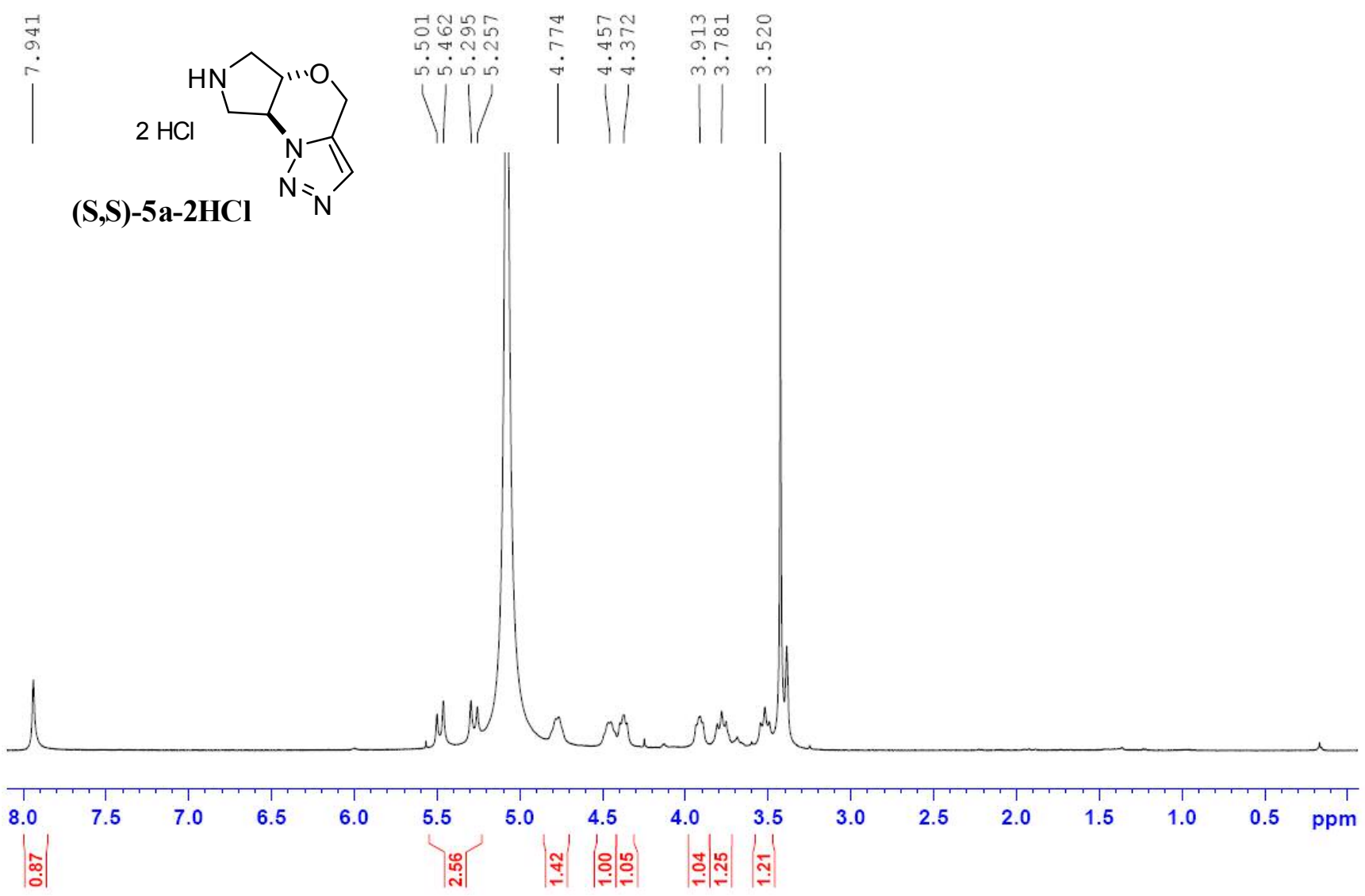



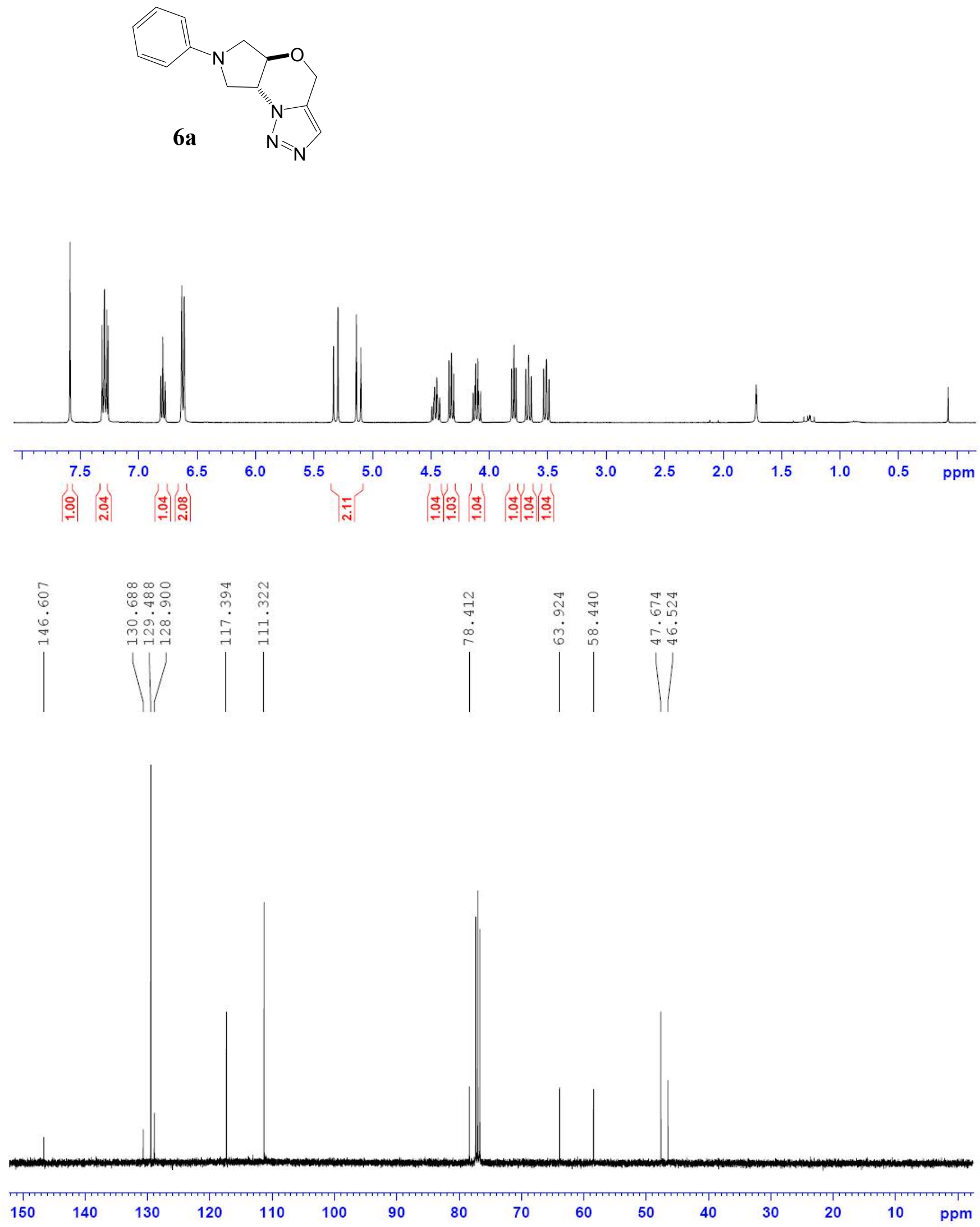
in

N $\infty \sim^{\infty}$

जि

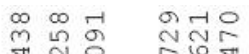

$\therefore \dot{\nabla} \dot{\nabla} \dot{x}$

1/

ill

11
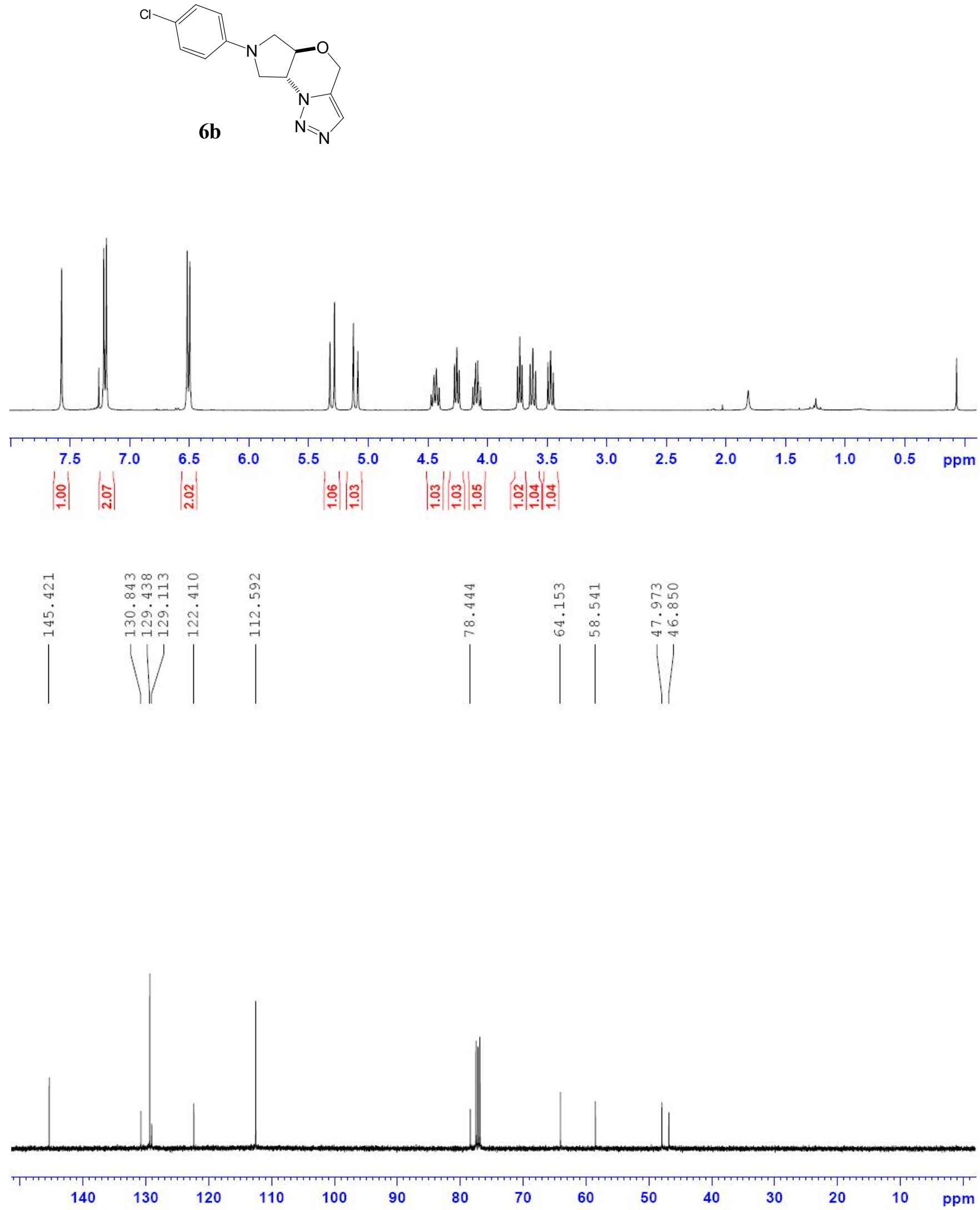

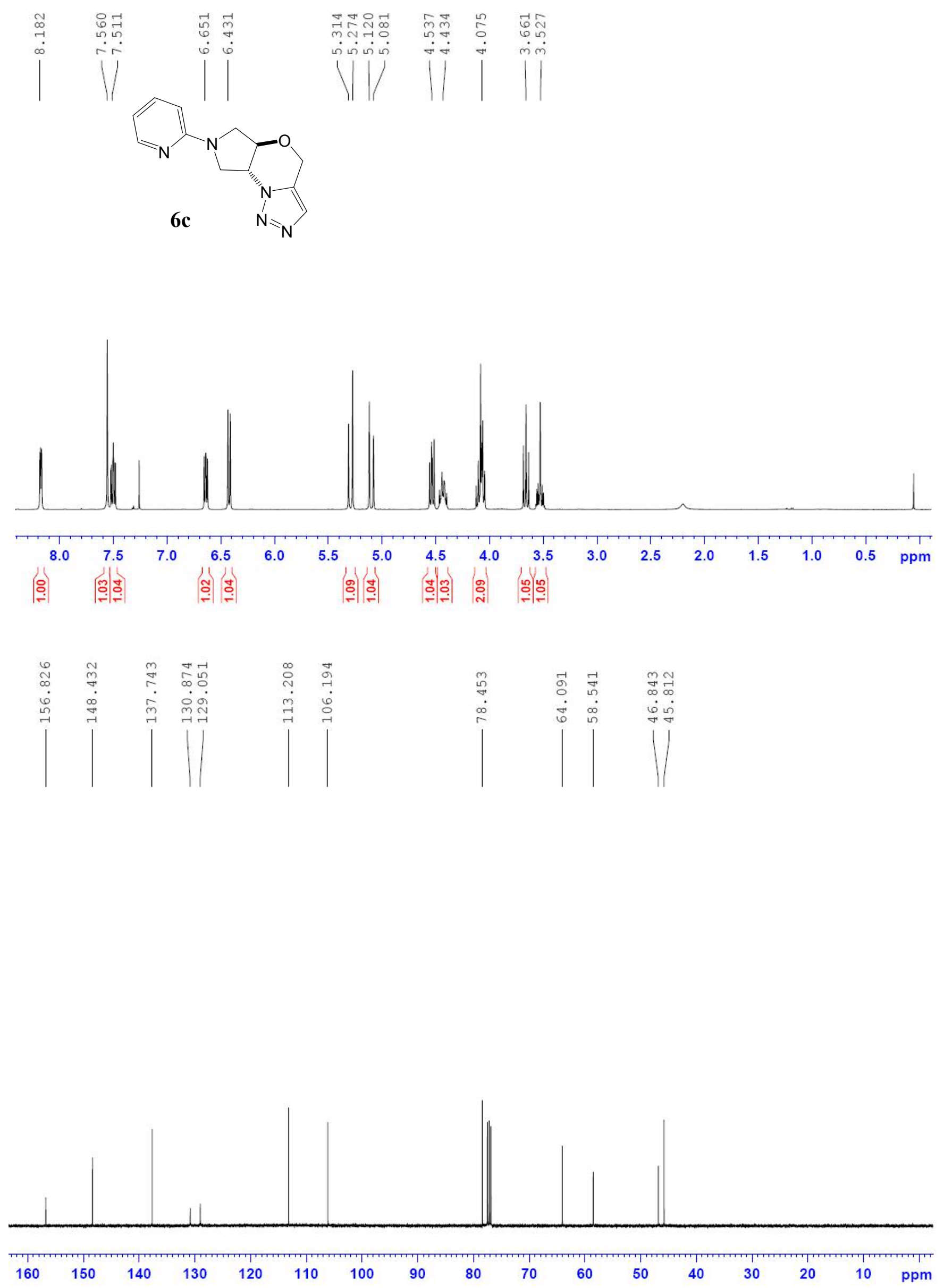

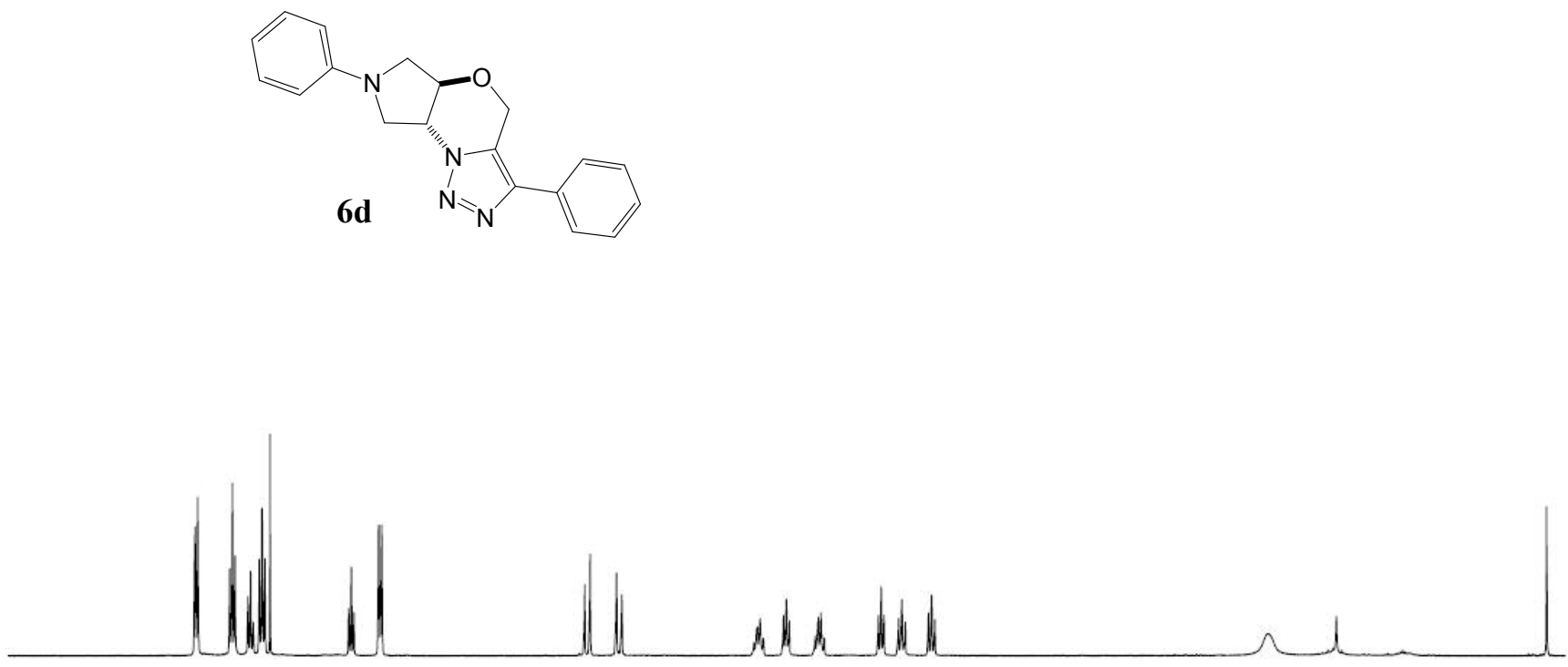

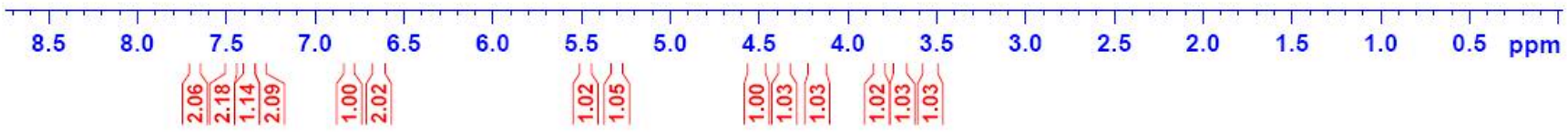
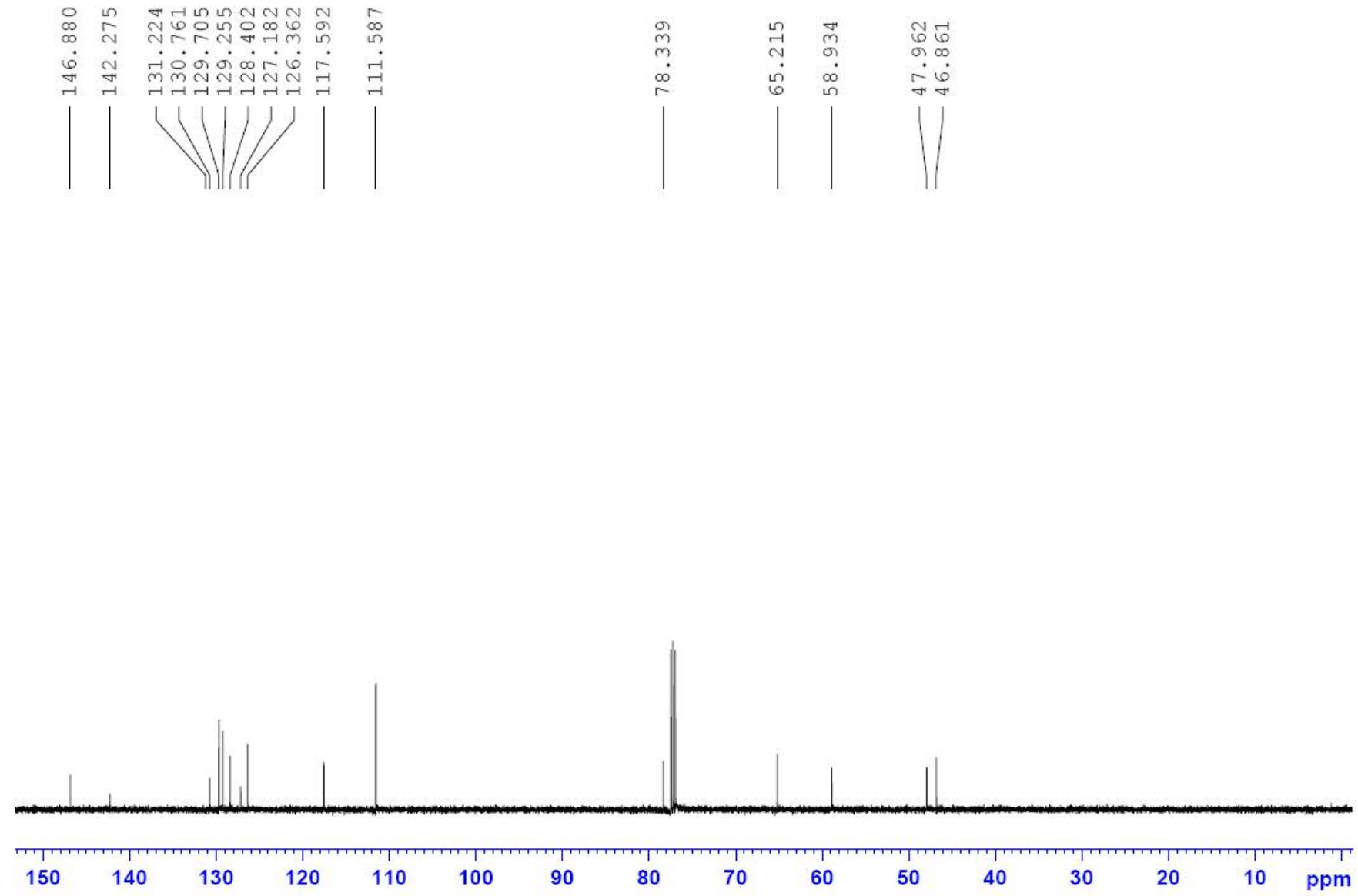
$\underline{\text { HPLC Chromatograms }}$

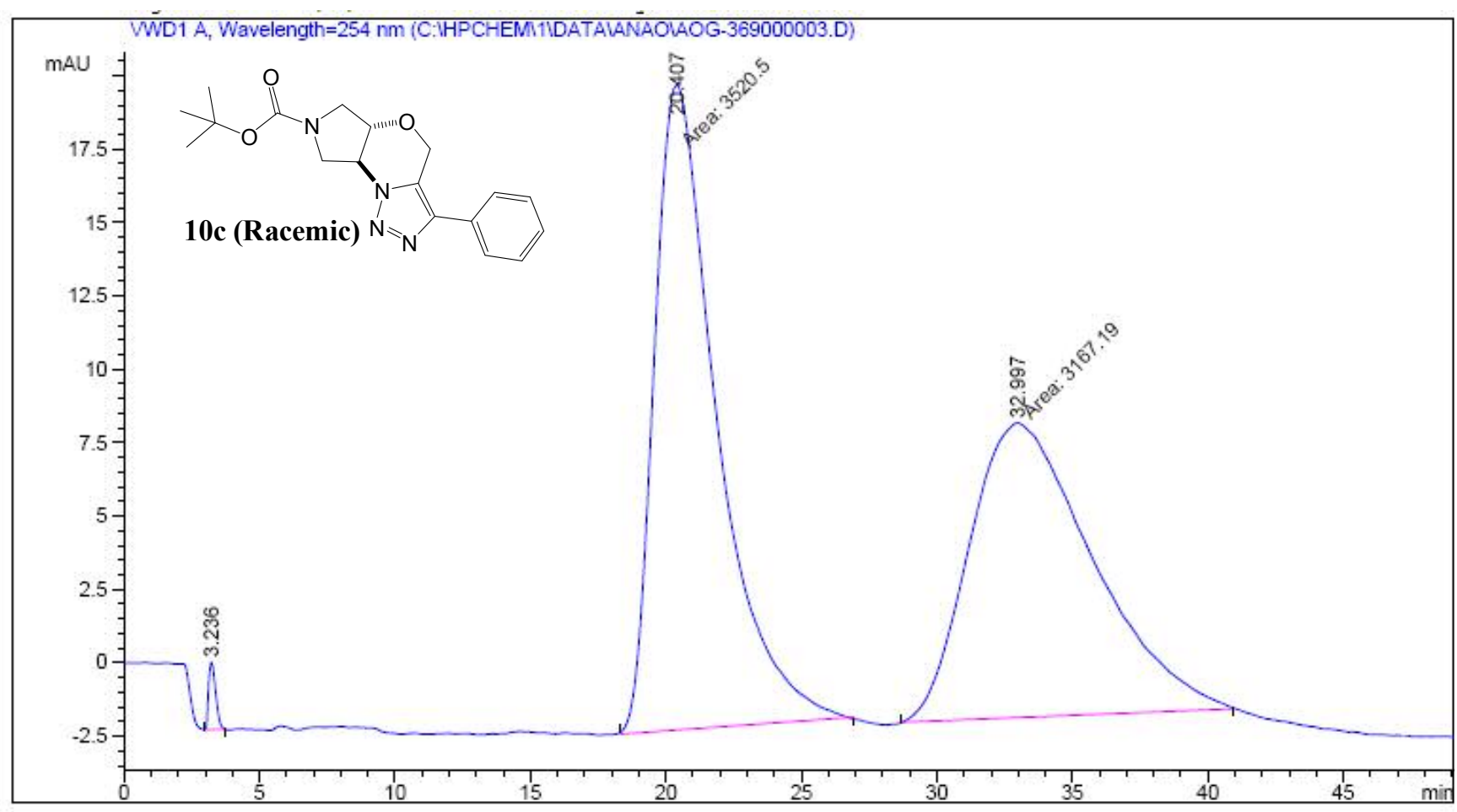

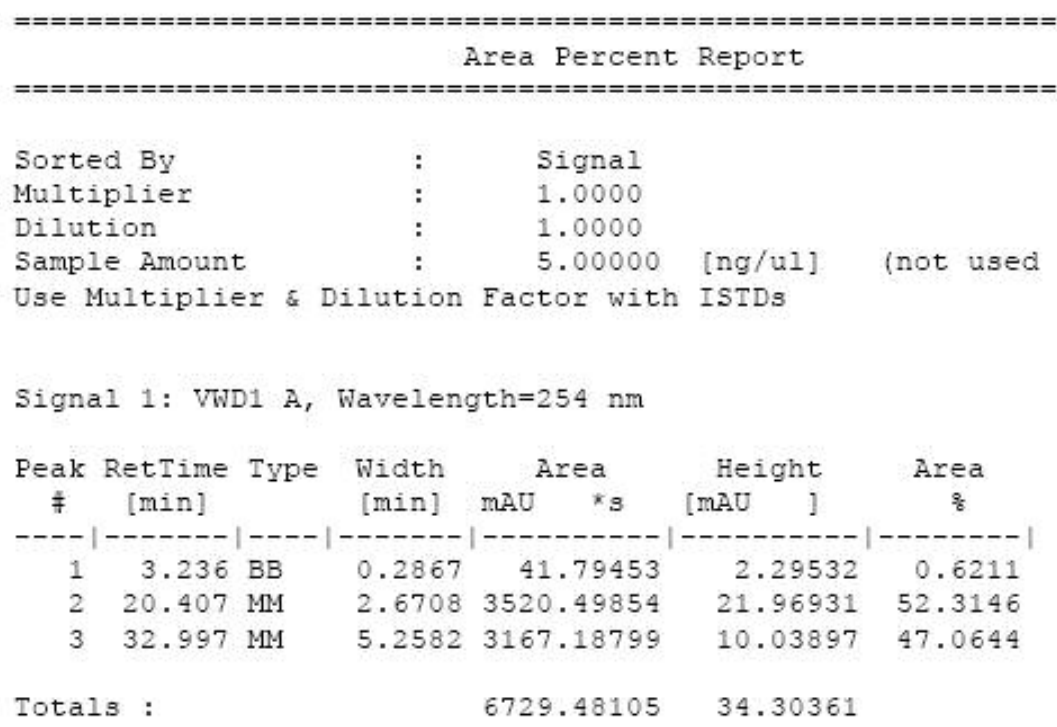




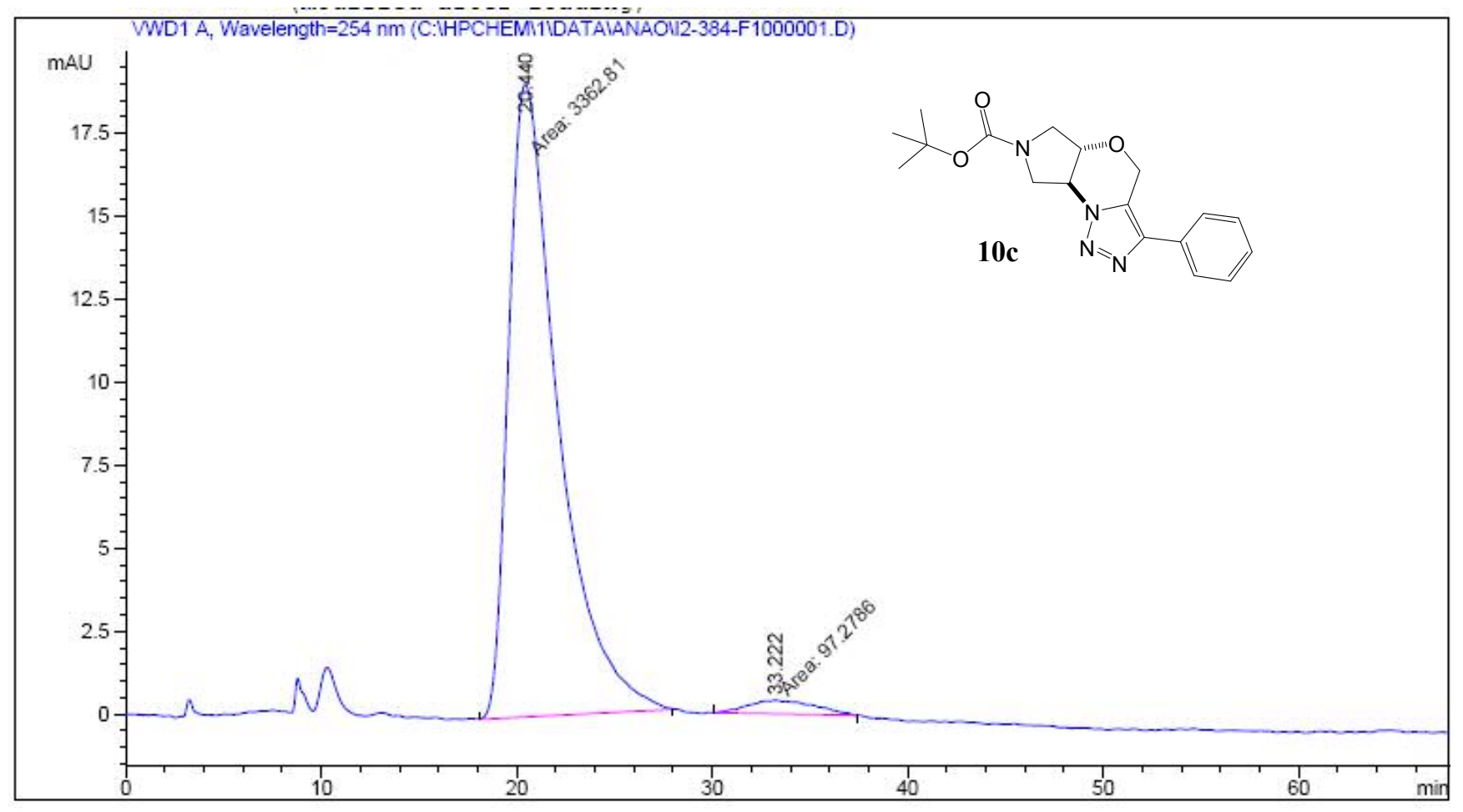

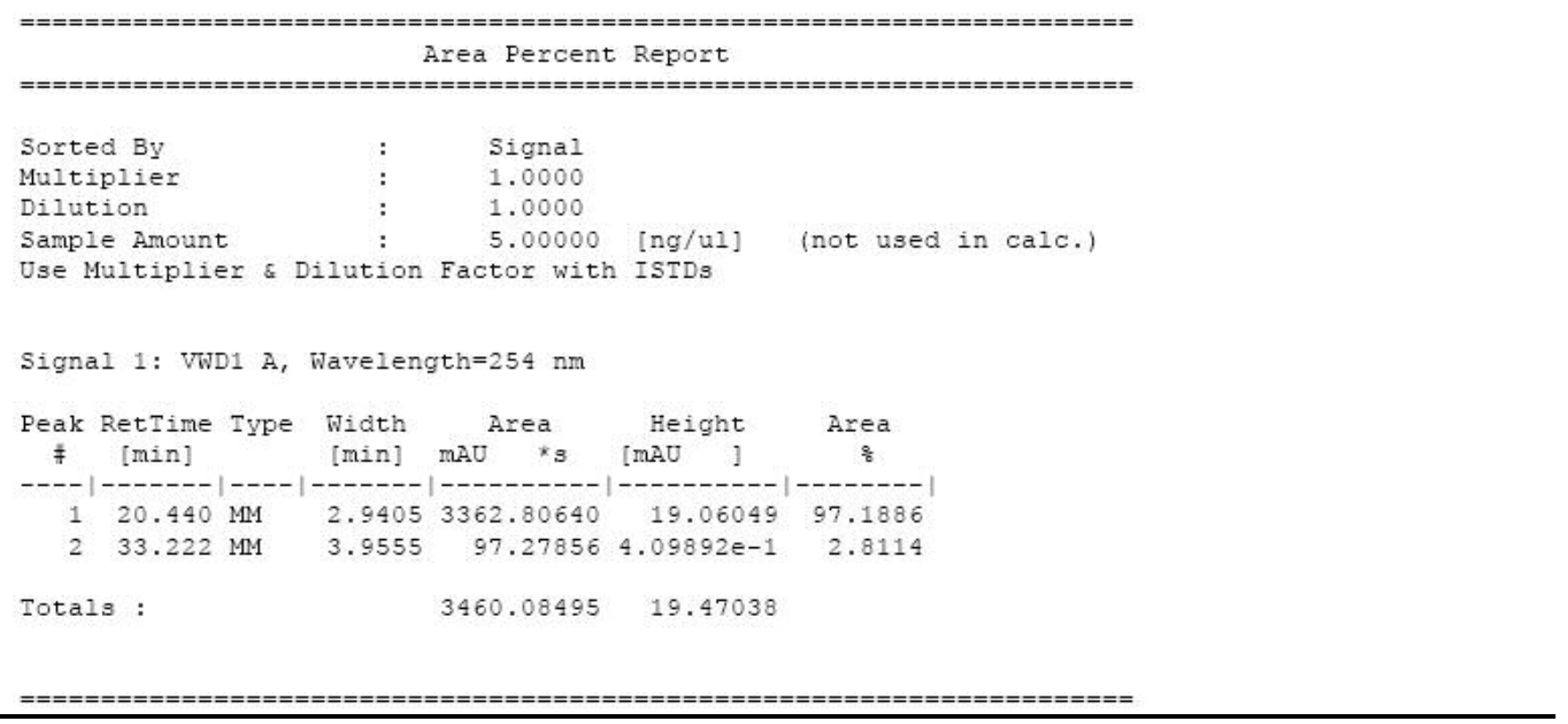




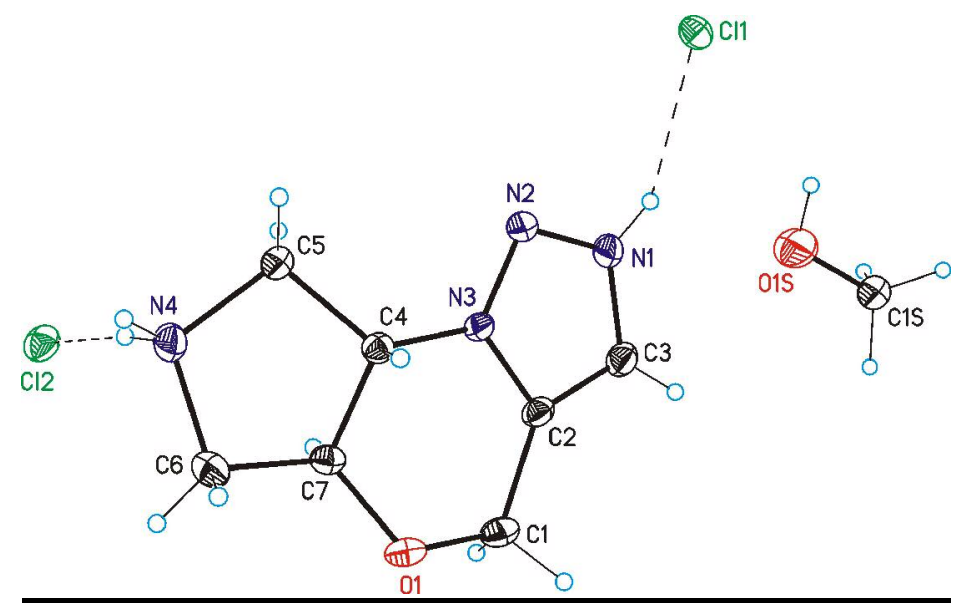

$(\mathrm{S}, \mathrm{S})$ configuration of $\mathrm{C} 4$ and $\mathrm{C} 7$ was confirmed by X-Ray analysis. Flack parameter 5a $(2 \mathrm{HCl})$ : $0.01(5) .^{5}$

CCDC 679898 contains the supplementary crystallographic data for this paper. These data can be obtained free of charge via www.ccdc.cam.ac.uk/conts/retrieving.html (or from the Cambridge Crystallographic Data Centre, 12 Union Road, Cambridge CB21EZ, UK; (fax: (+44) 1223-336-033; or

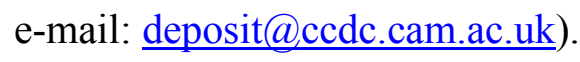

\section{Pharmacological study}

Representative triazole compounds were tested in a primary biological screening against 160 receptors (MDS Pharma Services) at $1 \mu \mathrm{M}$. Significant responses (>50\% inhibition or stimulation for Biochemical assays) were noted.

\section{General procedure for the affinity for the sigma-1 receptor assay.}

Brain membrane preparation and binding assays for the $\sigma 1$-receptor were performed as described (DeHaven-Hudkins, D. L., L.C. Fleissner, and F. Y. Ford-Rice, 1992, Characterization of the binding of $\left[{ }^{3} \mathrm{H}\right](+)$ pentazocine to $\sigma$ recognition sites in guinea pig brain, Eur. J. Pharmacol. 227, 371-378) with some modifications. Guinea pig brains were homogenized in 10 vols. (w/v) of Tris-HCl $50 \mathrm{mM} 0.32 \mathrm{M}$ sucrose, pH 7.4, with a Kinematica Polytron PT 3000 at 15000 r.p.m. for 30 s. The homogenate was centrifuged at $1000 \mathrm{~g}$ for $10 \mathrm{~min}$ at $4{ }^{\circ} \mathrm{C}$ and the supernatants collected and centrifuged again at $48000 \mathrm{~g}$ for $15 \mathrm{~min}$ at $4{ }^{\circ} \mathrm{C}$. The pellet was resuspended in 10 volumes of Tris- $\mathrm{HCl}$ buffer $(50 \mathrm{mM}, \mathrm{pH} 7.4)$, 
incubated at $37^{\circ} \mathrm{C}$ for $30 \mathrm{~min}$, and centrifuged at $48000 \mathrm{~g}$ for $20 \mathrm{~min}$ at $4{ }^{\circ} \mathrm{C}$. Following this, the pellet was resuspended in fresh Tris- $\mathrm{HCl}$ buffer $(50 \mathrm{mM}, \mathrm{pH} 7.4)$ and stored on ice until use.

The radioligand used was $\left[{ }^{3} \mathrm{H}\right]-(+)$-pentazocine at $5.0 \mathrm{nM}$ and the final volume was $200 \mu 1$. The incubation was initiated with the addition of $100 \mu \mathrm{l}$ of membrane at a final tissue concentration of approximately $5 \mathrm{mg}$ tissue net weight $/ \mathrm{mL}$ and the incubation time was $150 \mathrm{~m}$. at $37{ }^{\circ} \mathrm{C}$. After incubation, the membranes were collected onto pretreated glass fiber filterplate (MultiScreen-FC, Millipore), with polyethylenimine $0.1 \%$. The filters were washed two times with $200 \mu 1$ of washing buffer $(50 \mathrm{mM}$ Tris $\mathrm{Cl}, \mathrm{pH}=7.4)$ and then $25 \mu \mathrm{l}$ of Ecoscint $\mathrm{H}$ liquid scintillation cocktail were added. Microplates were allowed to set for several hours and then quantified by liquid scintillation spectrophotometry (1450 Microbeta, Wallac). Nonspecific binding was determined with $1 \mu \mathrm{M}$ haloperidol.

\section{$\underline{\text { References }}$}

\section{EP0985664}

2. (a) Martínez, L. E.; Leighton, J. L.; Carsten, D. H.; Jacobsen, E. N. J. Am. Chem. Soc. 1995, 117, 5897. (b) Schaus, S. E.; Larrow, J. F.; Jacobsen, E. N. J. Org. Chem. 1997, 62, 4197.

3. WO9524400

4. Wrobel, J.; Li, Z.; Dietrich, A.; McCaleb, M.; Mihan, B.; Sredy, J.; Sullivan, D. J. Med. Chem. 1998, $41,1084$.

5. a) H.D. Flack, Acta Cryst. 1983, A39, 876. b) H.D. Flack, G. Bernardinelli, Acta Cryst. 1999, A55, 908. c) H.D. Flack, G. Bernardinelli, J. Appl. Cryst. 2000, 33, 1143. 